ANA MARTA DOS

REMÉDIOS BERNARDO PINTO FAUSTINO
STORYTELLING EM REALIDADE VIRTUAL: AJUDAR CRIANÇAS COM MEDO DO ESCURO STORYTELLING IN VR: HELPING CHILDREN WITH FEAR OF THE DARK 

ANA MARTA DOS

REMÉDIOS BERNARDO PINTO FAUSTINO
STORYTELLING EM REALIDADE VIRTUAL: AJUDAR CRIANÇAS COM MEDO DO ESCURO

\section{STORYTELLING IN VR: HELPING CHILDREN WITH FEAR OF THE DARK}

Dissertação apresentada à Universidade de Aveiro para cumprimento dos requisitos necessários à obtenção do grau de Mestre em Comunicação Multimédia, realizada sob a orientação científica do Doutor Mário Jorge Rodrigues Martins Vairinhos, Professor Auxiliar do Departamento de Comunicação e Arte da Universidade de Aveiro. 

Dedico este trabalho aos meus pais e aos meus avós. 

o júri / the jury

presidente / president Prof. Doutor Luís Francisco Mendes Gabriel Pedro

Professor Auxiliar da Universidade de Aveiro (Presidente)

Prof. Doutora Cátia Sofia Afonso Ferreira

Professora Auxiliar da Universidade Católica (Vogal)

Prof. Doutor Mário Jorge Rodrigues Martins Vairinhos

Professor Auxiliar da Universidade de Aveiro (Vogal) 

Agradeço profundamente à minha família e amigos pelo apoio prestado durante este percurso académico. Desejo também agradecer ao meu orientador, o professor Mário Vairinhos, por me ter aconselhado com tanta paciência durante este ano letivo. Um agradecimento muito especial também para o Salvador e para o Tomás.

Esta dissertação não teria sido possível sem todas as partes.

Muito obrigada a todos. 

palavras-chave

resumo
Realidade virtual, fobia do escuro, jogos para crianças, histórias, narrativas interativas, Oculus Go.

A utilização de aplicações de realidade virtual para tratamento de fobias está a tornar-se cada vez mais popular, mas muitos destes tratamentos requerem a assistência e/ou presença de um psicólogo ou terapeuta. Ademais, a maioria das terapias de realidade virtual são visadas para fobias sociais ou para distúrbios de ansiedade. $O$ medo do escuro é um dos medos mais comuns em crianças e pode transformar-se numa fobia durante a sua vida adulta, mas ainda não é possível de prevenir ou tratar com programas terapêuticos de realidade virtual. Uma medida para ajudar crianças a ultrapassar os seus medos num ambiente seguro, em conjunto com familiares ou zeladores, pode ajudar a melhorar relações familiares e a apaziguar o stress que a fobia do escuro cria no lar. Este trabalho de investigação concebeu, implementou e avaliou um protótipo de realidade virtual com testes de usabilidade em ambiente simulado e desenvolveu um caso de estudo com um utilizador final em contexto próximo do real. Concluiu-se que o caso de estudo documenta reações emocionais positivas face ao protótipo e à sua narrativa. Os resultados do presente estudo são bastante promissores, no entanto, o grau de medo do utilizador final não é comparável a uma criança com fobia diagnosticada, pelo que, no futuro, devem estender-se os testes a utilizadores diagnosticados com fobias. 

keywords

abstract
Virtual reality, phobia of the dark, children's games, storytelling, interactive narratives, Oculus Go.

Though using virtual reality as a substitute for exposition therapy in phobia treatments has become more popular in recent times, many of these treatments require the assistance of a psychologist or a therapist. Furthermore, most of virtual reality therapy is targeted at socially based phobias or anxiety disorders. Fear of the dark is one of the most common fears in children and can develop into a diagnosed phobia in their later lives but has yet to be prevented or treated with virtual reality therapy programs. A measure to help children overcome their fears in a safe environment together with their caretakers could help improve familial relationships and ease the stress that this kind of phobia introduces in home life. This investigation developed, implemented and evaluated a virtual reality prototype with usability testing and established a case study with a final user in an effort to approximate this investigation to reality. It was concluded that the case study documentations find that the user had positive emotional reactions towards the prototype and its narrative. The results of this research's testing are quite promising, though the final user's degree of fear is not comparable to a child with a diagnosed phobia of the dark. Future work should therefore include testing with users diagnosed with phobias. 



\section{INDEX}

INTRODUCTION

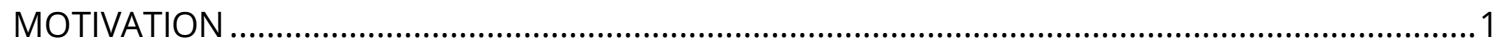

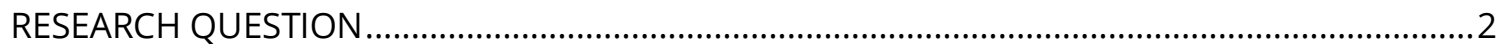

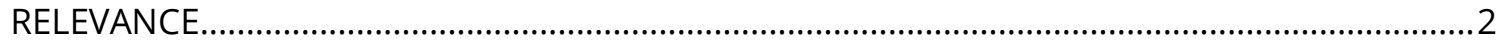

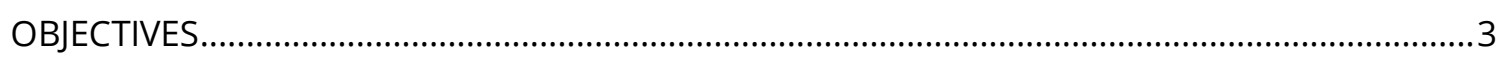

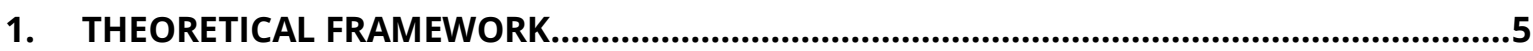

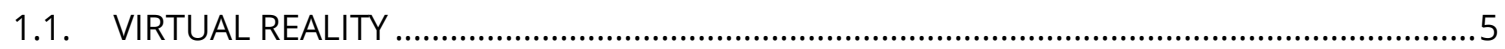

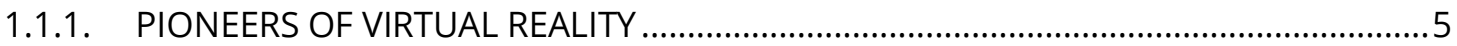

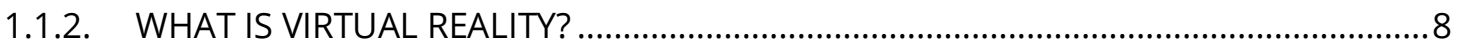

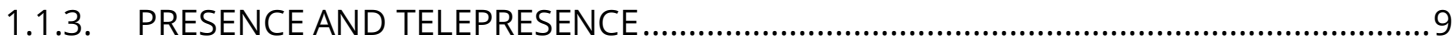

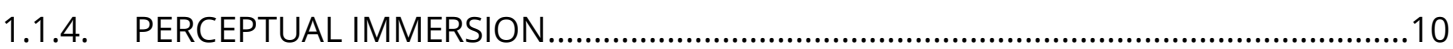

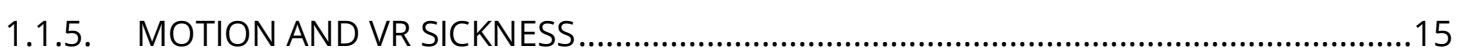

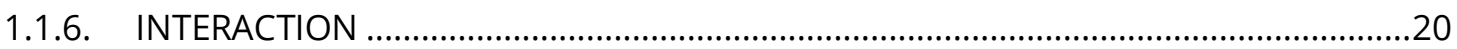

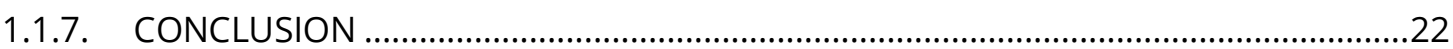

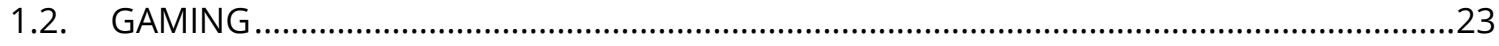

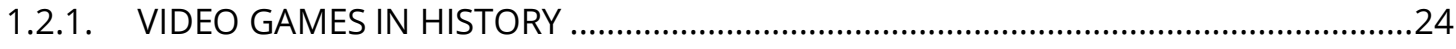

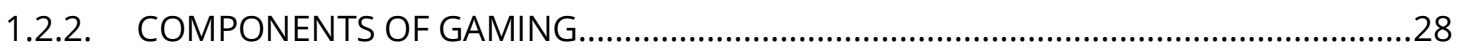

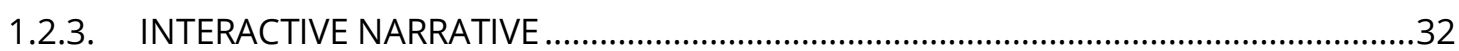

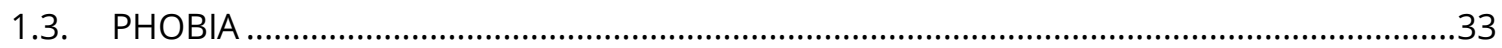

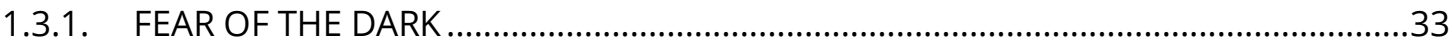

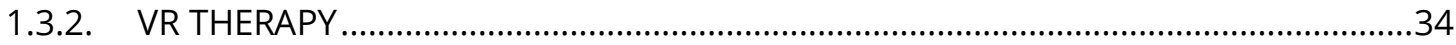

1.3.3. GAMES FOR CHILDREN WITH FEAR OF THE DARK........................................................

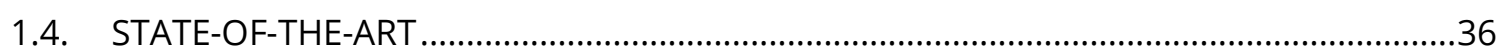

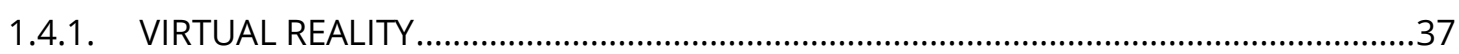

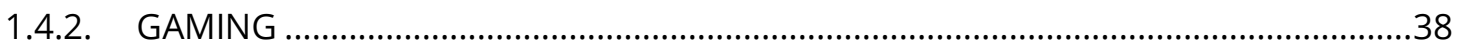

2. METHODOLOGY

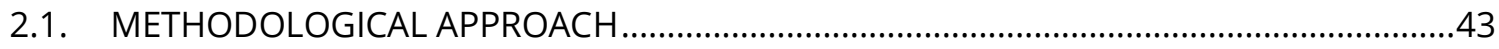

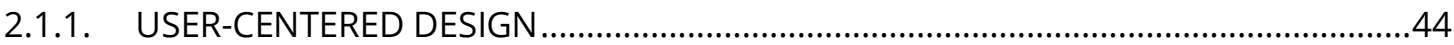

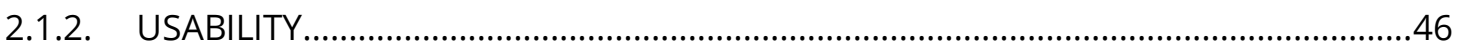

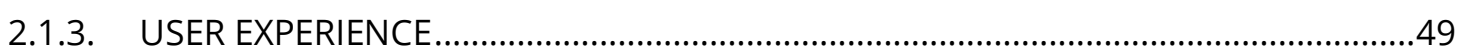

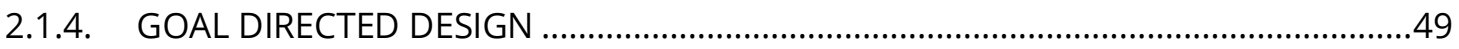

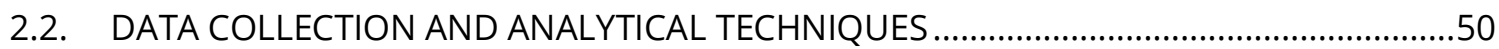

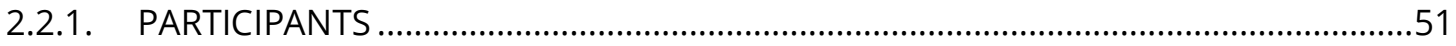




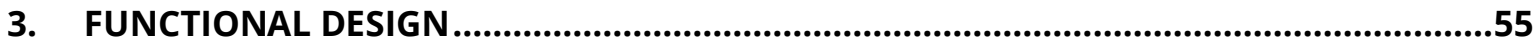

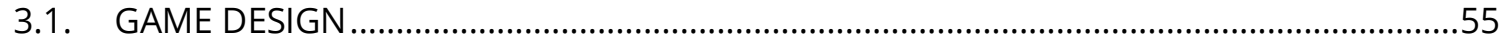

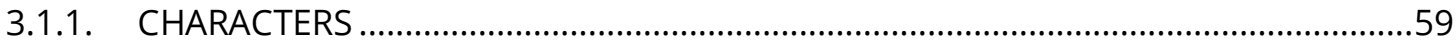

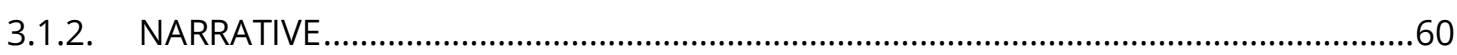

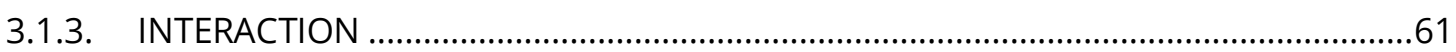

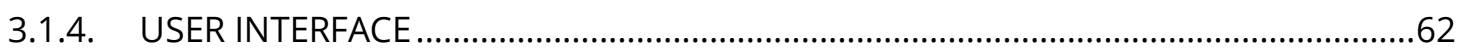

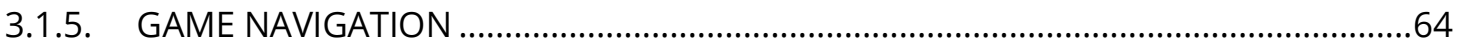

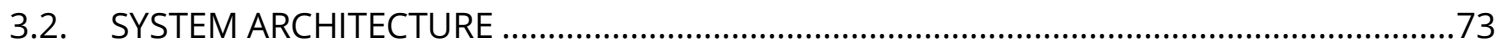

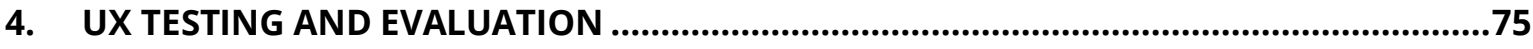

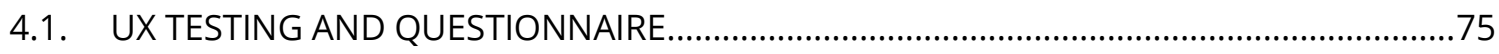

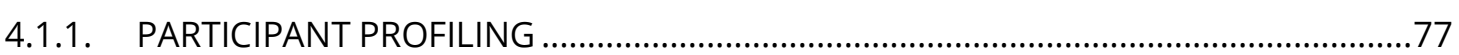

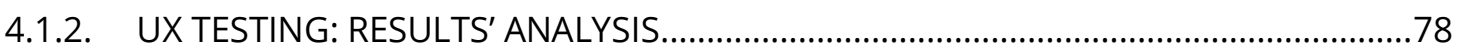

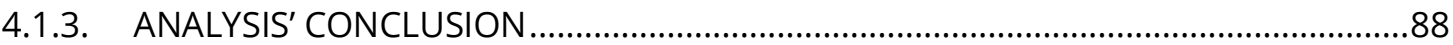

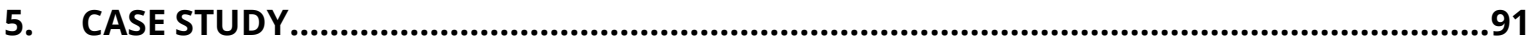

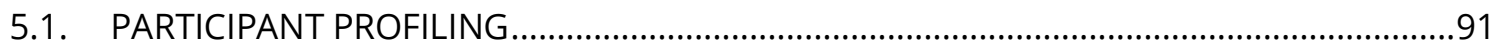

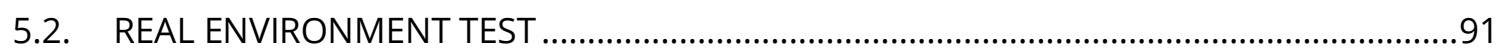

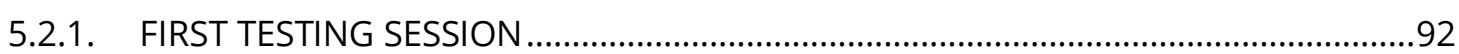

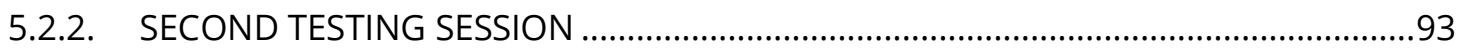

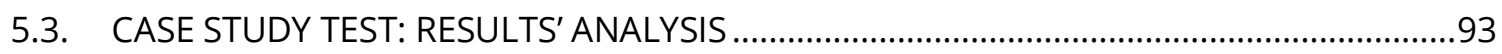

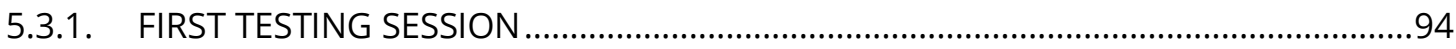

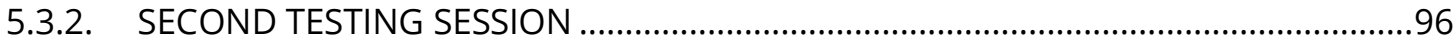

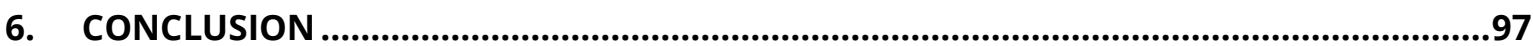

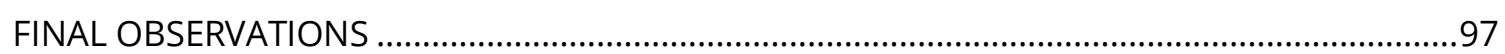

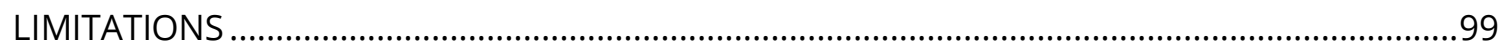

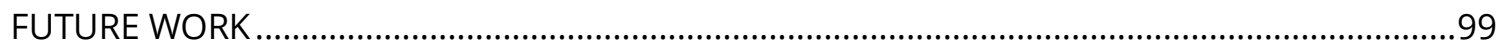

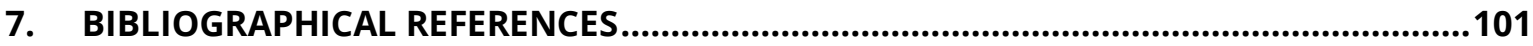

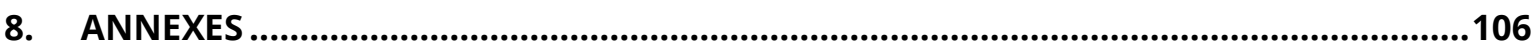




\section{LIST OF FIGURES}

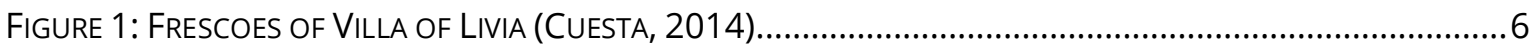

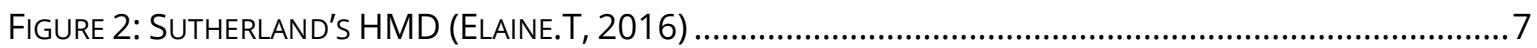

FIGURE 3: ZELTZER'S AIP CUBE (ADAPTED FROM ZELTZER, 1992 FOR READIBILITY PURPOSES) ............................ 8

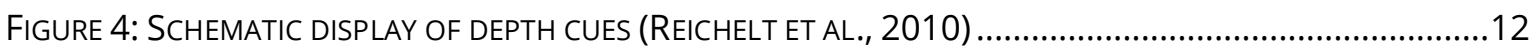

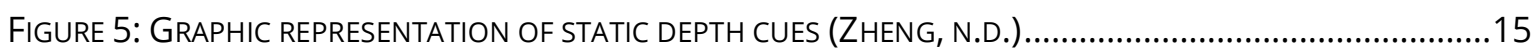

FIGURE 6: REPRESENTATION OF LINEAR ACCELERATION CAUSED BY THE MACULA (ENCYCLOPADIA BRITANNICA,

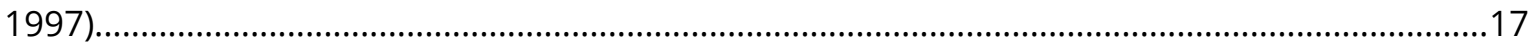

FIGURE 7: COMPARISON BETWEEN NATURAL VIEWING AND STEREOSCOPIC VIEWING WITH A 3D STEREO DISPLAY

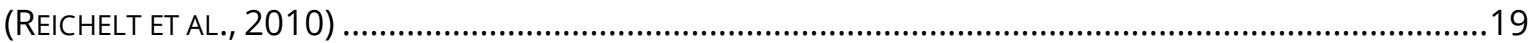

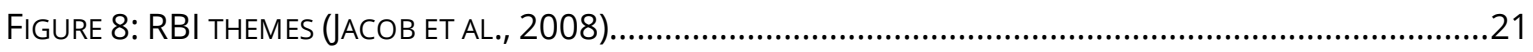

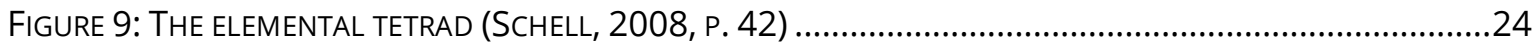

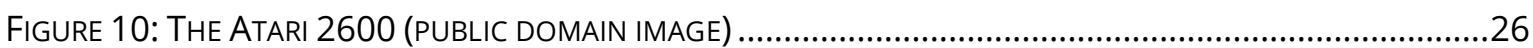

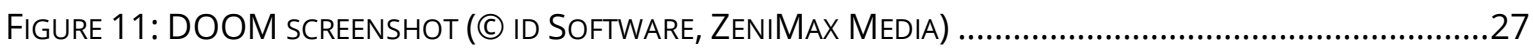

FIGURE 12: MEASUREMENTS OF AUDIENCE CONTROL (ADAPTED FROM CRAWFORD, 1997, PP. 11-12).............29

FIGURE 13: VRT IN CLINICAL PSYCHOLOGY (ADAPTED FROM VENTURA ET AL., 2018, P. 104) ...........................34

FIGURE 14: SCREENSHOT OF NoW I CAN Do HEIGHTS (๑ OXFORD VR) (FREEMAN ET AL., 2018) ........................39

Figure 15: A screenshot of the \#BeFearless' School Life mode ("SAmsung \#BeFearless Fear of

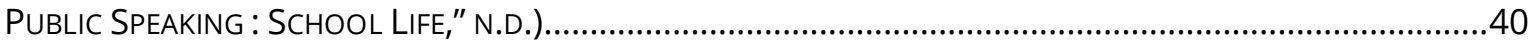

FIGURE 16: INTERFACE QUALITY AS A FUNCTION OF THE NUMBER OF DESIGN ITERATIONS (NIELSEN, 1993) ........46

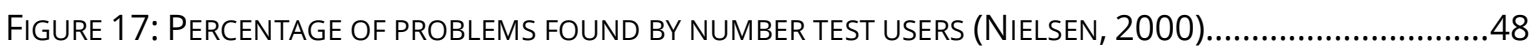

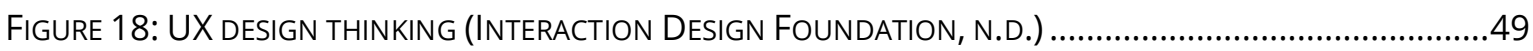

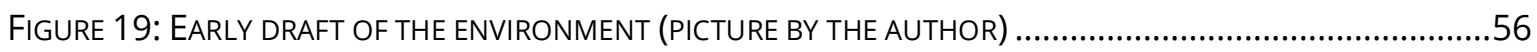

FIGURE 20: CONCEPTUAL SCHEMATICS OF THE WORLD MAP (PICTURE BY THE AUTHOR) ...................................57

FIGURE 21: TOP ISOMETRIC VIEW FROM THE 3D MODEL OF THE WORLD AS IT APPEARS IN UNITY3D (PICTURE BY

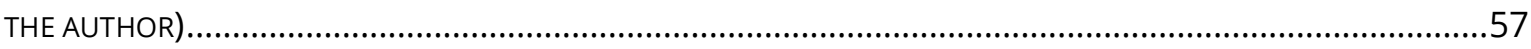

FIGURE 22: PROTOTYPE SCREENSHOT: A NON-PLAYER CHARACTER AND ENVIRONMENT (PICTURE BY THE AUTHOR)

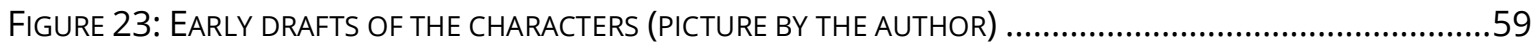

FIGURE 24: ANIMAL 3D MODELS IN IDLE POSITION (PICTURE BY THE AUTHOR).............................................59

FIGURE 25: DiALOGUE ACTIVATION BUTTONS (DISABLED AND ENABLED, RESPECTIVELY) (PICTURE BY THE AUTHOR)

FIGURE 26: Dialogue UI WITH THE BUtTON TO ADVANCE TO THE NEXT LINE AND DIALOGUE UI WITH THE

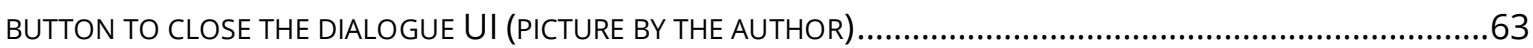

FIGURE 27: NPC BEING INTERACTED WITH IN-GAME (PICTURE BY THE AUTHOR) .............................................63

FIGURE 28: INVENTORY UI AS IT APPEARS IN-GAME. THE FOUR SQUARES BELOW THE WORLD'S MAP ARE MEANT TO

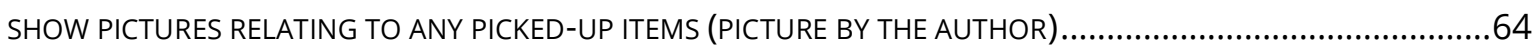

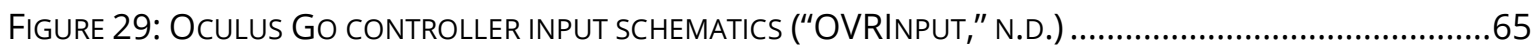

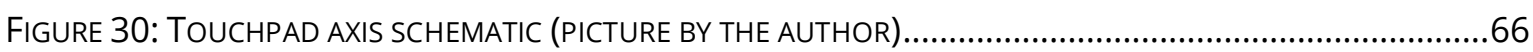

FIGURE 31: UNTARGETED TELEPORT POINT (LEFT) AND TARGETED TELEPORT POINT (RIGHT) (PICTURE BY THE

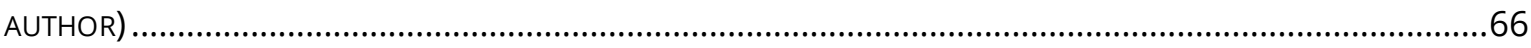

FIGURE 32: INVENTORY UI DISPLAYED IN UNITY'S EDITOR (PICTURE BY THE AUTHOR) .....................................67

FIGURE 33: EXAMPLE OF RAYCASTING AND DEMONSTRATION OF LASER POINTER CONTROLLER (TARGETING THE

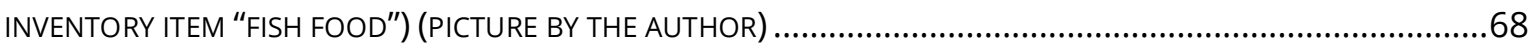


FIgURE 34: START MENU NAVIGATION SCHEMATIC (PICTURE BY THE AUTHOR).....

FIGURE 35: DEMONSTRATION OF LIGHTING LEVELS ON THE START MENU (PICTURE BY THE AUTHOR) ..................69

FIGURE 36: PROTOTYPE SCREENSHOT OF BRIDGE "GATE” (PICTURE BY THE AUTHOR) ………...........................70

FIGURE 37: PROTOTYPE SCREENSHOT OF FALLEN TREE "GATE” (PICTURE BY THE AUTHOR) ................................ 71

FIGURE 38: PROTOTYPE SCREENSHOT OF DARKENED CAVE ENTRANCE "GATE" (PICTURE BY THE AUTHOR) ............71

FIGURE 39: PROTOTYPE SCREENSHOT OF FOX HIDING IN BUSHES, BEFORE BEING FED (PICTURE BY THE AUTHOR) 72

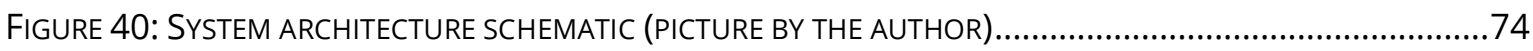

FIGURE 41: HISTOGRAM DETAILING TASK 1 DIFFICULTY CLASSIFICATIONS (PICTURE BY THE AUTHOR) ..................80

FIGURE 42: HISTOGRAM DETAILING TASK 2 DIFFICULTY CLASSIFICATIONS (PICTURE BY THE AUTHOR) ..................81

FIGURE 43: HISTOGRAM DETAILING TASK 3 DIFFICULTY CLASSIFICATIONS (PICTURE BY THE AUTHOR) ...................81

FIGURE 44: HISTOGRAM DETAILING TASK 4 DIFFICULTY CLASSIFICATIONS (PICTURE BY THE AUTHOR) ...................82

FIGURE 45: HISTOGRAM DETAILING TASK 5 DIFFICULTY CLASSIFICATIONS (PICTURE BY THE AUTHOR) ..................82

FIGURE 46: HISTOGRAM DETAILING TASK 6 DIFFICULTY CLASSIFICATIONS (PICTURE BY THE AUTHOR) ..................83

FIGURE 47: HISTOGRAM DETAILING TASK 1 SATISFACTION CLASSIFICATIONS (PICTURE BY THE AUTHOR)..............83

FIGURE 48: HISTOGRAM DETAILING TASK 2 SATISFACTION CLASSIFICATIONS (PICTURE BY THE AUTHOR)..............84

FIGURE 49: HISTOGRAM DETAILING TASK 3 SATISFACTION CLASSIFICATIONS (PICTURE BY THE AUTHOR) ..............84

FIGURE 50: HISTOGRAM DETAILING TASK 4 SATISFACTION CLASSIFICATIONS (PICTURE BY THE AUTHOR)..............85

FIGURE 51: HISTOGRAM DETAILING TASK 5 SATISFACTION CLASSIFICATIONS (PICTURE BY THE AUTHOR)..............85

FIGURE 52: HISTOGRAM DETAILING TASK 6 SATISFACTION CLASSIFICATIONS (PICTURE BY THE AUTHOR)..............86

\section{LIST OF TABLES}

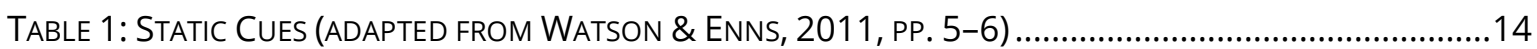

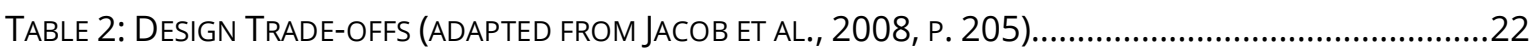

TABlE 3: ChARACTERISTICS OF GAMES (AdAPTED From SALEN \& ZIMMERMAN, 2004, P. 91) ..........................23

TABle 4: Common Game GenRes (CRAWford, 1997; Hansen, 2016; QI, 2014; SAlen \& Zimmerman,

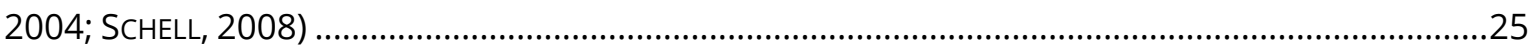

TABLE 5: DESIGN-BASED RESEARCH CHARACTERISTICS (ADAPTED FROM BAKKER \& VAN EERDE, 2015, P. 435) ...43

TABLE 6: NIELSEN'S (1995) ADAPTED USABILITY HEURISTICS VERIFIED IN THE LOW-FI PROTOTYPE ......................47

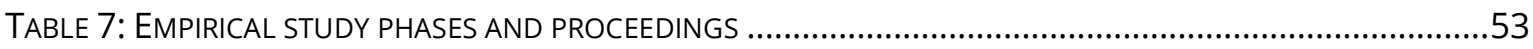

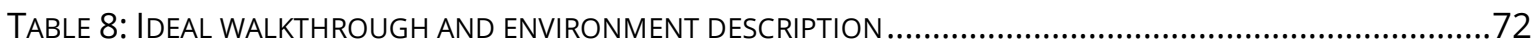

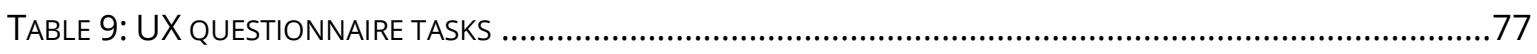

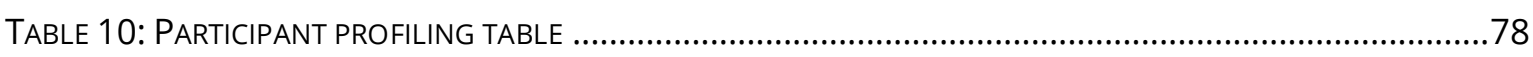

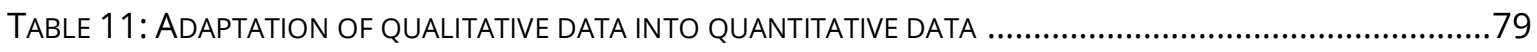

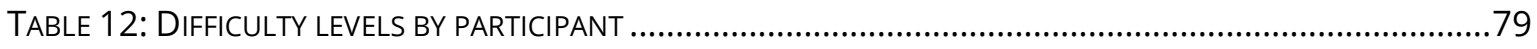

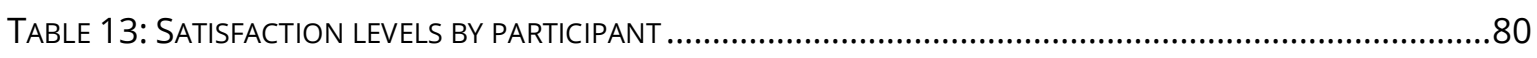

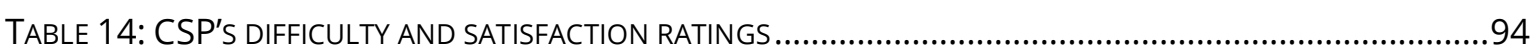




\section{LIST OF ACRONYMS}

- VR: Virtual reality

- HMD: Head-mounted display

- HCl: Human-computer interaction

- GUI: Graphical user interface

- RBI: Reality-based interaction

- WIMP: "Window, icon, menu, pointing device"

- AR: Augmented reality

- SDK: Software development kit

- 2D: Two-dimensional

- 3D: Three-dimensional

- VRT: Virtual reality therapy

- UCD: User-centered design

- HCD: Human-centered design

- DBR: Design-based research

- UI: User interface

- UX: User experience

- NPC: Non-player character 



\section{INTRODUCTION}

Virtual reality (VR) therapy has become increasingly more popular in the treatment of phobias and post-traumatic stress disorder, as it has been found to be more effective and less traumatizing than in vivo exposition therapy (Freeman et al., 2018; Garcia-Palacios, Botella, Hoffman, \& Fabregat, 2007; North, North, \& Coble, 1998; Opriş et al., 2012; Ventura, Baños, \& Botella, 2018). Despite this, most VR treatments are directed towards social anxiety-based phobias or post-traumatic stress disorder; there are few studies focusing on children as opposed to older youths or adults (Bouchard, 2011; Gutiérrez-Maldonado, Magallón-Neri, Rus-Calafell, \& Peñaloza-Salazar, 2009).

\section{MOTIVATION}

The motivating factor in this research is the usage of VR and video game development as instruments in areas outside of entertainment, one of which is VR simulations as a therapy for phobia-based anxiety.

The investigation became focused on children with fear of the dark after the researcher participated in early-phase focus groups' meetings and interviews arranged by the university's professors, both of which counted with the contributions of a psychology professor. The focus on fear of the dark as opposed to a social anxiety-based fear was justified on account of fear of the dark being a novel issue in VR-based therapy. Furthermore, the possibility to help phobic children (and, consequently, their caretakers) with the creation of a prototype specifically designed for them was a point of interest for the researcher, as well as for the Human-Computer Interaction community. In terms of practical development, the dark is easy to simulate graphically, which would greatly simplify the prototype's development and project time management and make it a feasible project.

The target audience of the VR game are children, as fear of the dark is one of the most common fears in children and is thought to be a normal part of their growth and development. However, a child's fear of the dark can develop into a diagnosed phobia in their later lives (Levos \& Zacchilli, 2015). 84.7\% of children between 7 and 9 years of age suffer from mild nighttime fears (Lewis, Amatya, Coffman, \& Ollendick, 2015). The fear of the dark can have a debilitating effect on a person's life - or, if a child is affected, their caretakers' lives also - as it generally inhibits leaving the house after dark, sleeping with a nightlight on, and suffering night terrors (American Psychiatric Association, 2013; Levos \& Zacchilli, 2015).

Virtual reality therapy can generate phobic stimuli in private spaces such as the child's home or a private office, which allows for greater control of public embarrassment and patient 
confidentiality (North et al., 1998; Ventura et al., 2018). This also allows for a better, more trustworthy way to relive traumatic events (Ventura et al., 2018). Adult patients also tend to choose VRT over in vivo exposure therapy (Garcia-Palacios et al., 2007), and child patients tend to have positive reactions to the use of VR in therapy, perhaps motivated by their interest on VR technology (Bouchard, 2011).

A measure to help children face and/or overcome their fears in a safe environment together with their caretakers could help improve familial relationships and ease the stress that this kind of phobia introduces in home life, as children are usually heavily dependent on their caretakers.

\section{RESEARCH QUESTION}

As this dissertation focuses upon VR therapy targeted at children, the research question should concern how one can develop a VR game for a specific audience, young children, with a specific problem, phobia of the dark. According to Quivy and Campenhoudt (2005), this question must be clear, pertinent, and practicable.

In the context of this thesis, the primary research question (1) is clear, as it unambiguously pertains to investigate the positive impact of a VR game on a child with phobia of the dark; (2) pertinent, as it relates to the specific audience and problem; (3) practicable, as it purposes the development of a VR game designed specifically for the target audience and problem, followed by testing and analysis of the results:

\section{CAN A VR STORYTELLING GAME POSITIVELY IMPACT A CHILD'S PHOBIA OF THE DARK?}

The practicable development of a game requires following certain guidelines and methodologies, further explained in the second chapter of this thesis, Methodology.

Moreover, a secondary question can also be considered pertinent once the first question has established a basis, in order to better understand the user's experience after playing the prototype and if the phobia of the dark-centered narrative affects the user emotionally:

2. CAN PHOBIA OF THE DARK BE INCORPORATED AS A PIVOTAL CONCEPT IN A GAME'S NARRATIVE AND/OR IMPROVE USER EXPERIENCE?

\section{RELEVANCE}

The central focus of this research is the development of a functional VR game prototype. 
Though using VR as a substitute for exposition therapy in phobia treatments has become more popular in recent times, many of these VR-based treatments require the assistance of a psychologist or a therapist.

Ideally, the prototype developed in the context of this research project approaches the usage of a VR game targeted at children in order to overcome a specific fear (i.e. the dark), without having to leave the comfort of their own homes and without having to pay for regularly-scheduled therapy. The fact that parental participation in the game can and should be factored in the experiment can also become a point of interest for parents or caretakers.

\section{OBJECTIVES}

This dissertation aims to understand the methods with which to apply VR in the treatment of phobias, more specifically children with diagnosed phobia or acute fear of the dark. Moreover, one should understand the effect caused by playing the game, which can be achieved through observation of the user as they play.

To satisfy the investigation's time frame, the project will result in a functional prototype, and not a finished game. The knowledge acquired through a thorough review of literature should serve as a basis for the prototype's development, as the review encompasses VR, gaming, and phobias. These concepts are elements which will influence the prototype.

The gameplay should be simple enough that the development of the prototype finishes early enough to allow for the observation of the user, both as they play and as they answer questionnaires regarding several aspects of the game, such as: user interface (UI) design, user experience (UX), and the prototype's relation to their fear. As the user is expected to be a child with phobia or acute fear of the dark, between the ages of 8 and 10 years old, the language of the game and the questionnaires should be more child-friendly than the academic norm.

The objectives of this study therefore comprehend:

1. Creation of a game narrative meant for therapeutic applications;

2. Development of a functional VR prototype in the established time frame;

3. Testing and analysis of usability and UX relating to the prototype's virtual environment and UI;

4. Creation and documentation of a case study with sample of target audience;

5. Analysis of case study testing (i.e. usability, UX, and emotional response);

6. Investigation of the prototype's future potential in therapeutic treatment of phobia of the dark; 


\section{THEORETICAL FRAMEWORK}

The theoretical framework of this research is divided in four subchapters, namely: (1) virtual reality, (2) gaming, and (3) phobia, being that the fourth topic concerns the (4) state-of-the-art. The first subchapter, Virtual Reality, offers an overview of the concept and technology through a summary of its history, what it is defined by, and explains the concept of VR outside of digital technology.

The second subchapter, Gaming, introduces a brief history of video games, along with the definition of what a game is, why people enjoy playing games, and how video games are a possible medium for education.

The third subchapter, Phobia, approaches the definition of phobia and fear, as well as supervising VR therapy guidelines and possible games for children with fear of the dark.

\subsection{VIRTUAL REALITY}

Virtual reality is currently glamorized as a groundbreaking technology and is frequently associated with the gaming industry. However, VR has been applied in all sorts of non-gaming activities, such as architectural or real-estate projects, cultural and learning events (e.g. virtual tours), and even clinically (e.g. VR-based exposure therapies or relaxation games) (GutiérrezMaldonado et al., 2009; Marques, 2016; Moore, Wiederhold, Wiederhold, \& Riva, 2002; Pinto, 2015; Zyda, 2005).

The potential of VR is no longer untapped, even as academics and researchers continue to find new purposes in which to utilize it. But before the evolution of VR technology normalized commercially available VR products, VR-based therapy, or virtual tours, there was only the idea of VR, and how it was later developed enough to become a concept.

\subsubsection{PIONEERS OF VIRTUAL REALITY}

In 1965, Ivan Sutherland suggests that VR would eventually encompass "interactive graphics, force-feedback, sound, smell, and taste” (Mazuryk \& Gervautz, 1999, p. 2).

This statement precedes the beginning of VR as a technology and is preceded by thousands of years of illusionary and immersive art, which arguably makes up a large part of what VR tries to achieve. Therefore, it makes sense to mention this illusive immersion, if only briefly.

Painters from the Roman Republic were adept at altering the perception of entire rooms because of their style of painting. The painted rooms were perceived to be larger than they were, and the 
people who visited them were put under an illusion of belonging to the place and time of the painting (Grau, 2003). This sort of illusion was achieved because of the architecture: a sealed enclosure that would surround the viewer and allow for the drawing's perspective to match the viewer's depth expectations, but also because of the spatial and temporal togetherness of the pictures on the walls (Grau, 2003; Reichelt, Häussler, Fütterer, \& Leister, 2010).

Unlike the squares of a comic book or frames of a movie, the Roman frescoes analyzed by Grau (2003) were not forming a chronological segment. They were instead a single moment captured by different points-of-view: a panorama, albeit one divided by the architectural restrictions of the rooms such as corners or entrances (see figure 1).

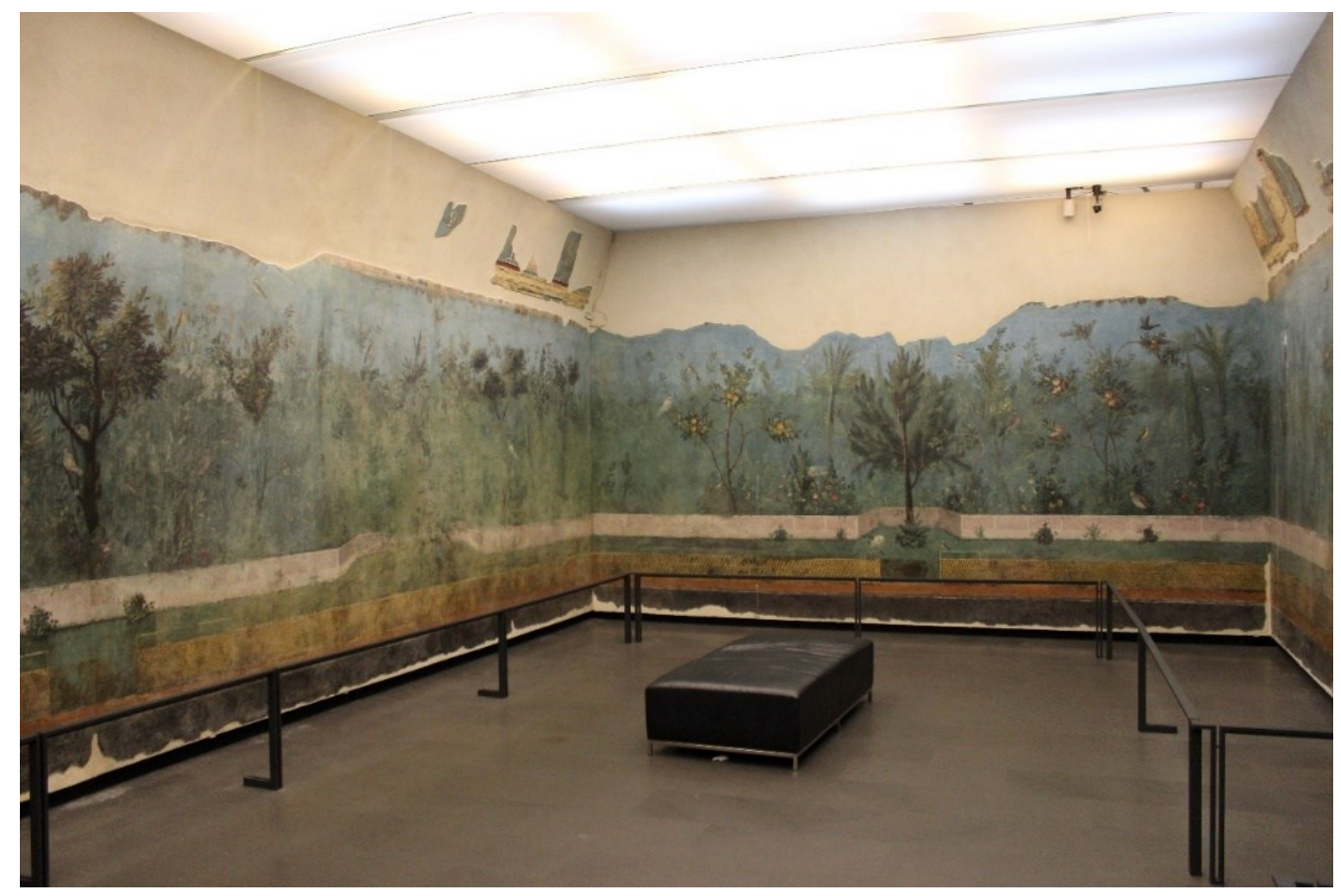

Figure 1: Frescoes of Villa of Livia (Cuesta, 2014)

The word panorama, nowadays, is commonly grouped with the art of photography. Popularized by the evolution of image-capturing devices, a panoramic picture is an unobstructed view of all directions surrounding the observer. The Roman frescoes mentioned by Grau (2003) utilized this method.

It wouldn't be until Morton Heilig invented Sensorama that panoramic videos became a possibility. Heilig's Sensorama was the first approach to a VR experience, utilizing not only sight but hearing, smell, and touch to augment the user's immersion. But where Sensorama's film offered deep absorption of its environment, it lacked interaction (Mazuryk \& Gervautz, 1999). 
The head-mounted display (HMD) of Sutherland (1968), which arguably became the precursor to today's VR headsets, was the first system to have appropriate hardware to complement the concept of VR. The HMD supported head-tracking and a continuously updating view in accordance to the user's head position and orientation (see figure 2).

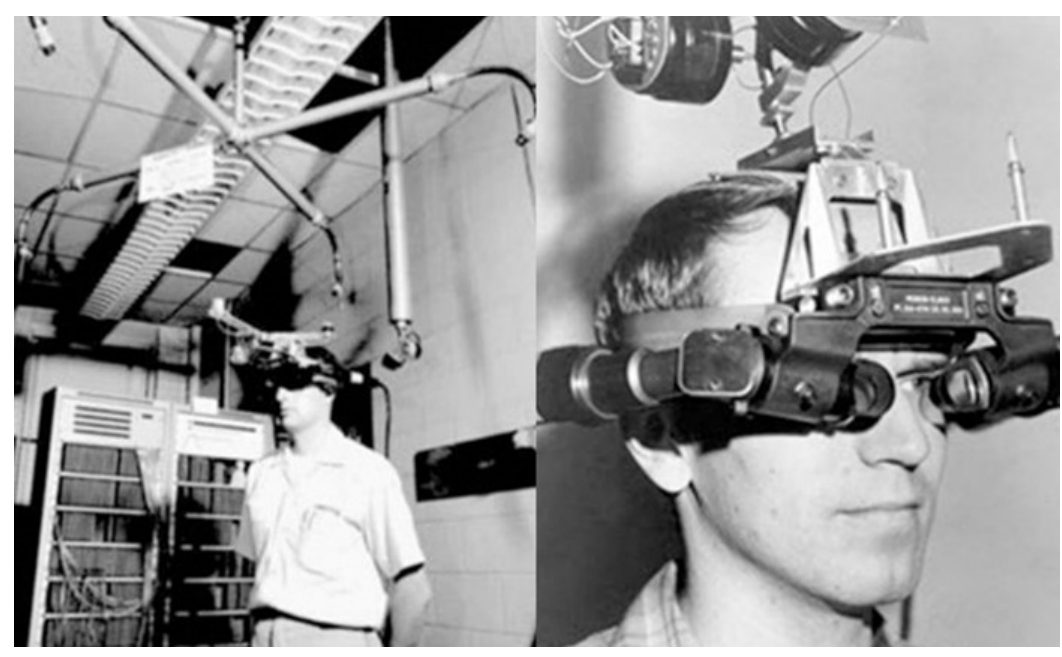

Figure 2: Sutherland's HMD (Elaine.T, 2016)

Sutherland's purpose was for the HMD to present the user with changing, position-dependent perspective images. This was made possible both by the head-tracking technology included in the HMD and by stereo-viewing, which placed two-dimensional images on the user's retinas and gave the illusion of depth, mimicking that which the human brain creates naturally. However, Sutherland's HMD still lacked the capacity for user interaction - the users of the HMD could only observe, even if they could change their point-of-view position in the virtual space (Sutherland, 1968). In addition, due to technological limitations at the time, the HMD was too large and heavy, and its development was too costly for individual consumer use.

Force-feedback would become a part of VR later, starting in 1967 with the creation of the University of North Carolina's GROPE prototype. The GROPE prototype used haptic technology to allow for manipulation of virtual wireframe-modelled molecules, as well as the representation of molecular docking forces. Haptic technology would later be used in the development of the data glove technology (Lowood, 2018; Mazuryk \& Gervautz, 1999).

The usage of a data glove would prove to be crucial in the concept of VR, since it made it possible to manipulate virtual worlds and their belonging objects - a function that was missing from Sutherland's HMD. Two of the earliest prototypes of data gloves, the Z-Glove and the DataGlove, were made from cotton. They were able to measure finger-bending by using flex sensors, were implemented with positioning and orientation systems, and gave tactile feedback in the form of vibrations (Zimmerman, Lanier, Blanchard, Bryson, \& Harvill, 1987). The DataGlove was the first VR device to be commercially available to the public, together with VPL Company's 
Eyephone HMD (1988), and is considered an iconic mark in VR's history. The usage of data gloves soon became connected with personal home-gaming systems, as could be observed with Nintendo's PowerGlove (1989) and VirtualBoy system (1995) (Lowood, 2018; Mazuryk \& Gervautz, 1999).

This meant VR was no longer limited to research labs and academic platforms. However, the link between entertainment and VR also meant that other projects' potential went largely unexploited, and that VR would become so associated with computer graphics that the lines between the two are still blurred today. As such, it is necessary to understand what VR is.

\subsubsection{WHAT IS VIRTUAL REALITY?}

VR is a medium intrinsically tangled with technology. Popular culture has transformed headsets into a symbol of VR. In turn, headsets have been made increasingly more famous as the gaming industry focuses more and more on VR. There are also examples of a virtual environment in the movie "Tron" (1982 or 2010), in which the main character is transported to a digital world. Both concepts are linked to entertainment, and neither could exist without the hardware that allows the experience. One cannot play a VR-specific game without a headset, just as the main character of Tron could not enter the digital world without the computer which housed its software.

David Zeltzer (1992) suggests a taxonomy of VR simulation systems based on three components: autonomy, interaction, and presence (AIP), better demonstrated on his AIP cube (see figure 3).

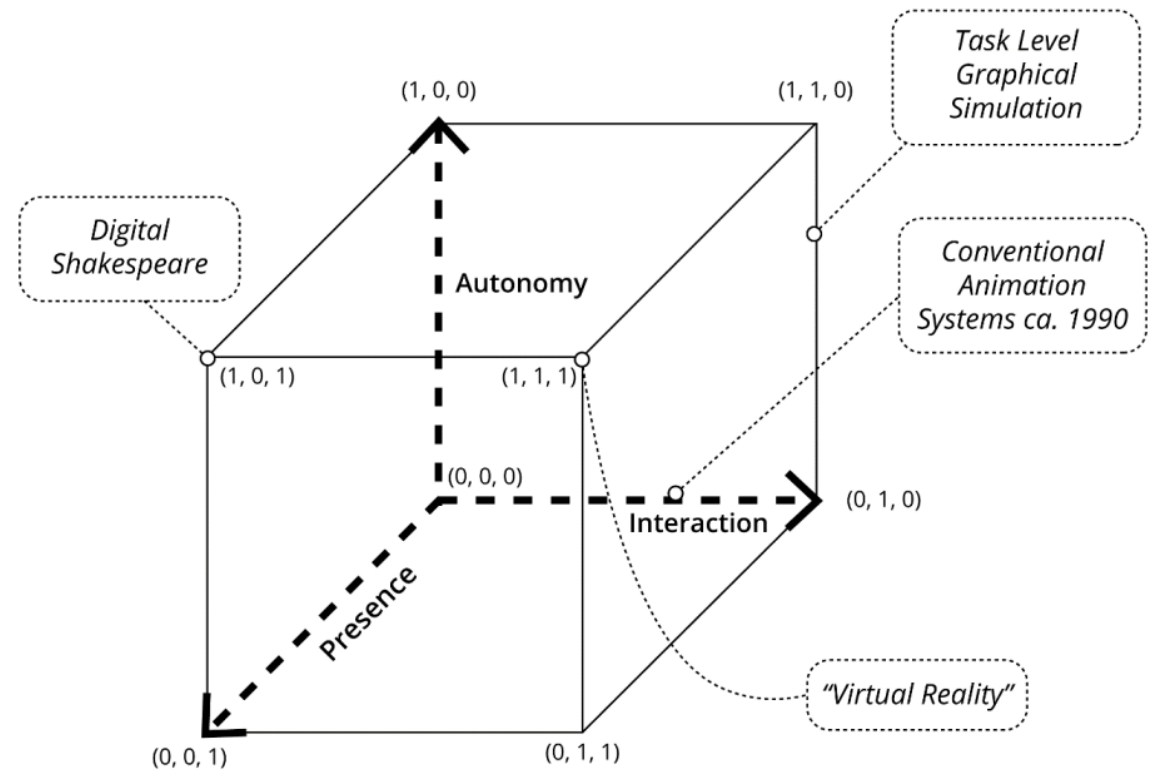

Figure 3: Zeltzer's AIP cube (adapted from Zeltzer, 1992 for readibility purposes) 
Autonomy as scale can range from passive to reactive and ranks the ability of a computational model to act and react to stimuli caused by the VR user. E.g. a geometric model that can be transformed and rendered is passive, while a model capable of reactive planning and "knowledge-based behaviors" is reactive (Zeltzer, 1992, p. 1). For further clarification, a virtual, physics-affected ball that bounces when it strikes certain predetermined areas is more active than passive.

Interaction measures the definition and modification of a model at runtime. E.g., a computer mouse can drag a folder or file at runtime, but a more complex program such as an animation system might require a rendering time before the user's desired outcome is complete (Zeltzer, 1992). VR applications should have, ideally, the highest value of interaction possible, which means the program be able to allow all inputs and posterior consequences at runtime. Interaction as a concept is described to a greater extent in section 1.1.6, Interaction.

However, the definition of VR cannot be limited to the devices that allow for someone to experience it. Steuer and Reeves (1992) approach this issue by means of distancing themselves from the subject of hardware, instead focusing on the human experience and the concept of presence. As such, the final component of the AIP cube, presence, will be further studied in the following section.

\subsubsection{PRESENCE AND TELEPRESENCE}

Presence is what allows someone to perceive the world around them (Steuer \& Reeves, 1992).

A person standing in a room can perceive the furniture around them using five senses and automatic mental processing. This lets them understand they are in an environment. This understanding is called unmediated perception, and it means the feeling of presence is so obvious that it is taken for granted (Steuer \& Reeves, 1992).

But when perception is mediated by technology, one suddenly perceives two environments: the unmediated environment, where the person exists physically, and the mediated environment, which is presented through a medium; this mediated environment can be anything from a temporally- and/or spatially-different location such as footage from World War II, to a computer animation of a virtual world like a location in a video game (Steuer \& Reeves, 1992). Zeltzer (1992) also connects interaction through a controller with the feeling of presence, and that presence could benefit from properly-designed controllers such as a DataGlove.

These are two different kinds of presence, which means they result in different kinds of perception. In order to distinguish between them, Steuer and Reeves (1992) use the term "telepresence" to describe that which is felt through a mediated environment. 
To summarize, "presence" is connected to the unmediated perception of environments, while "telepresence" is connected to the mediated perception of environments. And although Steuer and Reeves (1992) mention technology plays an essential part in telepresence, it is interesting to compare the concept to the previously mentioned Roman frescoes and the feelings they elicit. The frescoes are not digital technology, but they are still a communication medium that gives the observer the feeling of telepresence, of "being there" even though they are not.

Like the Roman frescoes, VR needs to be able to transport a user to another place and make them feel as though they are there. One of the ways for VR to achieve this is by successfully immersing its users in the environment.

\subsubsection{PERCEPTUAL IMMERSION}

This section refers to perceptual immersion in the context of VR. ${ }^{1}$

The feeling of telepresence largely depends on sight and/or hearing, as they are the two most important senses when it comes to providing information and monopolizing attention (Heilig, 1992; Mazuryk \& Gervautz, 1999). Sight contributes to 70\% of information, while hearing contributes to $20 \%$ (Heilig, 1992). Since sight largely overpowers the remaining senses, it makes sense that VR should work towards the simulation of graphical environments - but it is also necessary to remember that appropriate sounds are necessary to complete the experience.

As VR has yet to evolve to fully submerge its users' five senses, for now, and in the context of this study and subsequent experiences, one can propose that a HMD with built-in headphones is able to give the user the feeling of "being there" through $3 \mathrm{D}$ spatialized sound and the graphical simulation of environments (this proposal does not yet account for interaction, which is discussed later).

\section{Sound}

Sound can be used to give feedback upon completion of tasks, or to inform the user of, e.g., collisions between objects. Sound-based feedback thus augments immersion and does not require UI graphical elements to be placed on the screen (Mazuryk \& Gervautz, 1999). VR is, however, a more complex environment.

\footnotetext{
${ }^{1}$ Though narrative immersion and agency are also concepts relating to immersion, they will be approached in subchapter 1.2, Gaming, as they are more closely aligned with gaming than with VR.
} 
In order to give its users the feeling of immersion, VR requires that its sound displays simulate the sounds of the real world. This can be achieved through stereophonic sound, or stereo sound, which allows each human ear to capture a different sound.

Stereo sound is a method that uses two audio channels, independent from one another, to replicate real-life sound sources² ("Sound Systems: Mono vs. Stereo," n.d.). VR projects can use stereo sound to better manage audio sources and create spatial audio through three-dimensional auditory displays, which amplifies the feeling of realism and immersion in the virtual environment (Mazuryk \& Gervautz, 1999).

E.g., the engine chosen to develop the prototype, Unity3 $\mathrm{D}^{3}$, allows for the generation of spatial sound sources: Unity3D's built-in Audio Spatializer ${ }^{4}$ calculates the distance and angle from the audio source to the listener and adapts the sound gains of the left and right speakers ("Unity Manual: Audio Spatializer SDK," n.d.). Recent HMD hardware technology tends to include stereo speakers, which draw from spatialized sound sources and make it possible to emulate real world audio sources.

Simulation of realistic environments is dependent on these audio sources, but even more so on depth cues, which will be explained at length in the following section.

\section{Visual Depth Perception}

In the context of this study, the environment must be an approximate impression of the real world, which means it should be perceived with the help of real-life depth cues.

Though the graphic engine chosen to develop the project in question includes a camera capable of visually emulating most of the pictorial depth cues present in the human visual system (e.g. perspective), this alone isn't enough in recreating a realistic world, regardless of it being stylized or not. One must comprehend how humans perceive their environment before attempting to create a virtual one. This section addresses this necessity accordingly by delving into the subject of depth perception and depth cues; further information relating to Unity3D and why it is the most suitable engine for this project can be found under subchapter 3.2, System Architecture.

In order to push a button, one must firstly acquire visual information about the button in order to ascertain its position (i.e. the button's location relative to one's eyes). It is only after seeing where the button is located that one can relate its position to the position of the hand that will

\footnotetext{
${ }^{2}$ E.g. the position of actors in a scene at the time it was recorded.

${ }^{3}$ https://unity3d.com/

${ }^{4}$ https://docs.unity3d.com/Manual/AudioSpatializerSDK.html
} 
push it. This is made possible by depth perception, which is an ability belonging to sighted animals (Watson \& Enns, 2011).

Depth cues are an important part of depth perception (see figure 4). Depth cues are picked up by the retina and assimilated in the brain, allowing the user to perceive a three-dimensional environment, the volume in objects, and the object's relative position in said three-dimensional environment (Bowman, Mcmahan, \& Tech, 2007; Watson \& Enns, 2011).

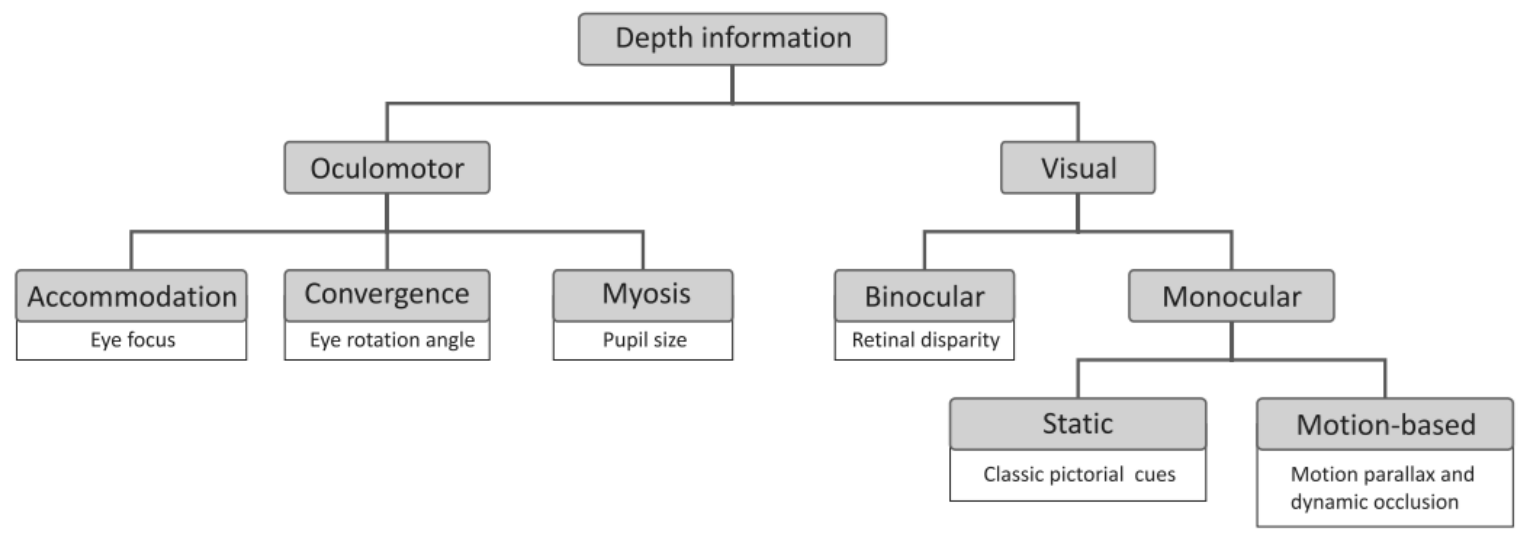

Figure 4: Schematic display of depth cues (Reichelt et al., 2010)

Human eyes are set apart by 5-6 centimeters, which results in slightly different images being projected onto each retina. This is called retinal disparity, which is a depth cue that enables, through the process of stereopsis, stereoscopic depth perception (Mazuryk \& Gervautz, 1999; Sekuler \& Blake, 1994; Watson \& Enns, 2011). Stereopsis relies on both retinas' perspectives to judge relative depth, i.e. it relies on binocular vision (Reichelt et al., 2010; Sekuler \& Blake, 1994), and is considered to be the strongest visual ability pertaining to humans (Sekuler \& Blake, 1994). Due to VR headsets being equipped with stereoscopic displays, unlike other conventional electronic media, stereopsis can also be considered extremely important for VR application development.

Accommodation and convergence are physiological, or oculomotor, depths cues, since they rely on physical reactions of the retina (Mazuryk \& Gervautz, 1999; Reichelt et al., 2010; Watson \& Enns, 2011). Accommodation is monocular, as a single retina can properly focus on an object, while convergence usually relies on retinal disparity, i.e. two eyes work together to achieve convergence (Reichelt et al., 2010).

Monocular cues are categorized as motion or static cues. Motion cues derive from motion of the observer and/or the observed, while static cues do not require both eyes (Reichelt et al., 2010; Watson \& Enns, 2011). In the category of motion, cues such as surface deletion and accretion allow, respectively, an observer to tell an object apart from the background and/or to determine 
its volume. Such cues offer crucial spatial information, even in mediums displayed in a twodimensional plan like motion pictures.

Another cue can be obtained from motion parallax, which occurs when the observer's location changes relatively to an observed stationary object. Items closer to the retina will seemingly move in the same direction as the observer, while items further away will move in the reverse direction (Watson \& Enns, 2011). Proper usage of motion parallax in displays can also improve stereopsis and accommodation by offering additional information about perceived objects (Reichelt et al., 2010).

Motion parallax differs according to what sort of motion causes it to happen. Passive motion (e.g. sitting in a moving car while watching the world) does not create muscular feedback in the observer, which means their sense of relative distance is less accurate than when participating in active motion (e.g. walking to a place while watching the environment) (Watson \& Enns, 2011). Since a typical VR experience only requires the user to move their heads and/or hands, it would not create enough muscular feedback to accurately judge distance.

Watson \& Enns (2011) suggest that the aforementioned cues are effective in judging the relative positions of objects, though not so much in deducing their absolute distance. Motion patterns are better at determining volume and relative distance of objects (Simon, 1967; Watson \& Enns, 2011).

Volume and shape of a rotating object can be perceived through kinetic depth, which means divergent rates of motion issue information about the relative distance between an object's features; this information is then analyzed by the brain and results in the perceiving of a threedimensional shape through its motion patterns (Watson \& Enns, 2011).

Non-rotating moving objects, however, fall into the category of looming, a depth cue again formed by motion patterns. An object that moves away or toward an observer accordingly alters the size of the region occupied on the retinal image, in which moving away decreases the size of the region, while moving closer increases it (Watson \& Enns, 2011).

Looming also helps an observer understand whether a moving object will collide with them; if the object retains its symmetry relatively to the retina, it will collide with the observer, while object asymmetry means it will not (Watson \& Enns, 2011). Interestingly, Watson and Enns (2011) observe that though the process of looming usually takes place without awareness, humans - even at their infancy - are highly sensitive to these cues.

As VR benefits more the inclusion of moving objects than of static imagery, since motion cues are more powerful in enabling perception, the static cues described by Watson and Enns (2011) have thusly been summarized into a table and a schematic for faster comprehension (see table 1 and figure 5 on the following pages). 


\section{LOCAL STATIC CUES}

Intersection of objects and their resultant edge junctions.

E.g., if a person stands in front of a glass pane, an observer knows, through the perception of the visible edge junctions, that the person is positioned is in front of the glass, not inside or behind it.

Shadows, which can be cast or attached.

Cast shadows are used to correctly infer the object's position relatively to the light source, as well as the environment surrounding it (since a cast shadow can serve as a cue to the object's position in space). These two assumptions can then be followed by a better understanding of the object's shape.

Attached shadows are shadows cast on the object by the object itself and make it possible to better determine its shape.

\section{GLOBAL STATIC CUES}

Comparison of images' relative Linear perspective: an retinal size: when this results in a observer can discern relative difference in retinal size, the distance in a scene through natural conclusion is that one of the observation of parallel the objects is further away from lines in the environment. Lines the eye than the other. This is moving further away from the based on assumptions formed by retina will appear to converge the observer's previous into the center of the setting, experiences and familiarity with called the vanishing point. the objects observed. ${ }^{5}$

Texture gradient: changes in size and spacing of a group of objects observed, enabled by the combination of other cues, i.e., images' relative retinal sizes and linear perspective.

A continuous gradient indicates that the environment has no changes, while a discontinuous gradient would indicate a sudden shift in surface orientation.

Relative height: observing of objects and assuming they are placed closer to the horizon than to the observer. This is impossible, for the horizon is regarded as an infinite distance and as such can never be closer to an observed object than the person viewing it.

Objects below the horizon tend to look higher the more distant they are from the viewer, while objects above the horizon tend to look higher the closer they are to the viewer.

Aerial perspective: distant objects appear more blurred, darker, and bluer than nearby objects (because of relative contrast, relative brightness, and relative hue, respectively). Aerial perspective depends on the presence of light to make these processes occur.

\footnotetext{
${ }^{5}$ This assumption is easily be subverted because of the human tendency to interpret non-right angles as right angles (Simon, 1967).
} 


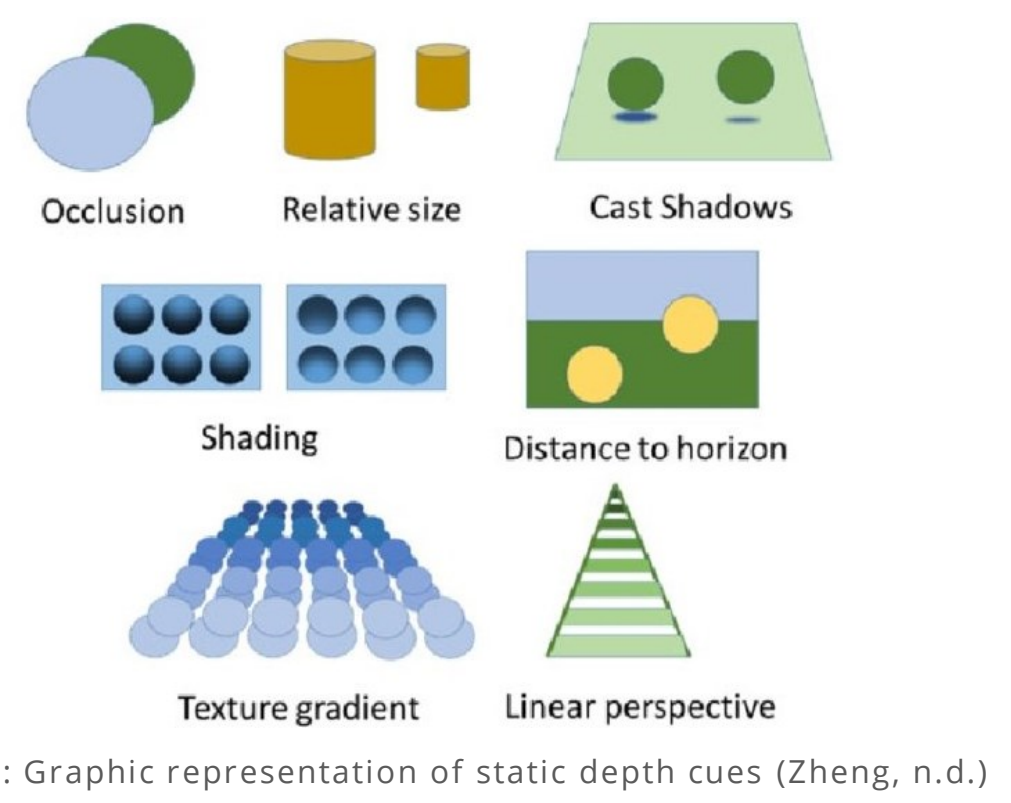

In keeping with the findings of Watson \& Enns (2011), it is proposed that static cues for depth develop later in humans, and are more complex than physiological and motion-based cues.

Therefore, in the context of this study, motion-based cues should be prioritized over static in order to facilitate the user's understanding of the virtual environment. However, motion-based cues in the context of VR should not be regarded as a foolproof way to emulate the real world, as they are the cause of symptoms similar to motion sickness (Laviola Jr., 2000). These issues therefore need to be addressed and understood, in order to better avoid or minimize them.

\subsubsection{MOTION AND VR SICKNESS}

VR sickness differs from motion sickness because VR users are often stationary, as opposed to a subject suffering from motion sickness (Robert S. Kennedy, Drexler, \& Kennedy, 2010; Laviola Jr., 2000). However, as their symptoms are extremely similar, this study will discuss both sicknesses.

Some of the symptoms occurring in both VR and motion sickness include pallor, eye strain, salivation, headaches, sweating, disorientation, vertigo (the user's surroundings appear to spin around them), ataxia (lack of equilibrium), nausea, and vomiting (Robert S. Kennedy et al., 2010; Laviola Jr., 2000). Nausea is the most prevalent symptom out of the previously mentioned symptoms (Robert S. Kennedy et al., 2010).

VR sickness' after-effects can develop even after the VR experience, which causes requirements to be set when using VR (e.g. abstaining from driving immediately after playing a VR game) (Laviola Jr., 2000). These requirements depend on how much time the user has been exposed to VR (Davis, Nesbitt, \& Nalivaiko, 2014; Laviola Jr., 2000). Additionally, as humans prefer not 
to feel sick, a VR experience that causes sickness will likely not be approached a second time (Laviola Jr., 2000), which VR developers should take in consideration as this could delay any significant evolution of technology and software in VR (Davis et al., 2014).

In order to avoid or minimize these symptoms, it is necessary to understand how the vestibular system works, as well as how it relates to visual perception and self-motion.

The vestibular system includes part of the inner ear, consisting of three canals that detect angular and linear acceleration. Each of these canals corresponds to one of the three dimensions where humans can move (Laviola Jr., 2000).

When a person moves their head, which results in angular acceleration, endolymph (a fluid) flows across the canals in order to inform the brain of this movement. This information is sent through the cupula, which are cells capable of tracking endolymph. Cupula work in a polarizing way: depending on the direction they move, they can be pushed or pulled, but not at the same time (Laviola Jr., 2000).

Most humans are equipped with two ears, so they have two vestibular components to work with. Vertigo occurs when the vestibular components are not in sync (i.e. if both cupulas are being pushed) (Laviola Jr., 2000).

Linear acceleration is detected through the utricle and the saccule, two organs composed by cells, which in turn are surrounded in a gelatinous material called the macula. The otolith (clusters of crystals) implanted in the macula provide the inertia responsible for moving the cells, thus allowing the perception of motion; if a human remains in motion for long enough, the otolith stabilize, and the human brain no longer perceives it is moving (Dichgans \& Brandt, 1978; Laviola Jr., 2000).

The polarization effect seen in the cupula also affects the macula. However, unlike the cupula, which tracks the angle of the head, the macula covers its direction: the macula of the utricle detects motion of the horizontal dimension, while the macula of the saccule detects motion of the vertical dimension (i.e. up, down, forward and backwards) (see figure 6). Both the utricle and the saccule are required for a person to stand upright when in a space affected by gravity. 


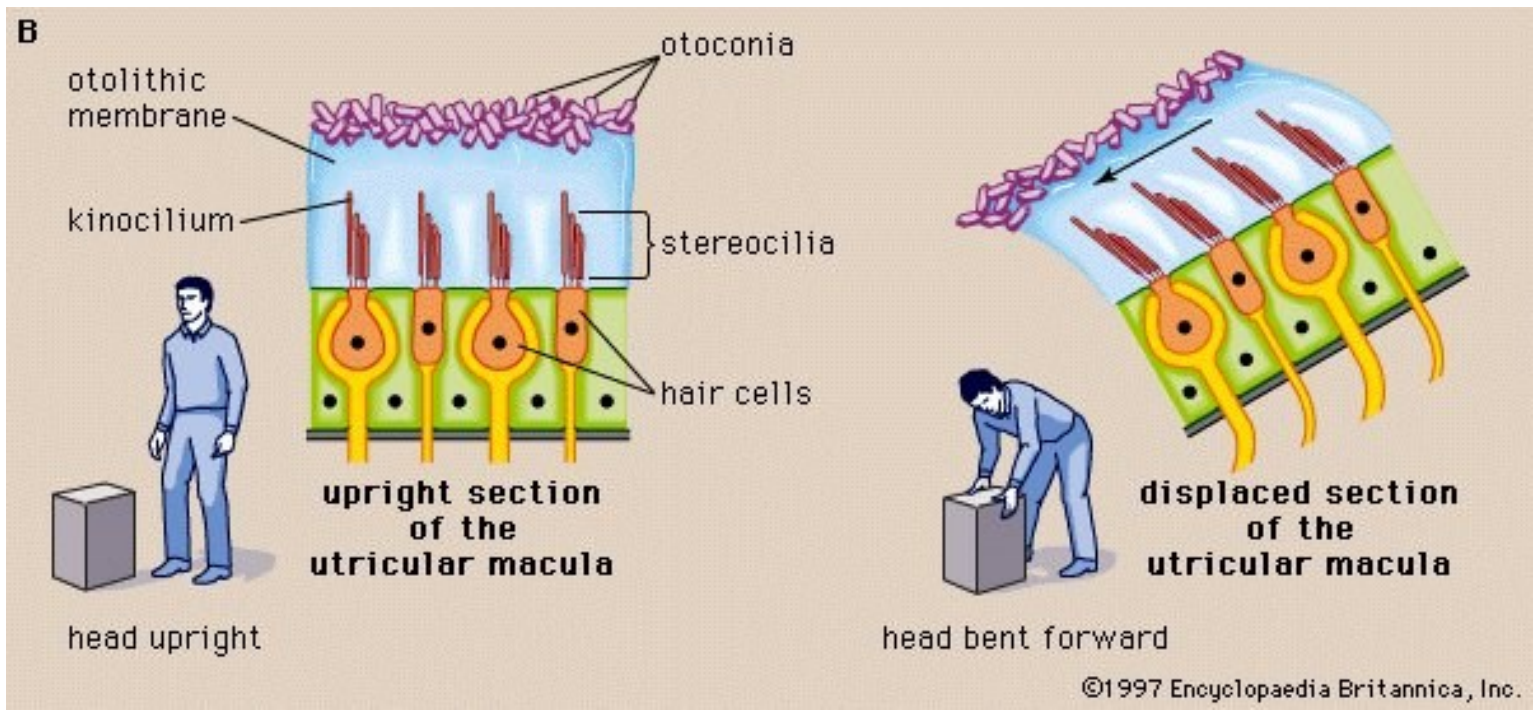

Figure 6: Representation of linear acceleration caused by the macula (Encyclopædia

Britannica, 1997)

In 1931, Tschermak (as cited in Dichgans \& Brandt, 1978, p. 759) suggests the feeling of selfmotion should be called vection. Visually-induced vection can be felt even in stationary humans, made possible in specific settings (Dichgans \& Brandt, 1978; Laviola Jr., 2000), one of which is the displays used in VR (Davis et al., 2014; Laviola Jr., 2000). This happens because of the apparent depth of objects in a virtual environment (Laviola Jr., 2000). Seeing as virtual environments should look realistic, this is a conflict that should be pondered upon.

In addition, according to Riccio and Hettinger (1992) these displays manage to reproduce the way the human eye translates self-movement (as cited in Laviola Jr., 2000). This reproduction of self-movement therefore creates vection (Laviola Jr., 2000).

Standard, actual self-motion is accompanied by vestibular information (Laviola Jr., 2000). Kennedy, Hettinger and Lilienthal (1998) suggest that when vection occurs, vestibular information does not exist: the person is not moving, they simply feel as if they do. This vestibular-visual systems relationship, or lack thereof, is the basis for sensory conflict theory (R. S. Kennedy et al., 1998; Laviola Jr., 2000).

The sensory conflict theory ${ }^{6}$ (SCT) suggests that a discrepancy between senses cause a conflict that the human body is unable to handle. This happens when a person expects something to happen as it did in a previous experience, but the sensorial information they receive is different (e.g. driving a car in a simulator does not give a person vestibular information which they might expect from previous driving in real life, resulting in VR sickness) (Davis et al., 2014; Robert S. Kennedy et al., 2010; Laviola Jr., 2000).

\footnotetext{
${ }^{6}$ Kennedy, Hettinger and Lilienthal (1998) denominate this theory as "perceptual conflict theory".
} 
Though SCT is accepted as the most probable cause for VR sickness, it has issues, namely: there is no way to predict or determine if the VR sickness will happen, or how grave it will be, and SCT has yet to explain why VR sickness affects some individuals, but not others (as cited in Davis et al., 2014; Laviola Jr., 2000).

Another theory is the Poison Theory, which suggests that physiological effects such as the discoordination of visual-vestibular system occur as a measure to induce vomiting, therefore removing any poison in a person's stomach (Davis et al., 2014; R. S. Kennedy et al., 1998; Laviola Jr., 2000). As this discoordination occurs whilst using VR systems, it causes the body to respond correspondingly (Laviola Jr., 2000). Though there has been some research to support this theory, it has the same issues as SCT (Davis et al., 2014; Laviola Jr., 2000).

There are factors associated with technology which these theories do not touch upon, in specific (Davis et al., 2014; Laviola Jr., 2000; Mazuryk \& Gervautz, 1999; Reichelt et al., 2010):

1. Position tracking error: lack of accuracy and jitters resulting from tracking devices will cause VR sickness.

2. Lag: visual delay after the user moves can cause VR sickness symptoms. Tracking must be efficient in terms of head movement in displays with 50-6ohz frequency. Binocular stereo displays can also cause shear distortion, a visual effect that makes the virtual environment lag while following the observer's motions.

3. Flicker: flickering images cause eye fatigue and distraction, which contribute to causing VR sickness symptoms. This can be corrected by using a display with an appropriate refresh rate.

4. Calibration: poor calibration increases susceptibility to VR sickness. The distance between the centers of eye pupils varies from person to person, which means a headset must be calibrated for an individual's needs.

5. Ergonomics: the headsets must be appropriate for the user in terms of weight and fit as to not feel uncomfortable or movement-restricting.

Also related to use of stereoscopic HMDs are visual discomfort and exhaustion. These are caused by the difference between observation of objects in the real world and observation of virtual objects in stereoscopic displays. Real world observation provides a correspondence between accommodation and convergence distance, but stereoscopic displays disrupt the correspondence as the eye is focused on a display as opposed to a real, distant object (see figure 7). This disruption forces the observer to override oculomotor processes that would otherwise cause visual discomfort or exhaustion (Reichelt et al., 2010). 


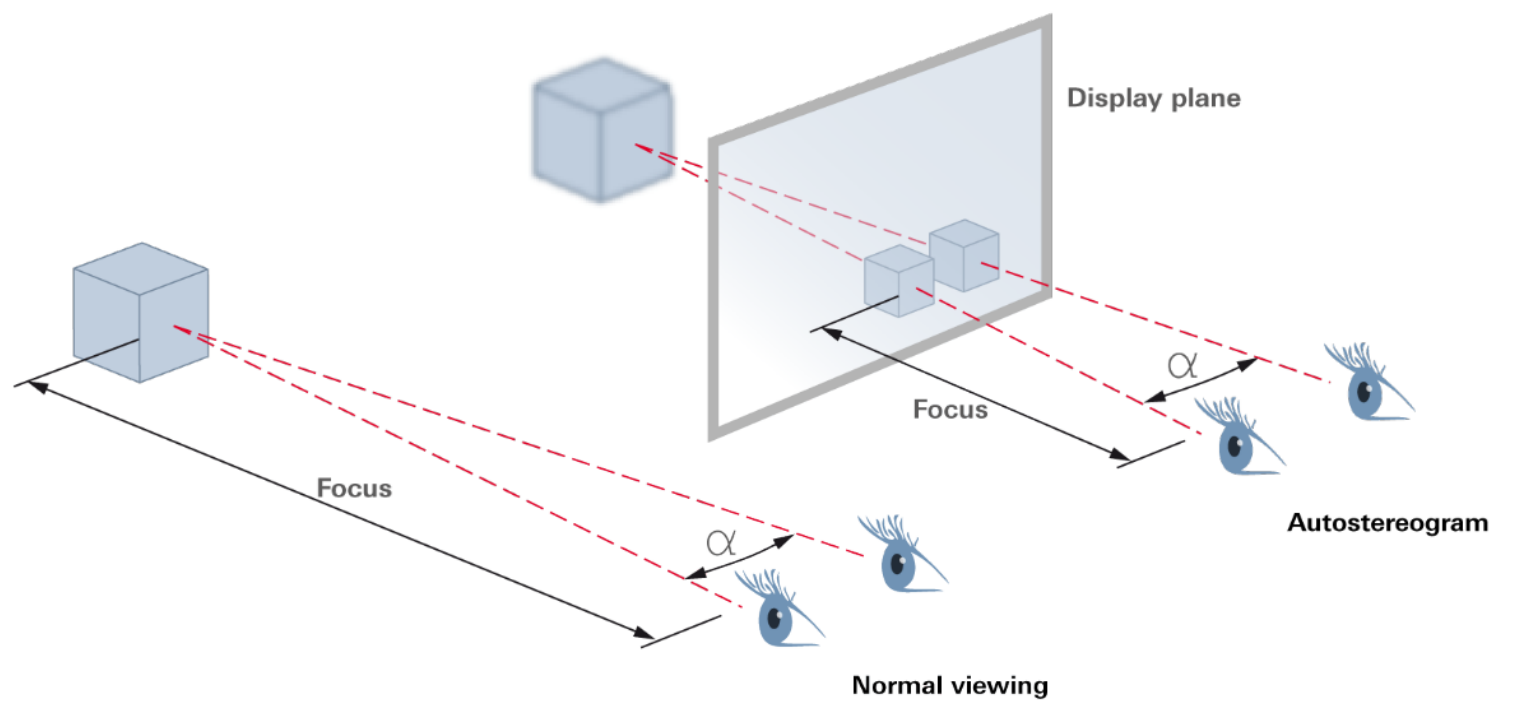

Figure 7: Comparison between natural viewing and stereoscopic viewing with a 3D stereo display (Reichelt et al., 2010)

In addition to technological issues, there are individual factors. Gender, age, illnesses, and the position of the user in the simulator can increase the susceptibility to VR sickness (Davis et al., 2014; Laviola Jr., 2000).

In the context of this study, the factor of age is important. Motion sickness affects children up to 12 years at a greater degree than it does older-age groups, so proper care should be taken to avoid inducing VR sickness in children (Davis et al., 2014; Laviola Jr., 2000). In addition, children who are susceptible to motion sickness will likely be susceptible to VR sickness (Davis et al., 2014).

The level of control of a user is related to their vulnerability to VR sickness. A higher level of control in the VR environment enables a better prediction of motion, which in turn prevents them from feeling VR sickness symptoms. The posture of the user is also important; they should sit instead of standing while experiencing VR (Davis et al., 2014).

Laviola Jr. (2000) lists off various ways to achieve a reduction of VR sickness symptoms, two of which are relevant to this research project: rest frames and adaptation.

A rest frame is a frame which a user perceives as stationary. If there are no rest frames for the user to observe, there is a higher probability that they will suffer from VR sickness (Laviola Jr., 2000). Anthes et al. (2016) suggest that the inclusion of a constant, independent visual cue can reduce VR sickness symptoms (e.g. a rest frame in the shape of a helmet-like display, as seen in most first-person shooter games).

Adaptation is the concept of allowing users to adapt to the shift in surrounding environment by controlling the amount of time they are exposed to VR environments. A gradual increase in 
exposure times allows the user to adapt and lessens the strain on the user's vestibular and visual systems. However, this method is strictly for entering VR environments, and does not offer relief to a user that returns to real-life environments (Laviola Jr., 2000).

Other methods include limiting virtual motion to a simple forward movement, with no long bursts of acceleration, and the avoidance of constantly shifting perspectives (Anthes et al., 2016). Smooth parallax motion cues and properly designed oculomotor cues (i.e. accommodation and convergence) can also augment a user's comfort during a 3D viewing experience (Reichelt et al., 2010).

On a final note, technological evolution in VR devices (e.g. increasingly high visual resolution of headsets) also prevents VR sickness through ergonomic and visual upgrades (Bouchard, 2011). If precautions are taken during VR experimentation, both in testing and in the design of the prototype, one can prevent the appearance of VR sickness symptoms. This applies both to adult and child participants, phobic or non-phobic (St-Jacques \& Bouchard, 2005).

\subsubsection{INTERACTION}

Humans interact with the world around them. The same should happen in a virtual reality.

Zeltzer (1992) suggests interaction is the ability to define and modify certain aspects of the virtual environment with immediate feedback. Most computers are interactive, making it possible to manipulate information in real-time with peripheral controllers (e.g. keyboard, mouse). This is called human-computer interaction (HCI).

The creation of the graphical user interface (GUI) allowed for new HCI approaches, one of which was the WIMP (Window, Icon, Menu, Pointing device) method (Jacob et al., 2008). The WIMP method, unlike its predecessors, does not require a user to know programming languages. As such, it has become the conventional method of HCI interaction, though it is currently sharing its position with touchscreens and the new interaction styles they have created: hand and fingerbased interaction as opposed to controller-mediated interaction. Jacob et al. (2008) propose that this new style of HCI, along with others such as handheld interaction, affective computing, or mixed and augmented reality (AR), are drawing strength from their users' unconscious mind, therefore tapping into their understanding of how reality is meant to work.

Virtual environments should offer their users natural ways to interact with them, and the most natural interaction is through the human body and its senses (Davis et al., 2014). Most people are certain that if they drop something, it will fall to the floor, even if they are unaware of the concept of gravity. It's this unaware understanding that Jacob et al. (2008) propose be employed into computer interaction as reality-based interaction (RBI). 
The framework designed for RBI focuses on four themes grounded in the real world (Jacob et al., 2008, p. 202):

1. Naïve physics: there is, generally, a common sense about how the physical world works, and the person has this common sense; this includes concepts such as gravity, friction, velocity, and relative scale;

2. Body awareness and skills: people are aware of their bodies, physically, and possess the skill to control and coordinate them; basing new interfaces on these skills would offer a set of input techniques (e.g. two-handed interaction);

3. Environment awareness and skills: people's sense of presence allows them to be aware of their surrounding environments, and they can manipulate and navigate within it; one can utilize spatial clues included in the environment to better navigate it, even without realizing (e.g. the presence of light and shadows provides depth cues);

4. Social awareness and skills: people are aware of other agents in the environment and can interact with them; these forms of interaction can be verbal, non-verbal, the exchange of objects, and collaboration on a task.

Jacob et al. (2008) suggest that these four themes are the foundations of today's evolving interaction styles, as the themes estimate what human interaction is like in the real world and attempt to adapt it to HCI (see figure 8).

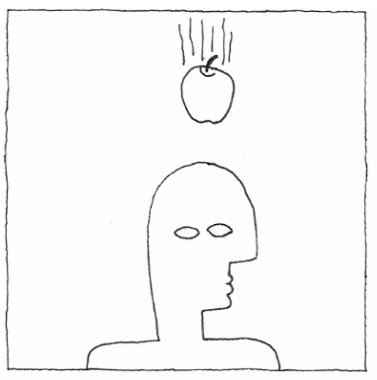

Naïve Physics

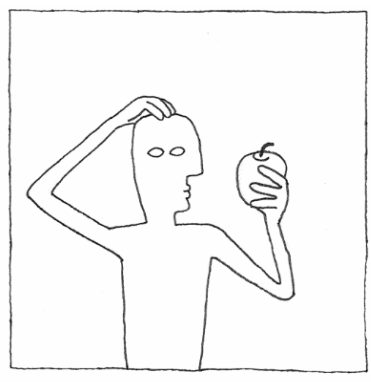

Body Awareness \& Skills

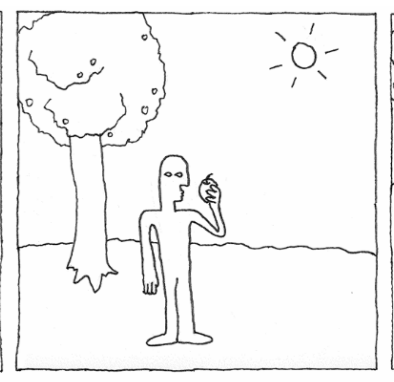

Environment Awareness \& Skills

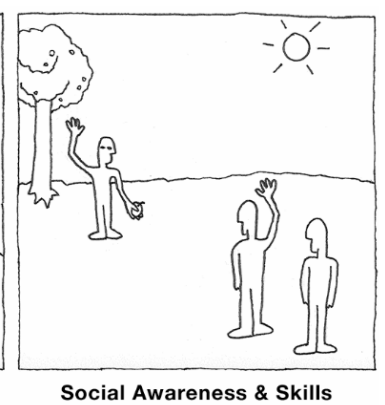

Social Awareness \& Skills

Figure 8: RBI themes (Jacob et al., 2008)

Developing a world where real-life knowledge and skills can be used for interaction would, in theory, make the experience easier for the users (Jacob et al., 2008), as they are already familiar with their bodies and the way they use them.

However, in order to properly respond to a user's needs, the interface used must include unrealistic features (i.e. features that would not be possible in the real world) in order to allow for more abstract, and useful, commands. E.g., archiving a group of items is faster with a command than it is by throwing them away with real-life-based gestures (Jacob et al., 2008). Considering this, Jacob et al. (2008, p. 205) enlist some qualities that such an environment should have, even if they are not completely grounded in reality (see table 2 ). 
Table 2: Design Trade-offs (adapted from Jacob et al., 2008, p. 205)

\begin{tabular}{|c|c|c|}
\hline Expressive power & Efficiency & Versatility \\
\hline $\begin{array}{c}\text { Users can perform many tasks } \\
\text { within the application domain. }\end{array}$ & Tasks are performed quickly. & $\begin{array}{c}\text { Users can perform tasks for } \\
\text { different applications. }\end{array}$ \\
\hline Ergonomics & Accessibility & Practicality \\
\hline $\begin{array}{c}\text { Users will not be harmed or } \\
\text { fatigued by performing tasks. }\end{array}$ & $\begin{array}{c}\text { Users with varying degrees of } \\
\text { abilities can perform a task. }\end{array}$ & $\begin{array}{c}\text { The system is practical to } \\
\text { develop and produce. }\end{array}$ \\
\hline
\end{tabular}

In the context of this project, there are some qualities which are more significant than others, such as ergonomics and practicality.

As the VR hardware used for this dissertation, Oculus Go, allows for the user to feel comfortable during a VR experience (as it is a commercially successful, properly designed product), ergonomics should be ensured from the start.

In terms of practicality, the project in development can be considered a prototype, and not a finished game. As it is being constructed by a single developer with time constraints, practicality is a quality that the prototype must guarantee. Moreover, interaction with the environment should be measured; giving the user total control over every facet of a system is nonproductive (Zeltzer, 1992). This complexity of control can be eased (Zeltzer, 1992) through the understanding of limiting versatility and expressive power (Jacob et al., 2008).

\subsubsection{CONCLUSION}

In conclusion, as a game directed at phobic children under the age of twelve, and after revision of the previous literature, there are several guidelines to follow in the area of VR: (1) language of the game-both literary and visual-must be clear and concise; (2) special attention must be taken in regards to VR sickness, such as limited times of exposure and an adaptation period (Anthes et al., 2016; Bouchard, 2011; Laviola Jr., 2000; St-Jacques \& Bouchard, 2005); (3) interaction with the virtual world should follow the real world's methods as closely as possible so as to draw out a child's common sense in regards to how reality functions (Davis et al., 2014; Jacob et al., 2008); (4) practicality in development should be prioritized (Jacob et al., 2008; Zeltzer, 1992). 


\subsection{GAMING}

A game is a system that represents a subset7 of reality through a subjective point-of-view; it should be self-sufficient, without needing information from outside of the game (Crawford, 1997). It must have a set of explicit rules ${ }^{8}$ that can address any situations that might occur ingame (Crawford, 1997; Salen \& Zimmerman, 2004).

Salen and Zimmerman (2004, p. 91) have gathered several definitions from different authors in order to offer a broader overview of what elements can be found in a game, most of which are also present in Schell's (2008) work (see table 3).

Table 3: Characteristics of games (adapted from Salen \& Zimmerman, 2004, p. 91)

\begin{tabular}{|l|l|l|}
\hline Rules limit the player & Make-believe and/or representational & Goal/outcome-oriented \\
\hline Activity, process, or event & Involves decision-making & Not serious and absorbing \\
\hline No material gain & Artificial, safe, outside of ordinary life & Creates special social groups \\
\hline Voluntary & Uncertain & Conflict or contest \\
\hline Inefficient & System of parts & A form of art \\
\hline
\end{tabular}

All but one of the authors refer to rules as a key concept of what makes a game. This is the only element in which most agree. But, as Salem and Zimmerman (2004) suggest, this conclusion is often in the eye of the beholder.

In regards to "make-believe", Crawford (1997) offers two-points of view: objectivism and subjectivism. These two complement each other, as the subjective reality one finds in games is born out of objective reality (Crawford, 1997; Salen \& Zimmerman, 2004). The perception the player has of the game is real to them (subjectivism), no matter how unreal the game's reality might be (objectivism), which Crawford (1997) credits to human fantasy.

\footnotetext{
${ }^{7}$ Since including the entirety of reality in a game is impossible, a game must only represent a specific part of it (Crawford, 1997; Salen \& Zimmerman, 2004).

${ }^{8}$ Rules differentiate a formal game from an informal game, which David Parlett (as cited in Salen \& Zimmerman, 2004) claims is undirected and results from 'playing around'. Informal games do not fit in the focus of this thesis, and as such will not be mentioned from here on.
} 
In a more technical stance, Schell (2008) breaks down games into four main elements (see figure 9), each of which englobes more specific characteristics (i.e. mechanics has procedures, aesthetics relate to the player's experience, and technology is branded as a medium as opposed to "high technology").

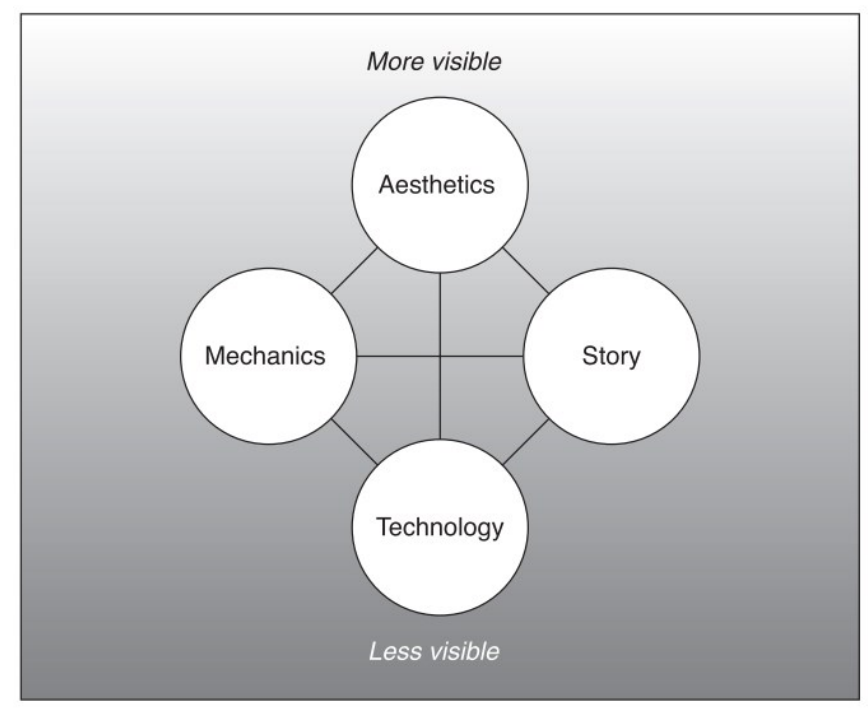

Figure 9: The elemental tetrad (Schell, 2008, p. 42)

Visibility refers to what the player perceives: the style and art of the game are visually assimilated and understood very easily, while the technology behind the video game is rarely remarked upon (though this can also be positively linked to a game which functions correctly and doesn't present issues or crashes to the player).

\subsubsection{VIDEO GAMES IN HISTORY}

Some games are still a part of popular culture even though they have long since been replaced with newer technology and design. Pong, Space Invaders, and Pac-Man are among some of the most famous and oldest commercial video games of all time, dating back to arcade machines: Pong was created in 1972 by Nolan Bushnell, Space Invaders was created in 1978 by Tomohiro Nishikado, and Pac-Man was created in 1980 by Toru Iwatani (Hansen, 2016).

Pong is called a paddle game by Crawford (1997), as the game revolves around a projectile that bounces from one paddle to the other. The original Pong was a two-player game where each player controlled one paddle (Crawford, 1997; Hansen, 2016).

Space Invaders can be called a combat game: the game's focus is on confrontation, and the player must attack the enemy while avoiding the enemy's attacks (Crawford, 1997; Schell, 2008). 
Pac-Man belongs in the category of maze games: defined by maze-like structures through where the player moves, and, occasionally, is chased by enemies (Crawford, 1997).

These three games fall in the category of action games ${ }^{9}$ : games played in real-time, requiring quick reflexes and habitual practice from the player, and reliant on graphics and sound (even if, by today's standards, these three games' graphics and audio are simplistic) (Crawford, 1997).

The action class of gaming also includes other types of games, such as racing and sports' games (see table 4 for a more modern overview of video game genres). They are not mutually exclusive.

Table 4: Common game genres (Crawford, 1997; Hansen, 2016; Qi, 2014; Salen \&

Zimmerman, 2004; Schell, 2008)

\begin{tabular}{|c|c|c|c|}
\hline \multicolumn{2}{|c|}{ Action } & Role-playing & \\
\hline Shooter & Fighting & Vehicle/racing \\
\hline Action-adventure & MMORPG & \\
\hline \multicolumn{2}{|c|}{ Adventure } & Strategy & Sports \\
\hline Advic & Music & Physical games & Simulations \\
\hline
\end{tabular}

In 1980, the same year as Pac-Man's release, Infocom's Zork was released for the computer, belonging to the second category of games: strategy (Crawford, 1997; Hansen, 2016). Zork is played with only a keyboard, as the player must write down what to do next, and has no images or audio. Zork was inspired by the first-ever text adventure game, Will Crowther's Colossal Cave Adventure, and was the first text-based game to be commercially successful (Hansen, 2016). Zork is an adventure game, as it has a character who moves through an intricate world full of sequential traps to be overcome and one final objective (Crawford, 1997).

Other strategic games include Dungeon and Dragons types (e.g. Baldur's Gate), wargames (e.g. Sid Meier's Civilization), chance (e.g. blackjack), educational and children's games (e.g. Hangman), and interpersonal games (Crawford, 1997).

A year later, in 1981, Shigeru Miyamoto created the concept behind Donkey Kong, a combat game which introduced the Super Mario franchise to the world, as well as the simple act of a jumping and running character in a video game (Hansen, 2016; Schell, 2008).

Meanwhile, Pong's commercial success allowed Atari to create the Atari 2600 (see figure 10), one of the first home consoles to allow players to switch game cartridges as opposed to the first-

\footnotetext{
${ }^{9}$ The original term "skill-and-action" has been adapted into "action" on account of obsolete terminology.

${ }^{10}$ MMORPG: Massively Multiplayer Online Role-Playing Game.
} 
generation home consoles which only played a single game; the Atari 2600 had a joystick and it allowed for 128 colors on-screen (Hansen, 2016; Smithsonian Institution, 2017).

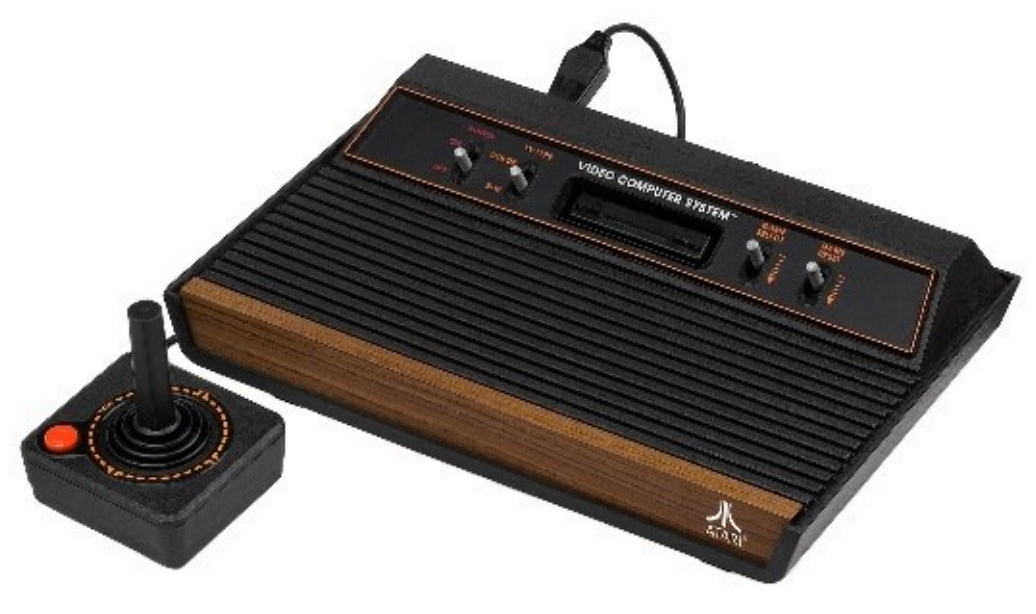

Figure 10: The Atari 2600 (public domain image)

In 1985, the Nintendo Entertainment System (NES) was one of the highest-grossing consoles in the market due to the success of the Super Mario Bros. games, and it was the NES that finally drew the focus of the video game market from arcades to consumer homes (Hansen, 2016; Smithsonian Institution, 2017).

Nintendo once again revolutionized gaming with The Legend of Zelda in 1986, adding built-in writable memory in the game cartridge. This allowed a player to save their place and progress in the game for the first time ever. Beyond that, The Legend of Zelda defined a new game type as a role-playing adventure game; it was the first open-world game on a console, and it was the first console game to have an accessible inventory (Hansen, 2016).

In 1988, Electronic Arts launched the sports' computer game John Madden Football for the MSDOS, Commodore 64, and Apple II (Hansen, 2016). John Madden Football had better 2D twodimensional (2D) graphics and sounds than many arcade and console games without sacrificing gameplay speed, along with realistic formations and weather conditions, and shifted the opinion of sports' games to a more positive position (Hansen, 2016).

The handheld console market began its ascent with the production of Tetris in 1989, a puzzlelike game which dominated the market and was responsible for Nintendo's Game Boy becoming a best-seller (Hansen, 2016).

In 1993, Robyn and Rand Miller took advantage of the new technology available to developers (i.e. a Pentium processor) and created a three-dimensional (3D) computer game based on storytelling narrative and puzzles as obstacles (Hansen, 2016). Myst boasted beautiful graphics, using 
screenshots of pre-rendered models as scenery in the game, and caused CD-Roms to become a viable format for delivering video game content (Hansen, 2016; Schell, 2008).

In the same year, DOOM instituted a new sub-category of combat games, the first-personshooter (FPS), where the player sees the world through a gun-toting character's eyes (see figure 11). DOOM was not the first FPS, but it was the most popular FPS game with a mobile player character and a walkable environment, and its influence can still be felt today in network-play, co-op story modes, game level designs, and even community local area network (LAN) parties ${ }^{11}$ (Hansen, 2016). These LAN networks soon evolved into using Internet, which allowed the creation of online, multiplayer games ("The History Of Gaming: An Evolving Community | TechCrunch," n.d.).

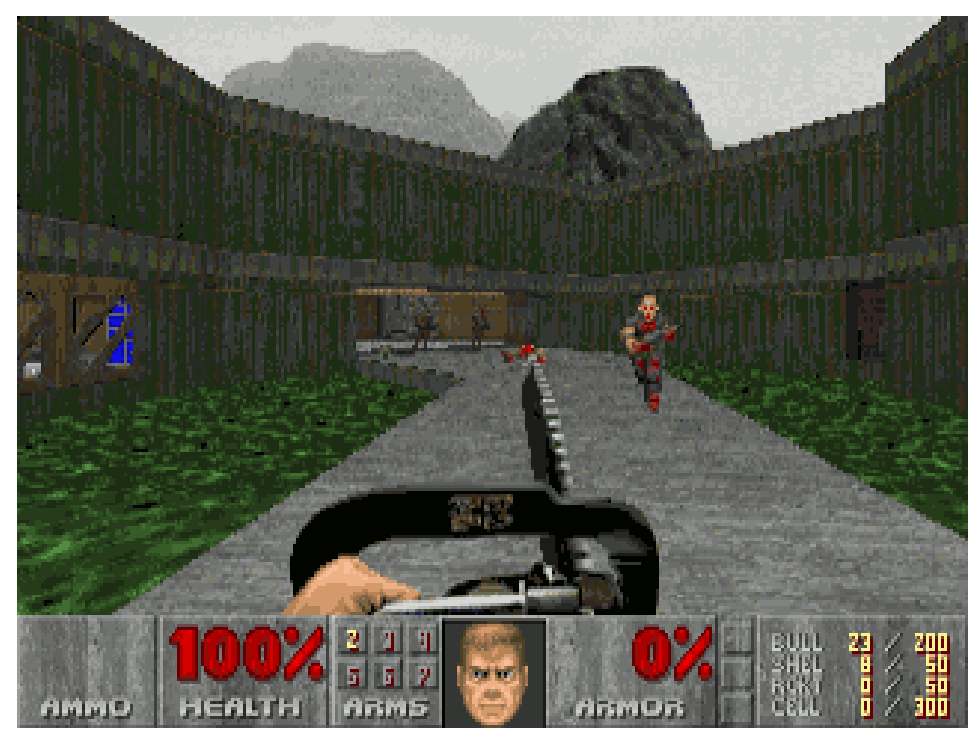

Figure 11: DOOM screenshot (c id Software, ZeniMax Media)

The console market caught up to the Internet-fueled computer in 2000 with the Sega Dreamcast, which had a $56 \mathrm{Kbps}$ modem and included a web browser, therefore focusing on the use of Internet ("The History Of Gaming: An Evolving Community | TechCrunch,” n.d.). The evolution of video games was then bolstered by the World Wide Web as technology began evolving at exponential rates.

Today, there are yearly gaming conventions broadcast all over the world, where the titans of industry showcase their next market-breaking video game, and the audience is no longer restricted to the typical 'gamer' archetype.

Consoles keep evolving and many of the brands than began the console movement have faded out into obscurity, unable to keep up (Hansen, 2016). The portability of modern computers

\footnotetext{
${ }^{11}$ A group of computers placed in the same room, connected to one another, which allowed for multiplayer games. LAN parties have since fallen out of fashion.
} 
means games are no longer confined to the desktop PC. Mobile games have surpassed expectations and brought in a new audience, which then created a new market of casual games as profitable as any of the full-fledged video game markets.

Games are everywhere now, and they are competing with other entertainment mediums (i.e. films). Games are now in the consumer's laptop, on the TV screen, and on their smartphone. They are easily accessible, can be bought digitally (thus removing the need to go into a physical store), and their category expansion ensures that everyone can play games.

Still, even as technology continues to evolve and change the way video games are perceived, the crux of video games has remained inalterable until today. Video games are still composed by the same elements and follow the same logic.

\subsubsection{COMPONENTS OF GAMING}

This section details gaming components such as interaction, conflict and safety, and motivation and enjoyment.

\section{Interaction}

The act of playing itself implies interactivity (Salen \& Zimmerman, 2004). Crawford (1997) and Salen and Zimmerman (2004) believe that interaction is a key aspect of what makes a game, because a game must offer an acknowledgement and a response to the player's input.

A game allows the player to traverse through different avenues of possibility, as they make choices and create their own story (Crawford, 1997), or even as they decide on a target instead of another (Salen \& Zimmerman, 2004). The player is therefore encouraged to explore the game as they wish (Crawford, 1997), since this choice deepens the feeling of interaction (Salen \& Zimmerman, 2004), which is why some games can be replayed time and time again: the allowance of a player's choice offers replay value. This replay value can also be connected with agency, which is the "satisfying power to take meaningful actions" (Roth \& Koenitz, 2016, p. 32). Interaction with a medium is the ability to meaningfully intervene in its universe, as opposed to gathering different meanings from it (Salen \& Zimmerman, 2004). It is possible to draw a scale of manipulability in order to situate this dynamism of choice, which is lacking from other art forms such as movies (as they always play out the same way).

Crawford (1997) also suggests that the audience's control can be measured in each entertainment medium (see figure 12). 


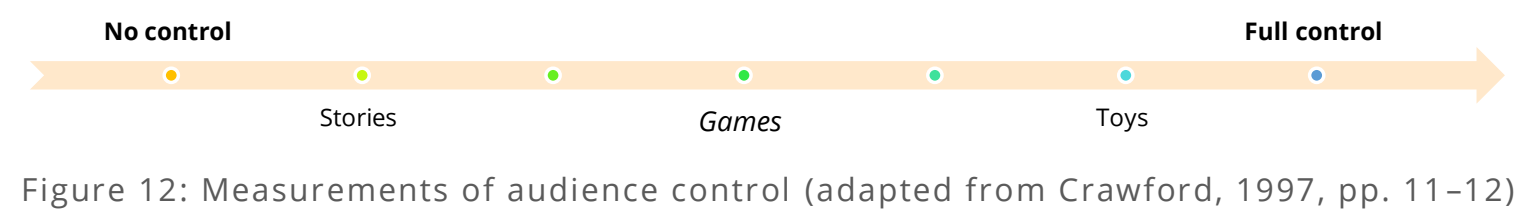

As control lowers, the interaction with the medium rises. Crawford (1997) exemplifies this relationship with the contrast between stories and toys: stories boast intricate details and plot twists but cannot be changed by the audience, while toys lack story detail but depend on the imagination of the user to provide entertainment. As games are situated in the middle of the control measure (intermediate control), they offer a balanced experience of both factors.

Crawford (1997) simplifies the importance of interaction through two parameters: interaction transforms a technical challenge into an interpersonal challenge, and a passive challenge into an active challenge.

An interpersonal challenge depends on the existence of an opponent, as opposed to a technical challenge which depends on a situation (Crawford, 1997). An active challenge is reactionary, which allows the player to approach it differently each time; a passive challenge is comparable to a puzzle, which will only offer the same challenge each time (Crawford, 1997; Schell, 2008). In the latter case, the player has no choice but to experience the puzzle as they had before.

While not all games depend on the existence of another human player in order to offer an interpersonal challenge, they can present a persona which serves this purpose (Crawford, 1997). Even if this persona is lacking, a game's response to a player's actions is enough to satisfy their need for interaction (Crawford, 1997).

Salen and Zimmerman (2004, p. 78) note that this response to a player can fail through the following aspects, which can negatively affect play and should be considered in the development of this project research's VR prototype:

1. Decisions made by the player feel arbitrary, when they should feel meaningful;

2. The player doesn't know what to do next, either from lack of information or poor design;

3. Losing the game without knowing why, caused by lack of information;

4. The player doesn't know if their action has an outcome, as there is no clear feedback to inform them;

This cause-and-effect relationship segues into the force driving it: conflict.

\section{Conflict and Safety}

A game must have an objective for the player to achieve (Crawford, 1997; Salen \& Zimmerman, 2004). To prevent the player from achieving this objective too easily, conflict is born in the shape 
of obstacles which create challenge (Crawford, 1997; Salen \& Zimmerman, 2004). However, this conflict should be fair, responsive, and purposeful so as to fit the game and not frustrate the player (Crawford, 1997; Salen \& Zimmerman, 2004), which requires there be an agent to form it (Crawford, 1997). In Nintendo's Super Mario, Mario's objective is to save Princess Peach, and the agent chosen to place obstacles in his way is his arch-enemy Bowser. As the agent fits the setting, and the obstacles are purposeful and responsive, this is a good example of conflict.

Conflict is necessary to a game because it produces active responses to a player's actions (Crawford, 1997; Salen \& Zimmerman, 2004). Crawford (1997) cautions that if conflict is removed from the game, interaction becomes impossible, and the game ceases to be a game (conflict can be mollified, however, through the introduction of cooperative elements).

Games are subjective representations of human reality, and as conflict is a part of that reality. Violence is often chosen to represent this conflict as it is the most obvious form of human conflict, but this is not necessary to a game, and can instead be depicted indirectly (Crawford, 1997; Salen \& Zimmerman, 2004). In the context of a game aimed at children, violence is better off being sidestepped completely.

In this manner, games allow humans to experience conflict that they would otherwise rarely feel, as is the case with first-person-shooter games, a notion which Crawford (1997) names 'safety'. It is this safety that allows a player to shoot at invading aliens without succumbing to his death on the battlefield. Safety doesn't mean, however, there are no consequences towards the player (Crawford, 1997). A particularly interesting penalty Crawford (1997) mentions is the loss of previously attained rewards, as opposed to the game dealing out a punishment. With this penalty, losing can motivate a player to try again, but the desire to win back rewards is not the only motivation that drives someone to play.

\section{Motivation and Enjoyment}

Crawford (1997) suggests that games are educational devices, and associates gameplay with the development of mammals and birds. Playing is an activity which humans consider to be infantile in nature: an unconscious realization that playing is useful for forming and educating young minds. The fundamental motivation of playing games is the player's desire to learn. This motivation is usually unconscious, and might be bolstered by other secondary desires, such as pleasure and play experience (Crawford, 1997; Salen \& Zimmerman, 2004).

Fantasy provides escapism, which games manage more superiorly than other entertainment mediums because games allow the player to interact with the fantasy(Crawford, 1997). This fantasy can be achieved through symbolic exploration of worlds unknown to the player and is critical to human recreation, as well as game-playing (Crawford, 1997). Motivation to play games 
is also bolstered by allowing the player to assume unrealistic or socially unacceptable roles, such as superheroes or ancient assassins ${ }^{12}$ (Crawford, 1997; Roth \& Koenitz, 2016; Schell, 2008). Furthermore, games allow for a player to exercise body and mind in an entertaining way (Crawford, 1997), be it by playing Nintendo's Wii Sports or by playing chess against another player.

Motivation is paralleled by enjoyment: players are motivated to play because of the previous aspects, but their motivation alone does not make a game fun. For a game to be fun, it needs motivation and enjoyment.

Enjoyment factors come in the shape of gameplay and sensory gratification. Gameplay is made up from the game's pacing and its required cognitive effort. Sensory gratification supports the fantasy by providing graphics and sound, therefore offering the player a greater degree of immersion. However, Crawford (1997) notes that sensory gratification is not a requirement of a game, and merely adds to its depth.

In order to specify, Salen and Zimmerman (2004, p. 330) cite Marc LeBlanc's, Michael Apter's, and Roger Caillois' categories for what gives players pleasure or enjoyment, which are adapted and condensed for faster assimilation:

1. Fantasy (imagination, role-playing, and make-believe);

2. Narrative (emotion arousal from drama and/or character identification);

3. Challenge (obstacle course and competition);

4. Fellowship (social framework);

5. Discovery (exploration);

6. Submission (to chance; the ritualized behavior of obeying system rules);

Beyond categorical paradigms, enjoyment also tends to happen if the player achieves flow ${ }^{13}$ (Roth \& Koenitz, 2016). This requires striking a balance between challenge and skill (Roth \& Koenitz, 2016), and can be exemplified in the form of Tetris, which lacks many of the categories above and still manages to instill flow in the player.

A final aspect of motivation is the individual player's tastes. As humans have different tastes, it is impossible to create a game that every player will enjoy (Crawford, 1997), but this problem can be partially solved through the development of games for target audiences. One such audience is, in the case of this research project, young children.

\footnotetext{
12 See: Insomniac Games' Marvel's Spider-Man and Ubisoft's Assassin's Creed series.

${ }^{13}$ Flow happens when the player's immersion is at such a level that the feeling of control over the game is heightened to a maximum (Weerdmeester et al., 2017). Alternatively, as described by Csikszentmihalyi, flow is a high degree of focus and enjoyment (as cited in Salen \& Zimmerman, 2004).
} 


\subsubsection{INTERACTIVE NARRATIVE}

The concept of interactive digital narratives isn't exclusively connected to video games, but it fits the context and aim of this research project regarding its narrative. VR projects often create narrative experiences, and interactors enjoy participating in such narratives (Roth \& Koenitz, 2016) like they would while playing a game.

Effectance is the effect of a chosen action and can be divided into global and local effectance (Roth \& Koenitz, 2016). Global effectance refers to the structure and ending of a story, and to the possible impact the player might have in them; local effectance refers to smaller, more immediate decisions in the narrative (Roth \& Koenitz, 2016).

As the narrative for this research project must be kept short and simple in order to maintain an achievable schedule of experiment sessions, local effectance should be prioritized. Autonomy of choice is still possible in a setting that prefers local effectance, as long as the choices allow for the feeling of freedom (Roth \& Koenitz, 2016).

Autonomy positively affects immersion, which Roth and Koenitz (2016) divide into perceptual and narrative levels. At the perceptual level, there is flow and presence. Maintaining flow through narrative progression can be a difficult task, but it is possible to do so by engaging audience in the narrative and interface, and defining the right amount of audience control (Crawford, 1997; Roth \& Koenitz, 2016).

At the narrative level, the concepts which apply to this project research's narrative are believability, role-identification and curiosity, being that suspense is a negative feeling in the context of a game for phobic players and as such will not be included (Roth \& Koenitz, 2016).

Believability, or suspension of disbelief, depends on the credibility of the worldbuilding, and requires a reactive environment which can be created through $\mathrm{AI}$ intervention or scripted responses to the player's choices (Crawford, 1997; Roth \& Koenitz, 2016; Salen \& Zimmerman, 2004). Role-identification, as previously mentioned, fulfills the desire for fantasy. Finally, curiosity plays upon the feelings of uncertainty, accomplishment, and surprise; e.g., after uncertainty, a player finds out what a mysterious key finally opens, and the reward is good (accomplishment) but not what they expected (surprise) (Roth \& Koenitz, 2016).

Role-identification and curiosity can generate feelings of satisfaction and self-efficacy, which may greatly motivate the player to carry on playing despite being afraid (Roth \& Koenitz, 2016; Weerdmeester et al., 2017). 


\subsection{PHOBIA}

According to the American Psychiatric Association (2013, pp. 197, 198), there are seven criteria for the diagnosis of a phobia:

1. Marked fear or anxiety about the object of their phobia (in the case of this thesis, the dark); in children, this fear can be expressed through crying, tantrums, freezing, or bodily clinging;

2. The phobic object provokes immediate fear or anxiety;

3. The phobic object is avoided or endured with fear or anxiety;

4. The fear is disproportional to the threat posed by the phobic object and to the sociocultural context;

5. The fear is persistent (to a minimum of six months);

6. The fear causes clinically significant distress in social and/or occupational areas of functioning;

7. The fear is not improved through the logical explanation of its symptoms;

Considering the difficulty of reaching out to children with clinically diagnosed phobia of the dark, a lesser degree of fear of the dark is also considered suitable for the purposes of this thesis, as many of the symptoms above also tend to apply. However, as stated above, this fear cannot be considered transient, which must be kept in consideration.

\subsubsection{FEAR OF THE DARK}

Muris et al. (2001) report that $84.7 \%$ of children between 7 and 9 years of age suffer from mild nighttime fears (as cited in Lewis et al., 2015). Fear of the dark in children can occur because of developmental and environmental factors, and neither of these need to be realistic or logical (Levos \& Zacchilli, 2015). Ethnic and cultural differences also influence the way this fear is perceived and expressed (Levos \& Zacchilli, 2015).

Although nighttime fears are not a diagnosable category, young children may have such disproportional fears of the dark that they meet the previous criteria for a specific phobia diagnosis (Lewis et al., 2015). This fear often disappears in adulthood, but Levos and Zacchili (2015) and Lewis et al. (2015) report that there are cases which persist even after childhood. In these cases, the fear becomes more realistic based on the assumption that dark spaces are more dangerous and riskier than lit-up spaces (Levos \& Zacchilli, 2015). This assumption can cause humans to avoid activities in darkened environments, which, adding to poor sleep quality and nighttime waking, can have a negative impact on a phobic person's life (American Psychiatric Association, 2013; Levos \& Zacchilli, 2015; Lewis et al., 2015). 


\subsubsection{VR THERAPY}

The Systematic Desensitization Theory (SDT) is rooted in the idea that gradual exposure of a patient to a phobic object or to imagined stimuli, both of which are meant to provoke anxiety (North et al., 1998), has a therapeutic effect. Conducted research indicates that people with phobias have difficulty with either scenario, be it imagining a scene which will make them anxious or facing a phobic object in vivo (North et al., 1998; Ventura et al., 2018).

Imagined scenes require the patient to have a good memory, as they only last approximately 250 milliseconds. Imagined scenes can also occasionally be generated from fake memories (Ventura et al., 2018). Virtual reality therapy (VRT) can generate these stimuli in private, more comfortable spaces, which allows for greater control of public embarrassment and patient confidentiality (North et al., 1998; Ventura et al., 2018). This also allows for a better, more trustworthy way to relive traumatic events (Ventura et al., 2018). Patients also tend to choose VRT over in vivo exposure therapy (Garcia-Palacios et al., 2007).

VRT also allows the patient to regulate the scenario themselves, which makes it seem safer and easier to deal with than in vivo therapy, all the while still maintaining an adequate level of realism (North et al., 1998; Ventura et al., 2018). In order to better understand the specifics of VRT, see figure 13:

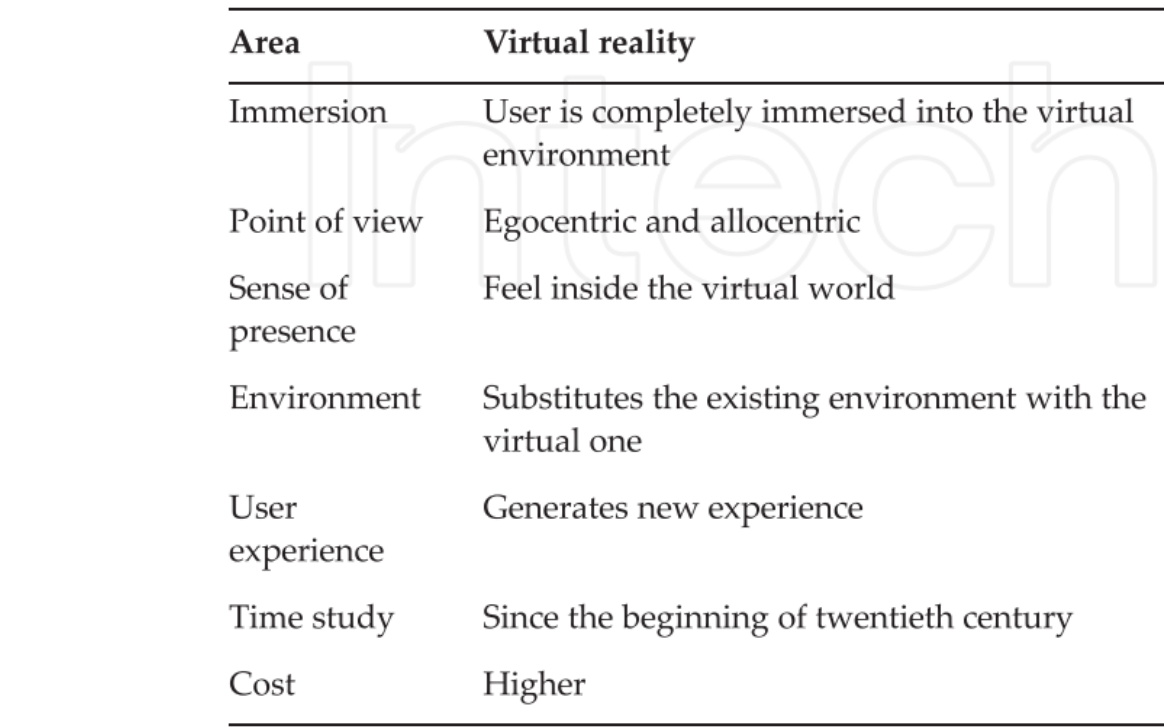

Figure 13: VRT in clinical psychology (adapted from Ventura et al., 2018, p. 104)

In their experiments, North et al. (1998) propose that virtual environments evoke the same anxiety and reactions as the phobic object in reality, even going as far as to make the patients feel symptoms such as heart palpitations, sweaty palms, and tenseness. The virtual 
environments utilized in the experiments were less detailed than a real scene, both visually and auditorily, but the patients still reacted as though their fears were being faced (North et al., 1998).

In the context of this thesis, this reaction to less-than-realistic scenarios allows for the design of the prototype in development to approach a more kid-friendly style, if necessary.

There are several safety issues that should be kept in mind when using VRT (North et al., 1998, pp. 7, 8):

1. Patients who suffer from panic attacks, heart disease, epilepsy, or that have been prescribed drugs with physiological/psychological effects should be excluded from all sorts of VRT sessions;

2. Patients who feel heavy effects of VR sickness should also be excluded from VRT sessions;

3. Patients should always be observed by a therapist in order to know, judging by the patient's distress levels, when to terminate the VR session;

4. Sessions should be run for 15 to 20 minutes, with the patient being sat down straight and wearing a headset which allows for partial view of their body;

As the prototype in development follows games specifically designed for children with fear of the dark, the presence of a therapist may not be required since the games should be played with the parents (as aforementioned). This is also based on the assumption that parents are, ideally, aware of their child's level of distress when facing a phobic object and know when to intervene in the VRT session if the child's anxiety becomes hard to handle. All previously mentioned safety issues will be considered when the case study participant selection process occurs, as well as during the case study testing.

\subsubsection{GAMES FOR CHILDREN WITH FEAR OF THE DARK}

The following section introduces games designed for children with fear of the dark. The usage of these games has been found to be significantly effective (Mikulas, 2011).

The games are meant to be played with the child's parents, preferably in the child's home; this allows for the child to feel more at ease and, as a VR-based game, isn't as much of a financial burden as regular therapy (Mikulas, 2011; North et al., 1998). The games are short and fun, so as to not bore the child, and can potentially treat the fear of the dark before it evolves into a more acute fear (Mikulas, 2011). Children are supposed to learn self-control skills at the same time they learn how to deal with their fear, which can ideally augment their sense of self-esteem and internal control (Mikulas, 2011). 
The procedures of the games are coordinated by the child's parents (Mikulas, 2011), but, as these are instructions, they can be adapted into the VR prototype in the form of textual information. The instructions are behavioral in nature, and include positive reinforcement (e.g. praise), the logic of shaping (e.g. increasing the time spent in the dark), and adaptation of the child's needs to the games (Mikulas, 2011).

As the level of fear differs from child to child, so too must the games vary (Mikulas, 2011). In terms of a functional prototype, this can be worked out through chapters in the game, allowing repeating earlier chapters if necessary. Asking the child if they are comfortable and want to play is also necessary, and one should never force the child to play, instead attempting to encourage them to do so (Mikulas, 2011). Backtracking should be used if the child is reticent (i.e. playing a previous, easier chapter, or playing just a segment of it).

Mikulas (2011) lists out a sequence of games used in his own experience, stating that they should preferably be played in order, but that mastery of one game is not needed for a child to move on to another. The list mentioned by Mikulas (2011, p. 321) has been truncated as some of the games are not adaptable to a VR prototype:

1. Blindfold game: the child wears a blindfold and tries to find a toy;

2. Puppet game: the child is taught to relax by tensing and relaxing muscles in the order of arms, hands, legs, and neck; this is later extended to include the face, the legs, the stomach, and the toes;

3. Animal-friends game: in the dark, the child must guess animal sounds;

4. Animals-on-the-wall game: the child makes animal-shaped shadows with their hands, which are then are projected onto a surface;

5. Find-the-noisy-box game: the child must find a noisy object in the dark;

Mikulas (2011) points out that these games are part of a storybook, Uncle Lightfoot, which tells a story about a boy with fear of the dark. In the story, the boy overcomes his fear by playing these games and feels proud of himself for doing so; he is therefore a positive role model, and the children who learn of the story desire to emulate him. The VR prototype should also have a role model persona in order to maintain this interest.

\subsection{STATE-OF-THE-ART}

In order to better understand the advancements in technology related to the core subject in this project research, as well as any recent methodologies to be feasibly applied in the prototype in development, it was necessary to create a state-of-the-art subchapter. This subchapter thus covers VR and gaming. 


\subsubsection{VIRTUAL REALITY}

As this project research concerns a VR game for regular consumer use, this section only addresses uncomplicated and affordable VR technology (both hardware and software) that is deemed adequate for the prototype in development.

\section{Hardware: Display}

In terms of display, VR can be experienced through mobile HMDs or wired HMDs (Anthes et al., 2016).

Mobile HMDs are wireless and do not require the use of a computer, as they use a smartphone to render the VR program; most mobile HMDs are cases which frame the smartphone screen, and all must include lenses for stereo-viewing (Anthes et al., 2016). The gyroscopes, accelerometers and magnetometers included in smartphones can be accessed and exploited to track head motion (Anthes et al., 2016).

Wired HMDs can include cameras to allow AR, as well as eye-tracking technology, and require the use of a computer (Anthes et al., 2016). Most are meant to be worn while sitting, though there are devices capable of tracking room scale in order to allow the user to walk during the experience (Anthes et al., 2016). Wired HMDs can include haptic support in the form of vibration for added immersion or in the form of controlling input; all of these HMDs come in the shape of wearable computing, as they must be worn or carried (Anthes et al., 2016).

One example of a mobile HMD is the hardware used for the prototype of this thesis, the Oculus Go. The Oculus Go has integrated speakers and microphones and boasts a lightweight design, weighing approximately 500 grams and measuring $19.05 \mathrm{~cm} \times 10.4 \mathrm{~cm} \times 11.4 \mathrm{~cm}$ (Lucas, 2018). Resolution per eye is $1280 \times 1440$, or 2560 x 1440 for both eyes, which is a higher resolution than its predecessor, the Oculus Rift, or its rival HTC Vive (both have 1080 x 1200 per eye or $2160 \times 1200$ for both eyes) (Lucas, 2018). The WQHD fast-switch LCD display helps to lower motion blur and motion sickness, as well as improving visual clarity; its refresh rate varies between 60 and $72 \mathrm{~Hz}$ depending on the app or game (Lucas, 2018).

The Oculus Go runs independently as it has a Qualcomm Snapdragon 821 processor included in its headset, which means it doesn't need to be connected to a computer or smartphone to run games or apps (Lucas, 2018). It needs, however, to connect to a smartphone to setup; this is possible through the Oculus' mobile app and is a relatively easy and quick task, though it requires Wi-fi access. 
Hardware: Input

As most VR experiences allow the user to interact with the environment, there is a need for controlling the user's input.

Anthes et al. (2016) categorize these systems as controllers, navigation devices, and tracking:

1. Controllers: hand-worn devices that have built-in buttons, joysticks, or touchpads; can be wired or wireless; usually built in pairs, so that the user can use both hands in a VR experience; some controllers offer haptic feedback in the form of controller vibration (Reactive Grip);

2. Navigation devices: used to create the illusion of movement, as well as to input coordinates in the environment in order to achieve that effect; traditional treadmills allow motion in one direction, while newer hardware allows for two-dimensional movement (e.g. Omnidirectional Treadmills);

3. Tracking: tracking the user's posture or upper-body position through magnetic tracking or Inertial Measurement Units combined with magnetic tracking; hand-based tracking dates back to the DataGlove's architecture (strain gauges inserted into gloves or fiber optics);

\section{Software}

A brief overlook of software development kits (SDKs) is necessary to understand their potential as well as to better advance the prototype developed alongside this research project. An SDK is a collection of software tools that allows the development of applications for a specific platform. Oculus has released several SDKs in order to allow independent app developing. Some of Oculus' SDKs can be used with Unity, the engine utilized in the development of this VR prototype (Anthes et al., 2016).

There are also web applications for VR, although many are only used in $360^{\circ}$ movies which are not considered VR due to lack of user interaction with the environment. Other applications include VRChat and High Fidelity, which allow for users to utilize VR as a chatroom of sorts (Anthes et al., 2016).

\subsubsection{GAMING}

Video games usually run on four main platforms: personal computers, consoles, arcade machines, and hand-held devices (e.g. smartphone). Each platform requires different 
specifications for running games, i.e. CPU speed, rendering power, and interaction design (Qi, 2014).

The development of video games requires expertise in different technological areas. Artistically, games rely on $2 \mathrm{D}$ and $3 \mathrm{D}$ art, being that $3 \mathrm{D}$ modelling has become the norm for modern video games. To showcase the art, it is necessary to properly render the models, as well as any included shaders and textures, and ensure that the game exhausts as little resources as possible while doing so. Sound is also a part of the artistic aspect of games, both in augmenting immersion (with sound effects or music) and providing auditive feedback in real-time to the user.

Most games nowadays also benefit from artificial intelligence (AI). Many games populate their worlds with non-player characters and agents who follow scripts and automated routes; it is in terms of conflict that AI manages to elevate the gameplay experience through algorithmic behavior (Qi, 2014).

Networking is also a staple for multiplayer games, allowing for players in different areas to play together at the same time. In order for networking to be possible, the game must be properly scaled and secured, and network bandwidth and latency need to be ensured (Qi, 2014).

As aforementioned, physics and interaction devices are also commonly present in video games (e.g. the feeling of gravity in a game, and the way a player interacts with it).

\section{Software: Now I Can Do Heights}

Now I Can Do Heights, pictured in figure 14, is a VR application developed in Unity for HTC Vive; it helps users with acrophobia (fear of heights) and is designed to be used without the assistance of a therapist (Freeman et al., 2018). The HTC Vive used in this VR therapy included the headset and the hand controllers.

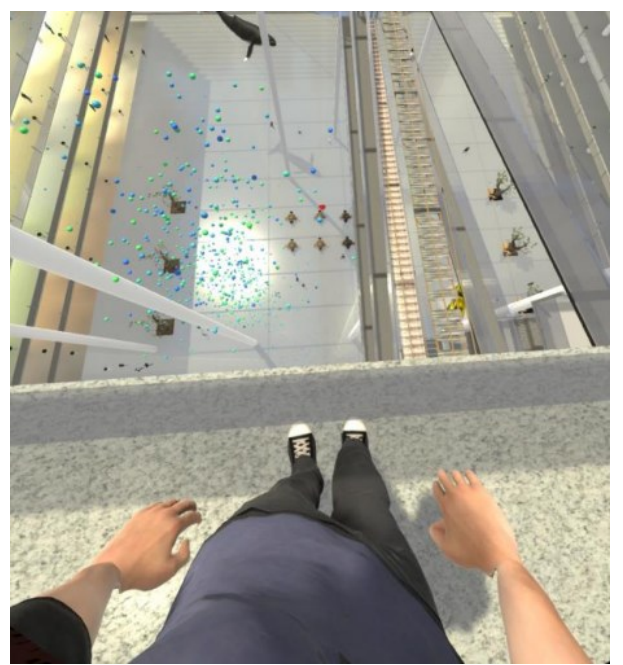

Figure 14: Screenshot of Now I Can Do Heights (ㄷ Oxford VR) (Freeman et al., 2018) 
Now I Can Do Heights includes a virtual coach, animated through motion-capture techniques, who first greets the user in a virtual office, then goes on to inform the user about basic acrophobia knowledge (Freeman et al., 2018). The user then evaluates their own level of fear and answers in-app on a scale of o to 10 ("I don't believe it will happen" to "I'm absolutely certain it will happen") (Freeman et al., 2018, p. 627). Participants are encouraged by the virtual coach to ensure their safety as the application goes on, as the treatment is based upon repeated behavioral experiment tests (Freeman et al., 2018).

After this first meeting on a first session (assessment stage), the virtual coach tours the building environment with the user and gives them the option to visit building floors one through five (Freeman et al., 2018). Randomized tasks, designed to be motivating, are then completed; though the task is randomized, its difficulty always begins at an easy level.

After the session is concluded, the virtual coach does another assessment where they describe the tasks completed, encourage the user, repeats learning points (e.g. "many people try to deal with their fear of heights by using defenses"), and ask the user if they felt safer than before (Freeman et al., 2018, p. 628). Sessions are saved at the end in order to carry on seamlessly from session to session (Freeman et al., 2018).

\section{Software: \#BeFearless}

For a more socially-based phobia, \#BeFearless is a series of VR experiences designed to help the user overcome fear of public speaking. \#BeFearless can be experienced through the Samsung Gear VR or the Oculus Go. There are three modes available for download: School Life, Personal Life, and Business Life (see figure 15 for a rendition of School Life's environment).

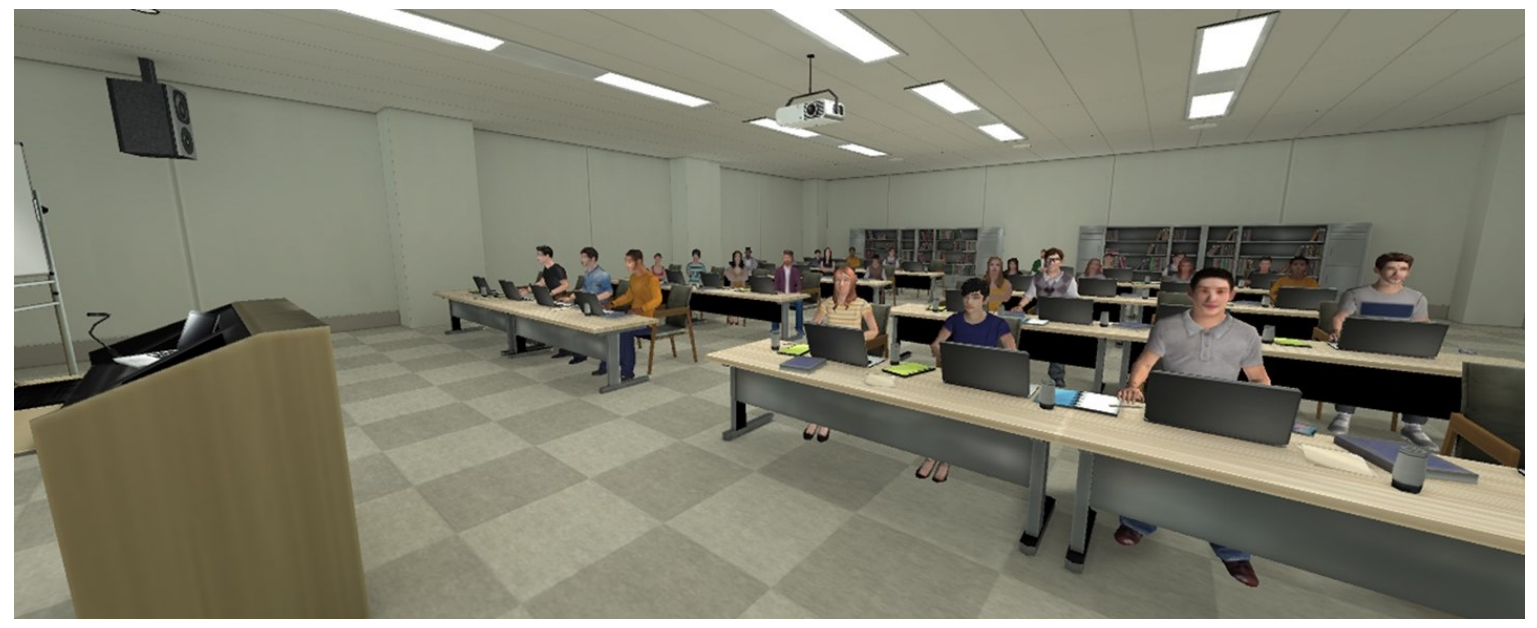

Figure 15: A screenshot of the \#BeFearless' School Life mode ("Samsung \#BeFearless Fear of Public Speaking : School Life," n.d.) 
Each mode approaches different situations in which the user is expected to speak, from a workrelated job interview or, at a more personal level, giving a toast. All three modes are meant for a single user, and they all use voice recognition software through the headset microphone.

The VR applications also respond to the user's "voice volume, speaking pace, eye contact, and heart rate" "'Samsung \#BeFearless Fear of Public Speaking - School Life on Gear VR | Oculus," n.d.), which can later be analyzed by the user in order to better understand their own state of mind, and ideally teach them how to assuage their fear of public speaking.

The selected VR experiences were carefully chosen to take part in this dissertation's state-ofthe-art because they propose to help the user overcome a reasonably common fear and use VR therapy in order to reach that goal, thus relating to the developing prototype. Although there are many more VR experiences which also relate to the prototype by using VR therapy or addressing specific fears, it would not be viable to list them all in the state-of-the-art. 


\section{METHODOLOGY}

Presentation of methodological approaches which allow for a proper framing of the project and its evaluation have been compiled in subchapter 2.1, Methodological Approach. This subchapter relates to the first phase of the practical development and documents the creation of a functional prototype which follows the methodological approaches later defined in this chapter: usercentered design, usability, user experience, and goal directed design.

The second phase of this chapter describes the principal phases of the empirical study of this investigation, which happen after the prototype has been developed; a set of usability guidelines will be implemented to better evaluate the prototype during UX testing.

The final focus of this chapter, presentation and framing of techniques and instruments of data collection, has been documented in subchapter 2.2, Data Collection And Analytical Techniques. This subchapter also includes requirements for the case study proceedings and its participant, as well as how both testing periods should occur.

\subsection{METHODOLOGICAL APPROACH}

In order to properly conduct the study upon which this thesis is grounded on, it is necessary to set a methodological approach (Quivy \& Campenhoudt, 2005). As this thesis benefits from literature review, focus group meetings, and, later, experiments and surveys, its approach has both quantitative and qualitative methods and can be defined as mixed.

Being that the objectives are grounded in theory and application, this investigation also shares characteristics with design-based research, which are listed out in table 5 .

Table 5: Design-based research characteristics (adapted from Bakker \& van Eerde, 2015, p. 435)

\begin{tabular}{|l|l|}
\hline \multicolumn{2}{|c|}{ Characteristics of Design-based Research } \\
\hline Holistic approach & Develops and tests theory at the same time \\
\hline $\begin{array}{l}\text { Analytical/theoretical generalization (capable of } \\
\text { being transferred to other situations) }\end{array}$ & $\begin{array}{l}\text { Causality is carefully handled and is grounded on } \\
\text { realistic, process-oriented views }\end{array}$ \\
\hline Researcher can be participant and/or observer & Design is necessary \\
\hline Reflective, cyclic process & Interventionist \\
\hline
\end{tabular}


This investigation can be separated into three phases: (1) preliminary/review, (2) concept/development, and (3) testing/evaluation.

In the second phase of the approach, concept/development, the investigation is exploratory in nature, since it proposes the conceptualization and development of a VR prototype that is, insofar, a pilot study, as well as the observation of any cause-and-effect relationships that might occur from user experimentation with the prototype. Furthermore, as the prototype in development concerns real users, meant to play and evaluate the prototype, user-centered design, usability design, user experience design (UX), and goal directed design are also part of the projectual methodology of this study.

The conceptualization of the prototype is included in this phase, beginning with early drafts of concept art (e.g. characters, levels, moodboards) and storyline (e.g. writing out the script for the characters' lines and coming up with an endgame mission).

The third phase of the research, testing/evaluation, is composed by user-testing and evaluation of the prototype. The testing group is ideally composed of individuals of young age with phobia of the dark, but, as previously noted, this is a hard-to-reach demographic. In this case, the individual's attributes are too specific to allow generalization, which requires a complex and deep analysis (Coutinho, 2013); this investigation can therefore be determined a case study. Furthermore, testing only one participant at a time is more viable and more practical: therapy working towards a goal requires trust and time, so the researcher should focus on one participant at a time.

The VR prototype can also be better adapted to the needs of a single participant (as opposed to a larger number of testers), as the functional prototype is meant to be used with a single child as the player, and, if needed, external support from therapists or parents.

Considering the target audience for the VR prototype (i.e. children often assimilate information much differently than teenagers or adults), UCD should be the method with which to work during development of the prototype.

\subsubsection{USER-CENTERED DESIGN}

UCD should always orbit around its user. Regardless of the designed artifact and the designer themselves, the focus of the construction should always be upon the user. In UCD and human- 
centered design (HCD) ${ }^{14}$, the designer's personal creative process should always come second to the user's needs and wants (Giacomin, 2014; Ritter, Baxter, \& Churchill, 2014).

However, UCD requires early analysis and testing of the construct (Ritter et al., 2014), while HCD prioritizes motivation and learning about the user before any implementation (Giacomin, 2014).

Giacomin (2014, p. 608) lists out several guidelines for this process, describing them as preconceived ways to optimize the artefact and satisfy the prospective user, whereas Ritter et al. (2014) describe these guidelines as requirements ${ }^{15}$ :

1. Understanding and specification of context of use (including users, tasks, environments);

2. Specifying the user requirements in enough detail to drive the design;

3. Producing design solutions that meet these requirements;

4. Conducting user-centered evaluations of these design solutions and modifying the design to consider the results;

The last item refers to iteration, which is a methodology in which a construct or artefact is refined through user evaluation and testing (Nielsen, 1993). Iteration is not the simple replacement of interface elements, but improvement of the interface as a whole based on knowledge gleaned from earlier iterations (Nielsen, 1993). With each iteration, there is another test, and another series of corrections to the design, which will, in turn, heighten the system's usability (see figure 16).

This concept, initially proposed by Norman (2013) has been altered by successive contributions, and now forms the basis of the UCD methodology.

\footnotetext{
${ }^{14} \mathrm{HCD}$ is a movement related to UCD. HCD is a more recent paradigm based on communication, interaction, empathy and stimulation of its users, as opposed to simple human-system interaction. It is meant to understand what users want even better than they do (Giacomin, 2014; Ritter et al., 2014). ${ }^{15}$ Both authors are citing the International Organization for Standardization, article ISO 9241-210, albeit at different points in time.
} 


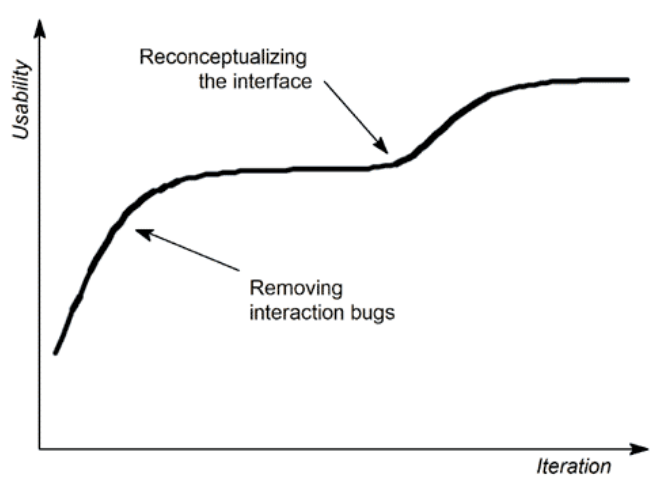

Figure 16: Interface quality as a function of the number of design iterations (Nielsen,

1993)

Iteration is therefore heavily dependent on user testing. However, in the context of this thesis and respective prototype, the continuous involvement of the ideal user would be unfeasible on account of their young age. In this case, the repeated testing and evaluation of the prototype can be conducted without yet having an ideal test participant, allowing for the development of the prototype to happen in parallel with usability tests.

This constant participation of the user follows in line with the methodology of UCD, in terms of usability testing. At this stage of development, the prototype was altered and corrected after each test, and was then tested again with a different user (as per iteration design).

\subsubsection{USABILITY}

Usability is a concept composed by several characteristics, usually a set of methods and techniques for assessment of interactive interfaces. Its purpose is making these interfaces easy and pleasing to use (Federoff, 2002; Nielsen, 2001).

These characteristics are "functionality, usability, learnability, efficiency, reliability, maintainability, and utility or usefulness.", being that they are not mutually exclusive (Ritter et al., 2014, p. 47). Nielsen (1993) adds rememberability, capacity for error recovery, and pleasure of use to this list, but points out that usability is a measure of how well functionalities can be used, not of how useful they might be. Finally, ISO norm 25010 defines usability as an intrinsic quality of the system as well as a quality in system use, being that it comprehends effectiveness, efficiency and satisfaction, freedom from risk, and context coverage ("ISO 25010," n.d.).

Usability can be divided into two methods: heuristics and usability tests.

In the context of this study, and according to Nielsen's (1995) usability heuristics, the focus of the development should be upon the heuristics listed below in table 6 . The investigator must 
define which objectives should be prioritized in their project, in order to focus on them during development of the prototype (Nielsen, 1993).

Table 6: Nielsen's (1995) adapted usability heuristics verified in the low-fi prototype

Nielsen's Usability Heuristics

\section{Prototype Interface}

\begin{abstract}
Visibility of system status: feedback constantly
keeps user informed within reasonable time

Match between system and reality: system should

feel familiar to the user, with logically ordered information

User control and freedom: undoing mistakes should be quick and easy

Consistency and standards: words and situations must always maintain the same meaning
\end{abstract}

VR ideally runs in real-time

Error prevention: design should prevent problems, either by checking for them or asking the user for confirmation on an action

Recognition over recall: the user should not have to remember previous interface information

Aesthetic and minimalist design: dialogues should not have irrelevant information
Obligatory due to the target audience (i.e. children between 8 and 10 years)
The interface should be simplistic and easy to access or always accessible and always present on-screen

In order to ascertain the prototype's level of usability and after following the previous usability heuristics, a questionnaire or an interview must be drawn-up. These should be answered in a controlled setting under observation.

Federoff (2002) has a set of heuristics based on Nielsen's work, modulated specifically for video games, and suggests, citing Nielsen (2000, 2001), that a maximum of five testers are enough to point out any heuristic violations after playing the game twice.

Due to the short narrative and simple gameplay of the prototype mentioned in this thesis, careful consideration of the heuristics compiled by Federoff (2002) is necessary in order to select those which better apply to the prototype. Furthermore, in a test with the ideal participant, the 
heuristics outlined would have to be adapted into simpler language or remade into easier yesor-no questions to ensure the child's comprehension and subsequent answer. Testing the prototype in development with a convenience sample group of five people before introducing the prototype to the child ensures there are less errors to contend with later, as shown below in figure 17.

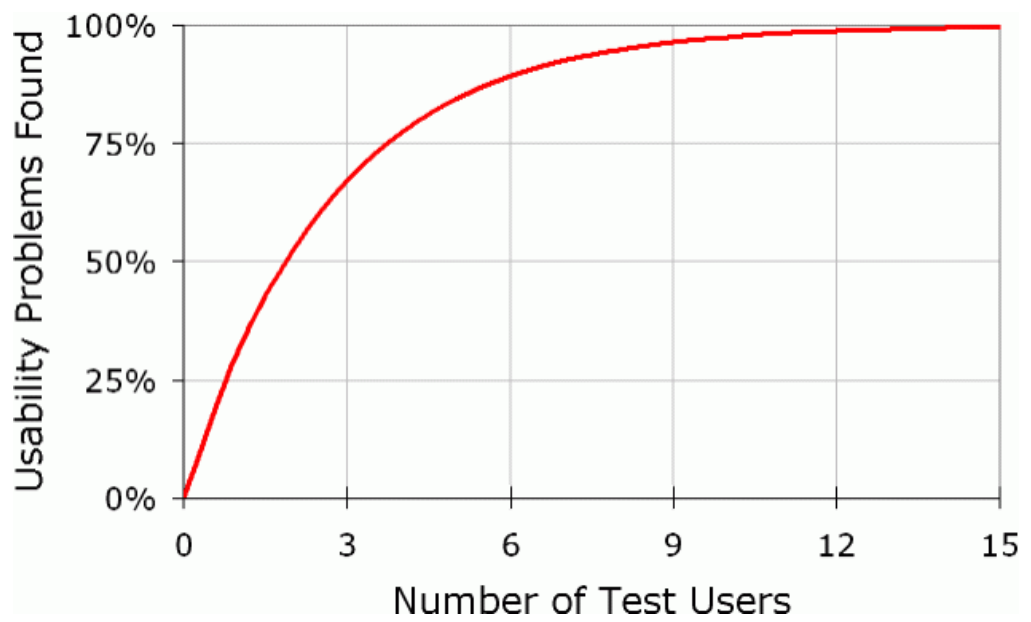

Figure 17: Percentage of problems found by number test users (Nielsen, 2000)

In addition to the heuristics by Federoff (2002), the usability metrics by Nielsen (2001) should, ideally, also be used. However, as Nielsen (2001) recommends a minimum of twenty testers per test, and collection of metrics is both expensive and slow, this kind of measurement will likely be discarded in favor of usability testing.

Usability testing should touch upon learnability, efficiency, memorability, errors, and satisfaction. Testing is usually done under researcher observation while they complete previously assigned tasks, and, following the tenets of iteration, is conducted repeatedly from early development to the prototype's release (Nielsen, 2013).

This ensures usability issues are identified and corrected early on, in order to improve the prototype before launch. Usability tests are usually conducted on prototypes with different levels of fidelity as development proceeds ("What is Usability Testing? | Interaction Design Foundation," n.d.). The tests that fit the context of this project research include (Churm, 2012):

1. Explorative testing: used in the early phase of development to assess preliminary design usability factors and user thought process;

2. Test of assessment: used midway in development or as a usability test for technology evaluation; 


\subsubsection{USER EXPERIENCE}

User experience is a more recent evaluative approach in comparison to usability, and, unlike usability, its main objective is to extract sensitive information related to user motivation (both psychological and social) and real-world product use.

UX includes all parts of user interaction with "the company, its services, and its products" (Norman \& Nielsen, n.d.). It is a creation process (see figure 18) which puts user satisfaction first through the inclusion of techniques like branding, design, usability and function (Interaction Design Foundation, n.d.).

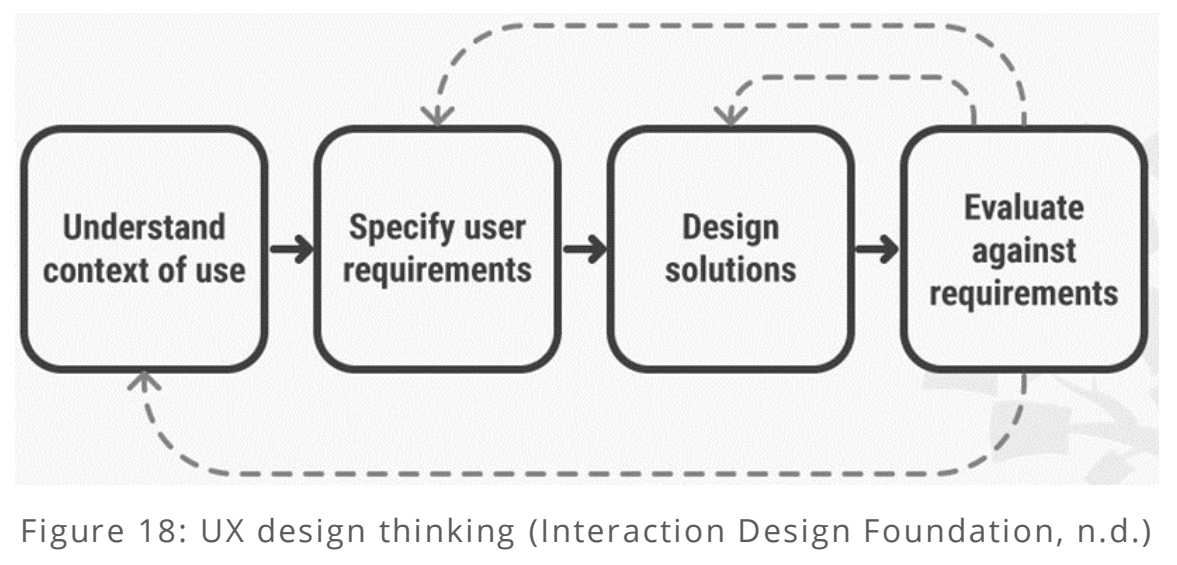

Summarily, UX is a concept which covers the overall quality of a product, in specific whether it is effective, pleasing, and fun to use. In the context of this project research, UX can be measured explicitly through the participant's conscious words as they play, as well as answering a questionnaire after they have reached the end of the game.

UX testing is necessary in order to gauge the participant's level of anxiety as they face their fears. Using a UX test in the convenience sample group is unnecessary, as they do not feel any sort of aversion or fear to the darkness. Hence, the UX testing should be carefully tailored to fit the ideal participant's needs and should only be used in laboratory testing, especially if the results are to be compared later (e.g. to observe if there is any evolution in the child's fear levels).

\subsubsection{GOAL DIRECTED DESIGN}

Goal directed design process dictates that design should come before programming. Alan Cooper modifies several guidelines for conventional software development by putting the priority on the design, listing them out as such (Cooper et al., 2014):

1. Design first; program second;

2. Separate responsibility for design from responsibility for programming;

3. Hold designers responsible for research, product quality and user satisfaction; 
4. Define one specific user for your product; then invent a persona-give that user a name and an environment and derive their goals;

5. Work in teams of two: designer and design communicator;

As the prototype in development is an individually led project, there are some guidelines which do not entirely apply to it. However, the concept/development phase should benefit from following those which do, namely prioritizing the design of the interface as opposed to tweaking it during programming, and the creation of a specific user persona to better perceive their goals. This latter point is especially effective in the context of this thesis, as it focuses on a specific kind of individual (i.e. children with fear of the dark).

Furthermore, following Cooper's guidelines should improve the prototype's quality and decrease time of development (Dubberly, 2001).

In the context of this study, both evaluation techniques (usability and UX) will be used at different phases. During and after the prototype has been developed, sessions of usability testing will test its level of functionality. UX testing will also be applied before and after the prototype's development stage: at the phase of conceptualization, wherein a participant belonging to the target audience will be informally involved with narrative and worldbuilding conception, and during the case study proceedings, wherein the participant actively and formally partakes in real environment testing.

\subsection{DATA COLLECTION AND ANALYTICAL TECHNIQUES}

This subchapter concerns both the instruments and analysis used in this investigation as well as its third and final phase, testing/evaluation.

This research is based on individuals of young age with phobia of the dark. As the individual's attributes are too specific to allow generalization, which requires complex and deep analysis of the case in question (Coutinho, 2013), this investigation can be determined a case study. The methodology used in this phase therefore belongs to the instrumental case study category - an empiric investigation based on inductive reasoning, depending on field work and based off several sources - which aims to collect data from the case (i.e. phobia of the dark) in order to understand another phenomenon (i.e. VR gaming as therapy) (Coutinho, 2013).

The instruments used in data collection and posterior analysis of said data can be separated into three categories: (1) the phase preceding testing of the prototype, (2) the phase happening in time with the testing, and (3) the post-testing evaluation phase. 
Typical data collection tools comprehend:

1. Determination of case study ideal participant (pre-testing):

i. Interviews;

ii. Questionnaires;

iii. Focus groups meetings;

iv. Low-fidelity prototype for usability/UX testing ${ }^{16}$;

2. User test of prototype with ideal participant (during testing):

i. Questionnaires;

ii. High-fidelity functional prototype ...

i. ... without ideal participant:

1. Usability and UX testing for design iteration;

ii. ... with ideal participant:

1. Usability and UX testing;

2. Real environment testing;

iii. Observation ${ }^{17}$ during laboratory tests;

\section{Analysis and presentation of data (post-testing):}

i. Evaluation of the data gathered along the process of development and testing;

ii. Testing and presentation of said data;

\subsubsection{PARTICIPANTS}

Coutinho (2013) refers to the sample used in this investigation as an extreme case sample: a unique case meant to offer data which is interesting and relevant to the investigator.

The sampling process of an extreme case sample is better for this approach because it is dynamic and sequential, which, as the study evolves, allows it to be altered to better complete the requirements of the study (Coutinho, 2013). Furthermore, it allows sample adjustment, and only concludes the sampling process when all available information about the sample has been assimilated (Coutinho, 2013). This is the most appropriate approach for this investigation; e.g. if an individual surfaces with all of the desirable characteristics, altering the sample will not change anything in the investigation as it has yet to include the participant.

Furthermore, as the case study is not based on sampling methods, the sample is always intentional (Coutinho, 2013). As this prototype is meant to satisfy specific requirements, the

\footnotetext{
${ }^{16}$ As aforementioned, it is advisable to begin usability/UX testing of the prototype before the ideal participant has been found.

${ }^{17}$ The researcher both observes and participates, as happens in design-based research.
} 
sample should only include one participant, being that they should be between the ages of 8 and 10 and ideally have a medically diagnosed phobia, or an acute degree, of fear of the dark.

Other ideal characteristics that would facilitate the experiment include: (1) the participant is interested in VR and/or video games, (2) the participant is situated geographically near the author of the thesis, and (3) the participant's caretakers are willing to be present in all the experiment's sessions.

This sample should be collected with the help of psychology professionals and/or academics. As mentioned, this sample can be collected using interviews and questionnaires, being that the objective is to find a participant who shares all three requirements stated above.

Regarding the previously mentioned UX/usability testing groups, they should be built from a sample of convenience in order to further facilitate the iteration and fine-tuning of the prototype during the concept/development phase.

The UX testing period should be done before the tests meant to evaluate the child's response to the prototype. This first phase of UX testing is meant to focus on iterative design (focused on testing the usability, interface, and gameplay) while the second phase will include the child and is meant to focus on their reaction to the prototype as opposed to user experience. Following the iteration design guidelines signifies that UX testing with a sample of convenience is a part of the prototype's development, and not a parallel process.

Empirical study phases have been schematized for easier comprehension (see table 7). 


\begin{tabular}{|c|c|c|}
\hline $\begin{array}{c}\text { PHASES OF } \\
\text { INVESTIGATION }\end{array}$ & PROCEEDINGS & ANALYTICAL TOOLS \\
\hline Functional prototype & $\begin{array}{l}\text { Establishing, developing, and } \\
\text { implementing a functional } \\
\text { design; }\end{array}$ & $\begin{array}{l}\text { 1. Research and review of } \\
\text { bibliographical references }\end{array}$ \\
\hline $\begin{array}{l}\text { Initial evaluation of } \\
\text { prototype }\end{array}$ & $\begin{array}{l}\text { Evaluation of prototype based } \\
\text { on usability and UX heuristics; }\end{array}$ & $\begin{array}{l}\text { 1. Questionnaires } \\
\text { 2. Observation of tests } \\
\text { 3. Transcription of observed } \\
\text { proceedings }\end{array}$ \\
\hline $\begin{array}{l}\text { Selection of ideal case } \\
\text { study participant }\end{array}$ & $\begin{array}{l}\text { Creation of ideal participant } \\
\text { profile based on previous } \\
\text { research and methodological } \\
\text { framework; } \\
\text { Selection of participant; }\end{array}$ & $\begin{array}{l}\text { 1. Interviews } \\
\text { 2. Focus groups' meetings }\end{array}$ \\
\hline $\begin{array}{l}\text { First evaluation of } \\
\text { prototype with ideal } \\
\text { case study participant }\end{array}$ & $\begin{array}{l}\text { Evaluation of prototype based } \\
\text { on usability and UX heuristics; }\end{array}$ & $\begin{array}{l}\text { 1. Questionnaires } \\
\text { 2. Observation of tests } \\
\text { 3. Transcription of observed } \\
\text { proceedings }\end{array}$ \\
\hline $\begin{array}{l}\text { Redefinition of } \\
\text { prototype design }\end{array}$ & $\begin{array}{l}\text { Incorporation of new } \\
\text { functionalities (e.g. lighting } \\
\text { options) as per iterative design }\end{array}$ & $\begin{array}{l}\text { 1. Review of former UX and } \\
\text { usability tests' } \\
\text { transcriptions }\end{array}$ \\
\hline $\begin{array}{l}\text { Second evaluation of } \\
\text { prototype with ideal } \\
\text { case study participant }\end{array}$ & $\begin{array}{l}\text { Evaluation of prototype based } \\
\text { on usability and UX heuristics; }\end{array}$ & $\begin{array}{l}\text { 1. Questionnaires } \\
\text { 2. Observation of tests } \\
\text { 3. Transcription of observed } \\
\text { proceedings }\end{array}$ \\
\hline
\end{tabular}




\section{FUNCTIONAL DESIGN}

This chapter concerns the methodology for the secondary phase of the investigation, focusing on conceptualization of the prototype and resulting game design. This work is documented in the first subchapter, Game Design, while the system requirements and architecture are discussed in the second subchapter, System Architecture.

\subsection{GAME DESIGN}

After revision of the previous literature, there are several guidelines to follow and issues to take into consideration before sketching a narrative in the development of a VR experience for children, namely: (1) language of the game-both literary and visual-must be simple, clear, and concise; (2) special attention must be taken in regards to VR sickness, such as limited times of exposure and an adaptation period (Anthes et al., 2016; Bouchard, 2011; Laviola Jr., 2000; StJacques \& Bouchard, 2005); (3) the narrative of the prototype must be child-friendly and must motivate the player into finishing the game (Mikulas, 2011; Roth \& Koenitz, 2016; Weerdmeester et al., 2017); (4) practicality in development should be prioritized (Cooper et al., 2014; Dubberly, 2001; Zeltzer, 1992). In this last regard, usage of Unity's Asset Store allowed the researchers to focus on the prototype's game design and programming, as opposed to timeconsuming 3D modelling.

The VR prototype allows a player to explore a setting at their own pace - a woodland which has been polluted by previous campers - guiding them through a short, simple story until they reach the farthest and darkest areas of the woods. The main theme of the narrative is based on protecting nature and to be a mindful and kind person.

The game is open world-like, allowing for easy and relaxed exploration, and has been stylized after the low-poly style of aesthetic. The woods are open for exploration, colorful, and nonthreatening. This is meant to put the player at ease, while the open world feeling is meant to inspire them to discover the surrounding environment.

The world has been divided into three differently lit areas, being that the first is set in daylight, the second one in a setting sun phase, and the third is set at night. The fourth and final setting of the game is included in the third area and happens in a dark cave where there are no light sources.

Early conceptualization sketches of the world's game can be seen in figure 19, figure 20, and figure 21. 
The first area is comprised of bright lighting and colors, being that the main colors are the bright blue of the sky and the bright green of the ground. It is a grassland area with flowers, bushes, and trees which are stylized in round shapes. The player character has set up camp in this area; the camping area includes a tent, a fire, and a bench with nondescript objects for immersion purposes. Sounds in the first area contain the buzzing of insects, occasional bird tweets, and, if the player approaches the river, running water sounds.

The second area is comprised of medium lighting and muted colors, being that the main colors are the bright orange of the sky and the warm brown of the ground. It is an area with mushrooms, chopped tree trunks, and bare trees which are stylized in tall shapes. This area is meant to emulate an area where trees are felled for wood, as there are two stacks of logs at either border of the area. Sounds in the second area contain a buzzing of insects which is more silent in comparison to the previous area, and, if the player approaches the river, running water sounds.

The third area is comprised of dark lighting and dark colors, being that the main colors are the dark blue of the sky and the dark reds and purples of surrounding flora. It is a mountainous area with rocks, a landmark large tree enclosed by fireflies and flowers, and trees which are stylized similarly to pine trees. Sounds in the third area contain the stridulating of crickets. The cave at the end of the third area has an ambience sound akin to a void, empty space, as well as running water sounds at the river's source.

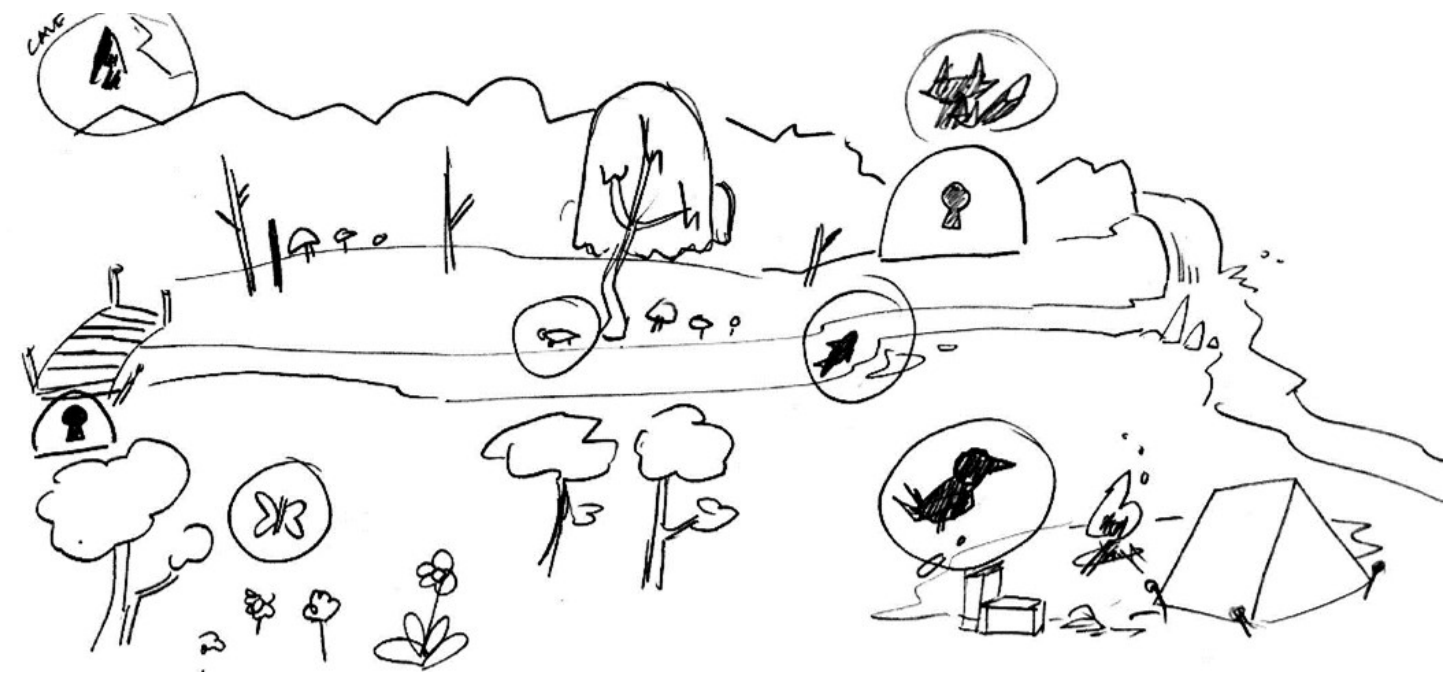

Figure 19: Early draft of the environment (picture by the author) 


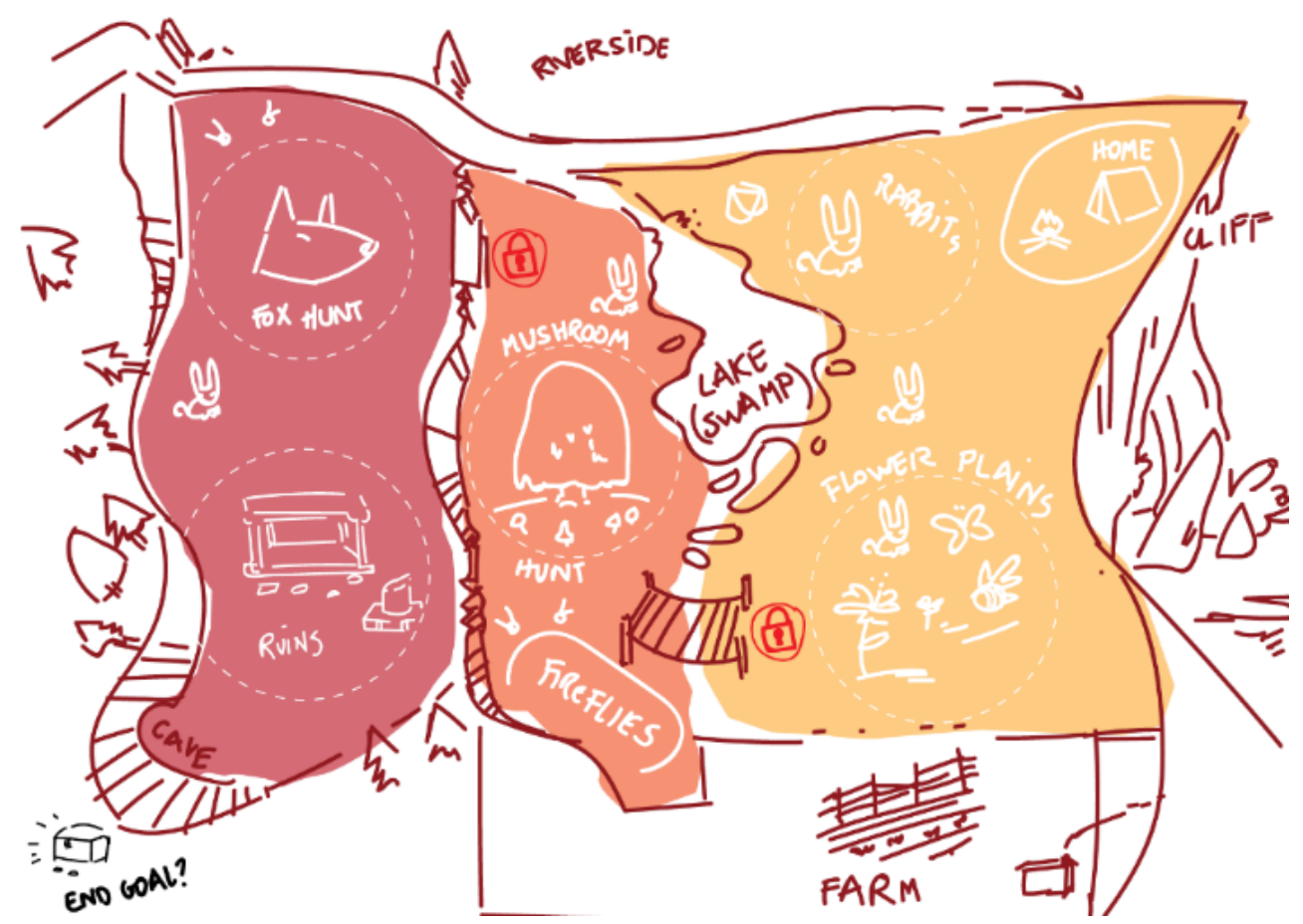

Figure 20: Conceptual schematics of the world map (picture by the author)

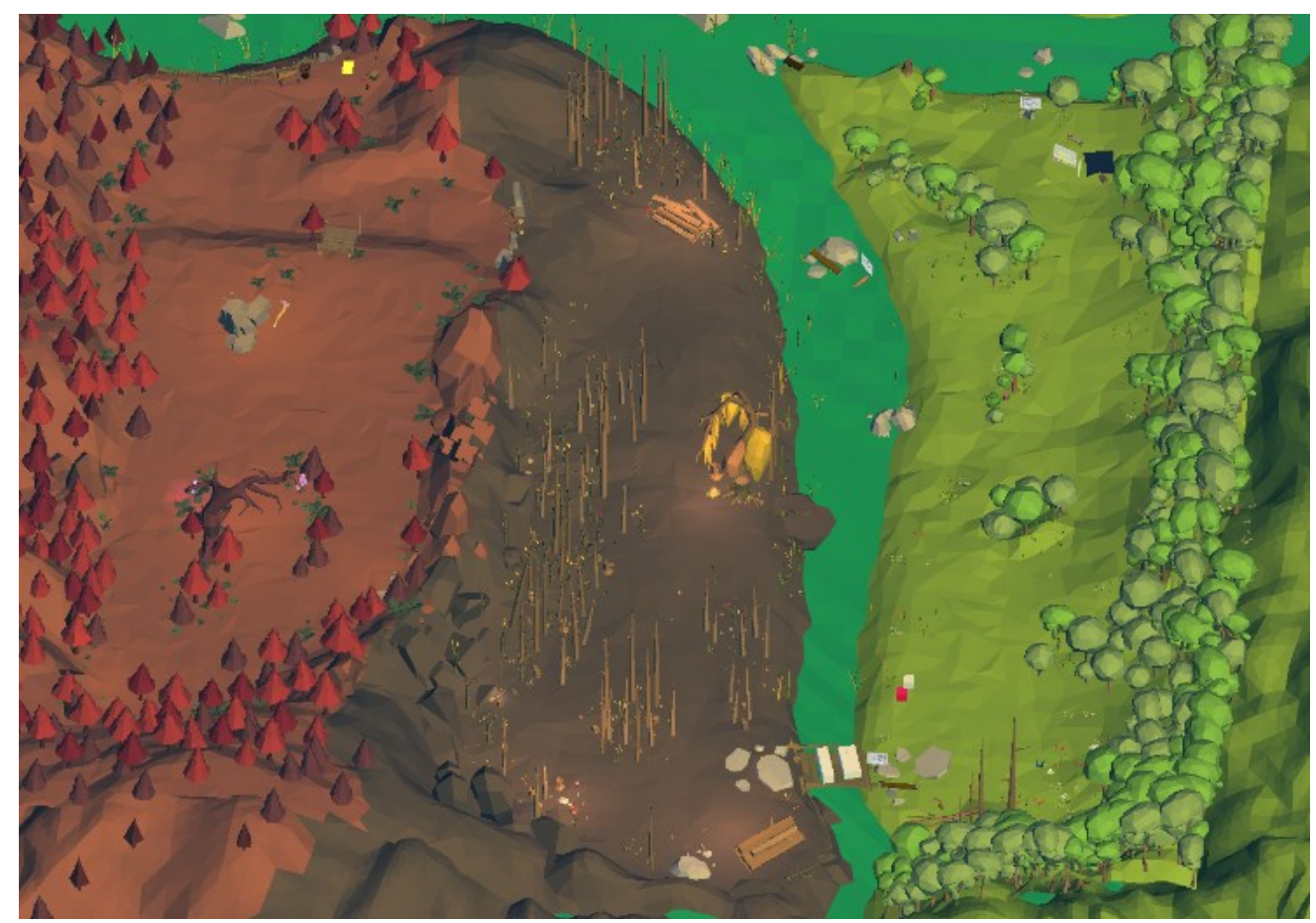

Figure 21: Top isometric view from the 3D model of the world as it appears in Unity3D (picture by the author) 
The world model was built with the help of $\mathrm{Gaia}^{18}$, exported to Blender for stylization and simplification (through application of Blender Boolean modifiers like 'decimate' to the mesh), and then imported back into Unity, where it was then populated with free $3 \mathrm{D}$ assets ${ }^{19}$ downloaded from the Unity Asset Store (see figure 22).

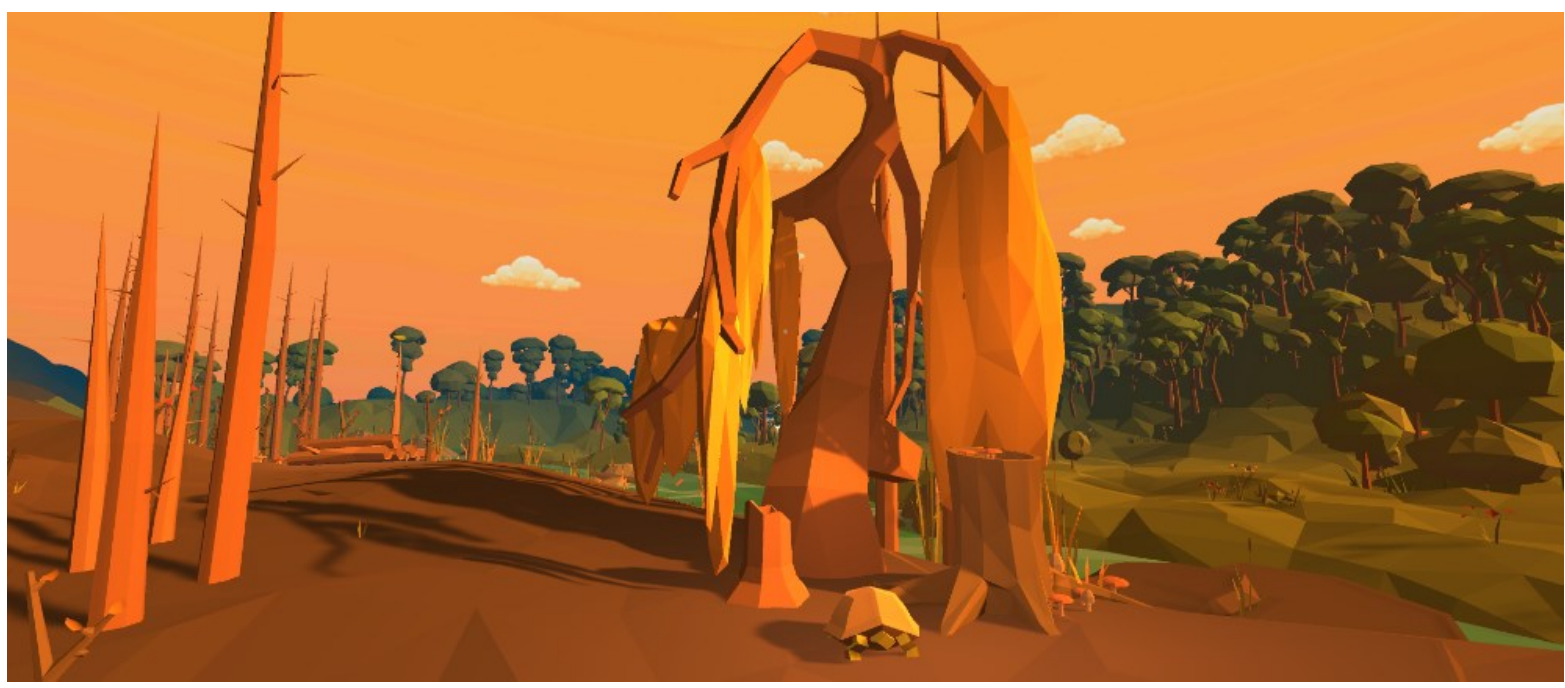

Figure 22: Prototype screenshot: a non-player character and environment (picture by the author)

The prototype's environment shares some characteristics with open-world video games, as the player can explore each area at their own pace before deciding to advance to the next one. This aspect was included in the gameplay to allow for the player to advance without feeling pressured by other factors such as in-game time or enemies. In order to immerse the player in the environment, ambience sounds were added to each area; these sounds are composed of insects buzzing, water running, and birds chirping, so as to not overwhelm the player.

The inclusion of game-like tasks in the shape of locked "gates" between levels is meant to take advantage of the motivational factor of the game, as the child must actively want to advance before setting out to do so. This desire to go on playing after fully exploring an area means they must complete the task related to the "gate" (e.g. a run-down bridge they must find planks for) in order to head into the next level.

Ideally, the end goal should be reached with minimal discomfort on the player's part, which could then be used as an incentive to explain that facing the darkness is easier than the child expects. The non-threatening environment the prototype is set in is also meant to add to this idea that the dark will not hurt the child, nor will it hide frightening events. Adding to this,

\footnotetext{
${ }^{18}$ A world-building asset for Unity.

${ }^{19} \mathrm{~A}$ complete list of assets used in the development of the prototype can be found in annex (see annex 12).
} 
familial or therapeutic support will also help the child conclude that their fear of the dark can be overcome.

\subsubsection{CHARACTERS}

The characters of the prototype are a crow, a fish, a turtle, a butterfly, and a fox.

Each of these animals have different roles, being that each role was thought out to better suit their real-world behaviors: (1) the crow serves as a guide of sorts, because it can fly and observe the world below; (2) the fish remains at a set position and will only help the player proceed to the next level if fed; (3) the turtle knows the lore of the world on account of its advanced age, but depends on the player to be moved around; finally, (4) the fox is located at the darkest area and will guide, follow, and aid the player if fed. An early draft of the characters' concept art can be seen in figure 23, while the final models used in-game can be seen in figure 24 .

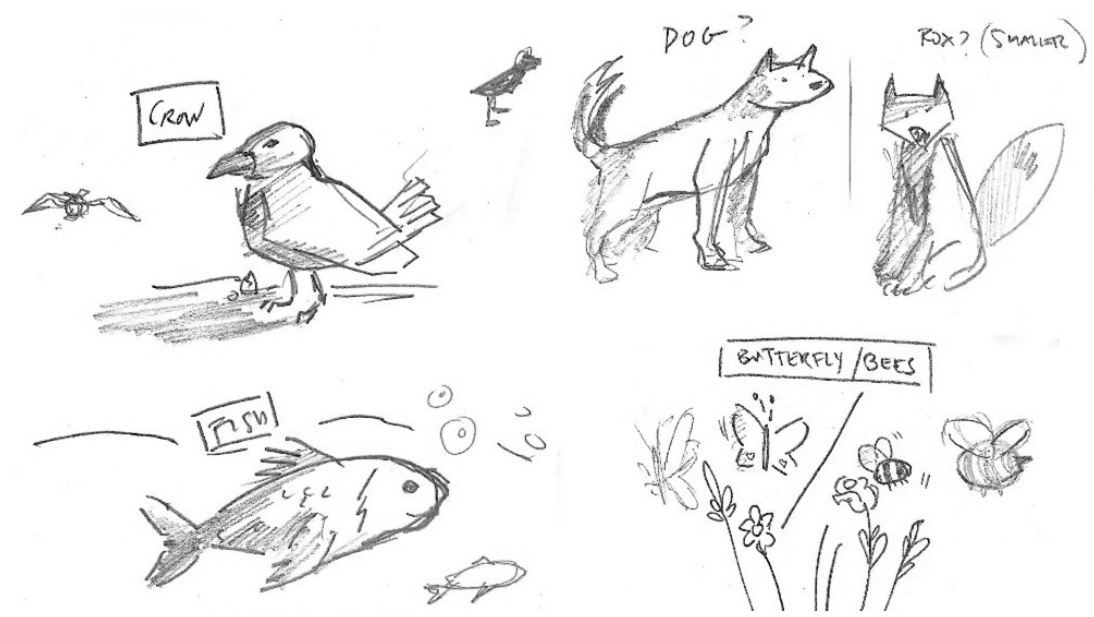

Figure 23: Early drafts of the characters (picture by the author)

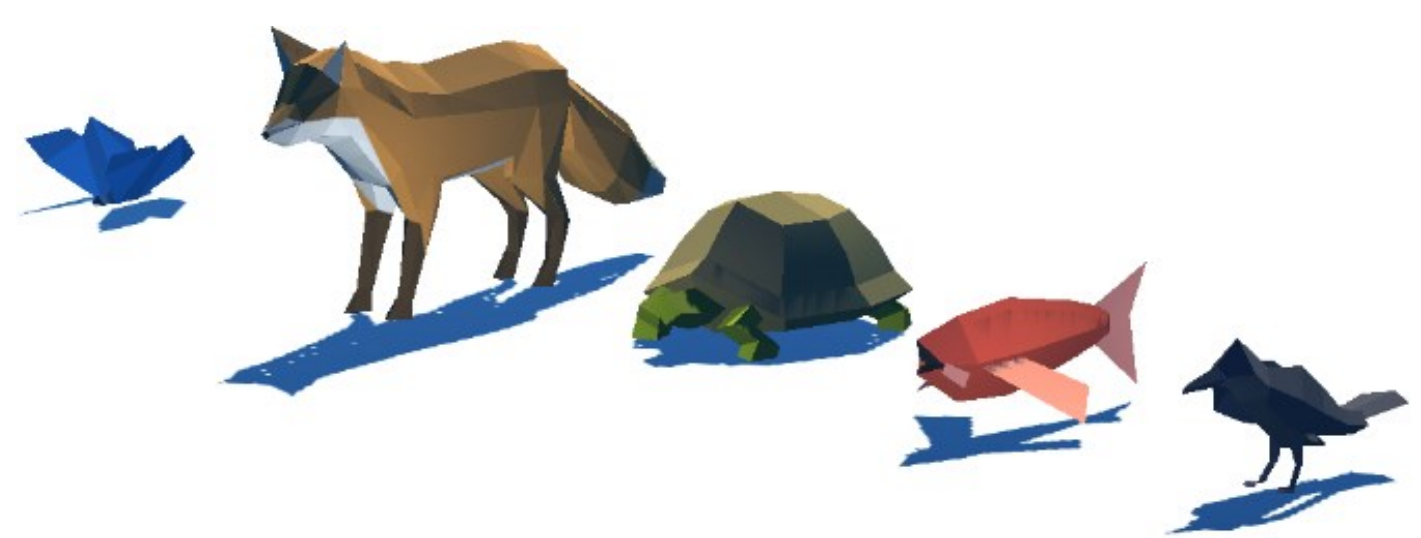

Figure 24: Animal 3D models in idle position (picture by the author) 
The contribution of these non-player characters (NPCs) will ideally make the player feel less frightened of the darkening areas, as well as making them feel escorted and safe. Using animal models for the NPCs as opposed to other human beings is meant to create a natural and fantastical world, which will then ideally augment the fantasy aspect of the game. Children are also usually fond of animals or feel curiosity towards them, which allows the game's characters to feel more sympathetic.

Furthermore, the Unity3D Asset Store offers several animal 3D models in low-poly style (as opposed to very few human character models which shared the visual style of the prototype), some of which already animated. These models conveniently matched the early concept art drafted in the early phase of conceptualization, and thus were added to the project.

\subsubsection{NARRATIVE}

The narrative is set in motion through the NPCs' lines, which can be read through the player's interaction with the $\mathrm{NPCs}^{20}$. This requires the story to be easy to follow and comprehend, which will then help the player progress through the game. The linearity of the narrative also helps in this matter.

The player is greeted at the start of the game by the crow NPC, who will let them know they are not the first visitors to the woods. After some tasks, the player will learn that the woods have been polluted by the visitors who came before them. The river that splits the environment has turned green as it has been polluted at its source, which is placed at the cave, the darkest level of the game. The NPCs will feed the player more information about this incident while they advance through the game, up until the player has read the full story and understood what the final quest of the game is (i.e. heading into the dark cave to clean up the river at its source).

The end of the game is then marked by the river turning light blue again, and the whole cast of NPCs watching the sun rise with the player. This is meant to give the player a positive reinforcement for facing their fear in order to help the animals.

Ideally, the storytelling aspect of the game will entice the player into finishing the game, even when they are facing against a continuously darkening environment.

\footnotetext{
${ }^{20} \mathrm{~A}$ script of the NPC lines can be accessed in annex (see annex 13). It is written in Portuguese, as the prototype was developed for Portuguese audiences.
} 


\subsubsection{INTERACTION}

The player may interact with the woodland creatures in order to understand what went on before they arrived at the forest, as well as interact with the world around them in simplistic yet immersive ways (i.e. tossing stones in a river or adding wood to the fire). By speaking with the NPCs, and by accepting their requests or reading the hints they give, the player can learn the whole history of the previous visitors of the woods, and how they polluted the area.

The aforementioned "gates" that bar the player's passage fulfill a measure of cognitive effort required by most games; they require active participation, which can be accomplished through interaction.

As previously stated, a game must have an objective for the player to achieve. To prevent the player from achieving this objective too easily, conflict is born in the shape of obstacles which create challenge. However, this conflict should be fair, responsive, and purposeful so as to fit the game and not frustrate the player (Crawford, 1997; Salen \& Zimmerman, 2004). Thus the gameplay factor of the prototype is made up from the game's pacing and its required cognitive effort. Considering the prototype's target audience, the game's pacing should be slow, as to give the player a sense of security as well as allowing them to adapt to the game, while the cognitive effort cannot be too elevated or too basic: though the player is also given hints in the shape of NPCs' messages, these are meant to bolster the narrative as opposed to telling the player where they should go. Thus, the required cognitive effort applied by the player while attempting to unlock these "gates" should also add to the motivation factor.

Since the target audience for this prototype is a young child, the cognitive effort required to advance through the game can be eased through the introduction of only one task at a time, being that the player has to finish their current task before being introduced to the next one. The three "gates" have been designed to be simple obstacles (e.g. a broken bridge or a fallen tree) which require the player to explore the level and interact with the NPCs for clues with which to find the solution to un-locking the "gate" (e.g. being aided by a fish or finding a hatchet).

In terms of player-world interaction, the player can grab and hold certain objects, which they can carry with them if the controller's trigger is being held down. These objects obey the laws of physics, and, as weighted objects with colliders ${ }^{21}$, are affected by gravity. This also allows them to be thrown or used as weights. Most of these "pick-up" objects do not impact the storyline in any way and were merely added to the game to make it more fun and immersive.

\footnotetext{
${ }^{21}$ Colliders are Unity components which work to emulate real-world physical collisions. Most 3D models in the prototype have a collider, which means that the player can collide against objects, carry them, or throw them against other objects. This ensures realism, and, consequently, immersion. E.g., the player cannot walk through a fence, instead coming to a halt.
} 
The growing darkness of the game is also measured by the player's interaction with the world. With each "gate" that the player manages to unlock, the environment darkens (e.g. the sky shifts from sunset to stars and the lighting dims). This can be reset by exiting the game, though the darkened states will always be triggered the first time the player passes by the "gates".

In addition, the darkness of the game can be adjusted on the start menu; the player may choose from three different levels of darkness before beginning the game.

\subsubsection{USER INTERFACE}

The interaction with the user interface (UI) is very simple, making use of only three different buttons to create the text box, advance through the text messages, and close the text box once the scripted dialogue has been read in full. The font used in the prototype's UI, LiberationSans, is sans-serif and has been chosen to ensure that the messages are readable and do not force the player to strain their eyes, as experiencing VR is already an exhaustive visual task. In order to further ensure this, the lines of dialogue of each NPC have been shortened and simplified to allow for a greater text size.

The dialogue UI is composed of three different buttons and a panel where the dialogue text is written. The dialogue UI contains a script that measures its distance to the player's position, which means the dialogue can only be activated if the player is at an acceptable distance from the activation button. If the player is either too close or too far from the button, they are unable to start a dialogue with the NPC, as the button is automatically disabled (see figure 25).

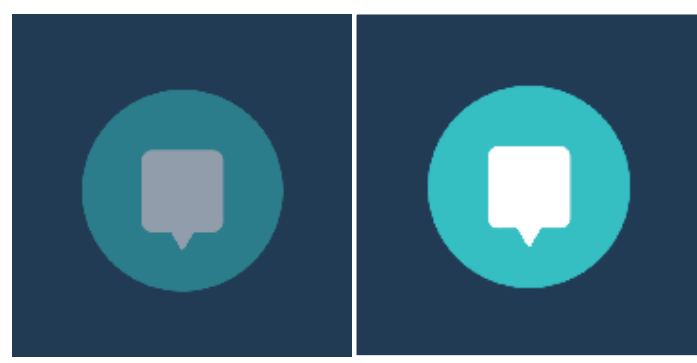

Figure 25: Dialogue activation buttons (disabled and enabled, respectively) (picture by the author)

This functionality was implemented after UX testing to prevent the text from appearing too close or too far from the camera; this would result in the player not being able to read the lines or not being able to click the button to advance dialogue (see figure 26 and figure 27). 


\section{NOME}

Lorem ipsum dolor sit amet, consectetur adipiscing elit.

Proin eu dictum metus.

Curabitur est ipsum, ultricies ac fringilla eget, elementum nec ex.

\section{NOME}

Lorem ipsum dolor sit amet, consectetur adipiscing elit. Proin eu dictum metus. Curabitur est ipsum, ultricies ac fringilla eget, elementum nec ex.

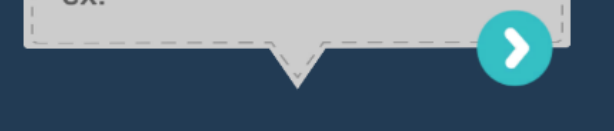

Figure 26: Dialogue UI with the button to advance to the next line and dialogue UI with the button to close the dialogue UI (picture by the author)

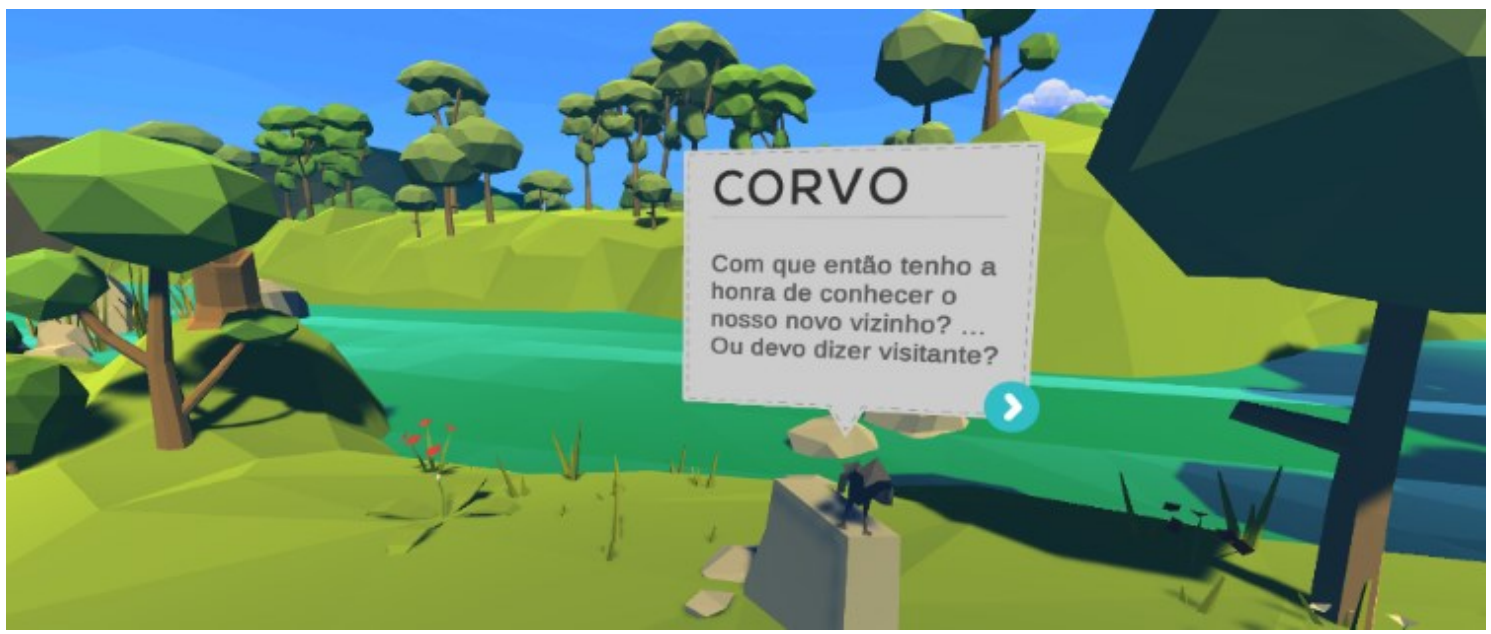

Figure 27: NPC being interacted with 22 in-game (picture by the author)

The inventory's UI has also been designed very simply to allow the entire interface to fit onscreen without needing further user input (see figure 28).

\footnotetext{
${ }^{22}$ As this game is meant to be tested with Portuguese audiences, its language is in Portuguese. The message being displayed in figure 27 reads: "CROW: So, I finally have the honor to meet our new neighbor? ... Or should I say visitor?"
} 


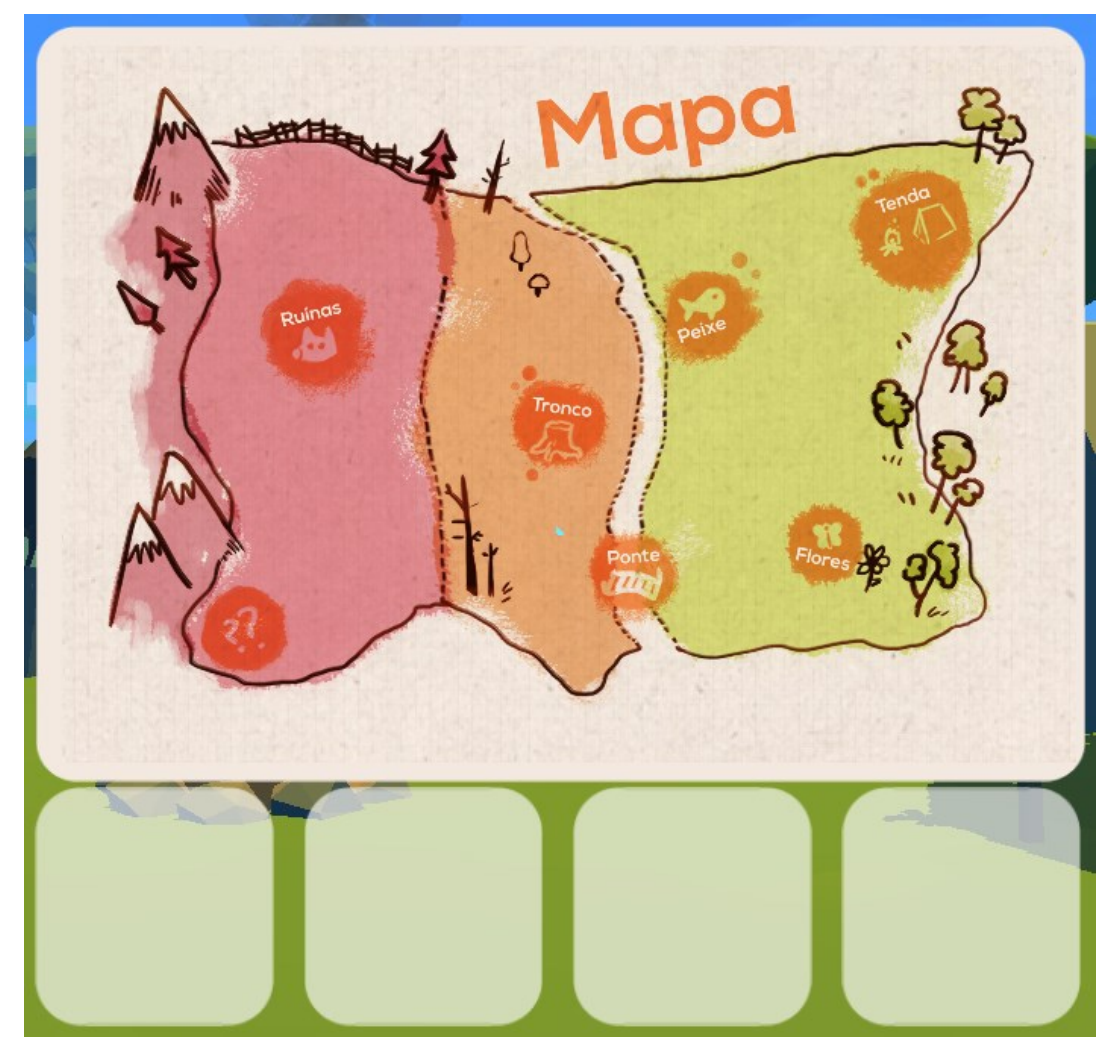

Figure 28: Inventory UI as it appears in-game. The four squares below the world's map are meant to show pictures relating to any picked-up items (picture by the author)

Subtle sounds were added to the dialogue buttons and to the act of inventory opening/closing, a clicking and a swishing sound respectively, to proportionate feedback to the player.

\subsubsection{GAME NAVIGATION}

In accordance to its target audience, the prototype's navigation is simple and straightforward, bordering on linear. The input system of the prototype requires both the Oculus Go's headset and its controller and will be explained in the following section.

In terms of hardware, the Oculus Go headset was deemed the most appropriate technology for this project as it boasts an affordable price, allowing for the VR prototype to be deployed in universities, hospitals, private therapy practices, or patients' homes at a reasonable price. The Oculus Go is also easy to carry on account of its small size and does not require further connections after the game has been installed.

Though HTC Vive was also available as a VR platform for this prototype, its system requirements were deemed too specific and fastidious to suit an easily-carried and easily-mounted VR game. 
Input

For the player to interact with the game, they must use the Oculus Go controller (see figure 29).

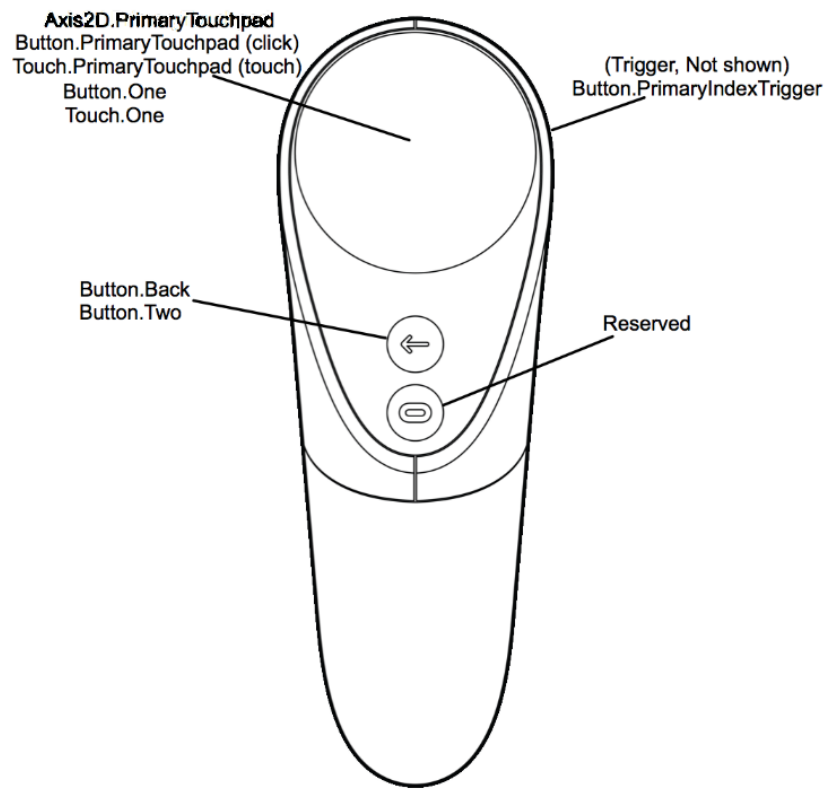

Figure 29: Oculus Go controller input schematics (“OVRInput," n.d.)

Though the headset dictates the rotation of the game's camera on the $\mathrm{Y}$ axis (i.e. if the player rotates their head to the left, the camera "follows" their movement), all other input from the player is sent from the controller.

The player moves in accordance to the player's thumb position on the touchpad, as the axis from the touchpad has been mapped to frontward, rightward, leftward, and backward movement (see figure 30).

It is important to note that the Oculus Go controller touchpad suffers from what appear to be software issues, which result in the forming of "dead zones" ${ }^{23}$ on the touchpad, particularly at the $[1,0]$ and $[-1,0]$ axis values. The code of the touchpad movement had to be specifically adapted around this issue but is otherwise expected to work faultlessly in non-defective touchpads.

\footnotetext{
${ }^{23}$ Dead zones are faulty areas on a controller which do not respond to user input, though some dead zones can also be purposefully created as resting zones for fingers.
} 


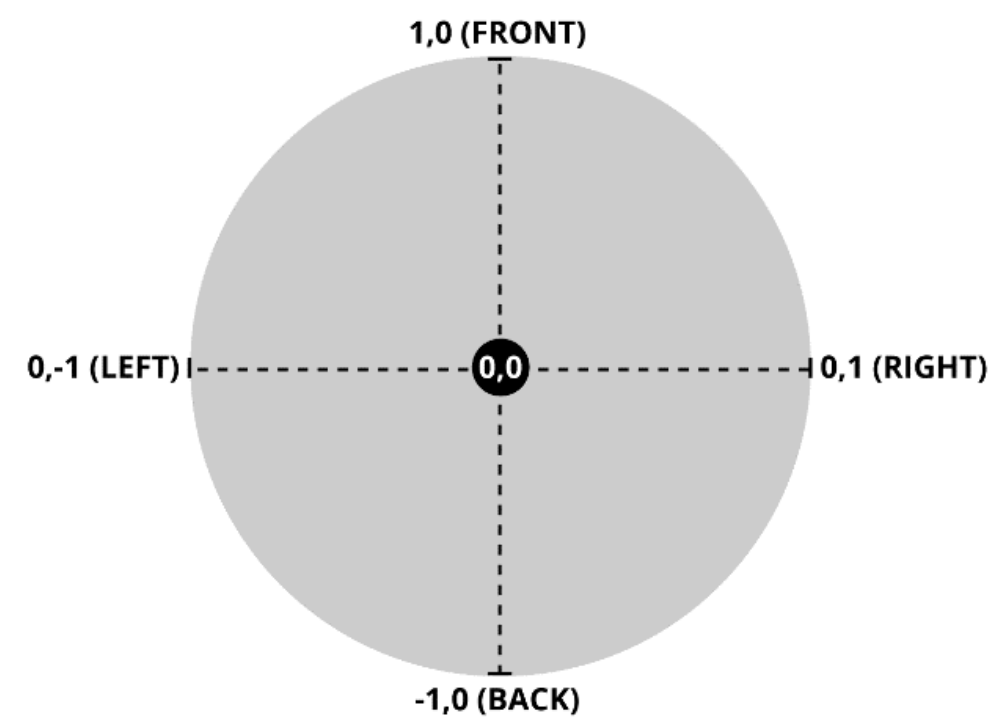

Figure 30: Touchpad axis schematic (picture by the author)

Alternatively, the player can also move through teleport points spread across the world (see figure 31), which can be interacted with the controller's trigger. If the player presses down on the trigger while targeting a teleport point, they will be teleported to the point's position.
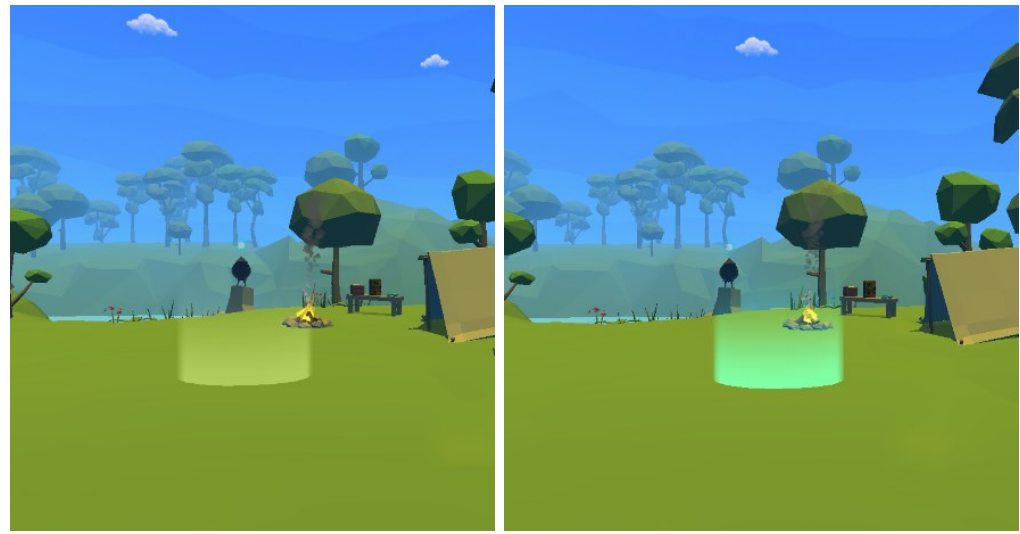

Figure 31: Untargeted teleport point (left) and targeted teleport point (right) (picture by the author)

The trigger is the main interaction button in the game and, for simplicity's sake, can be likened to a mouse's left click in a computer. All menu buttons, dialogue buttons, inventory items, and pickup-able items are interacted with through a trigger click.

The inventory UI also responds to the trigger, dropping inventory items back into the world when the player clicks an item's UI element in the inventory, or showing the item's name when the laser pointer hovers on the UI element (see figure 32 for a full display of the inventory's UI elements). 


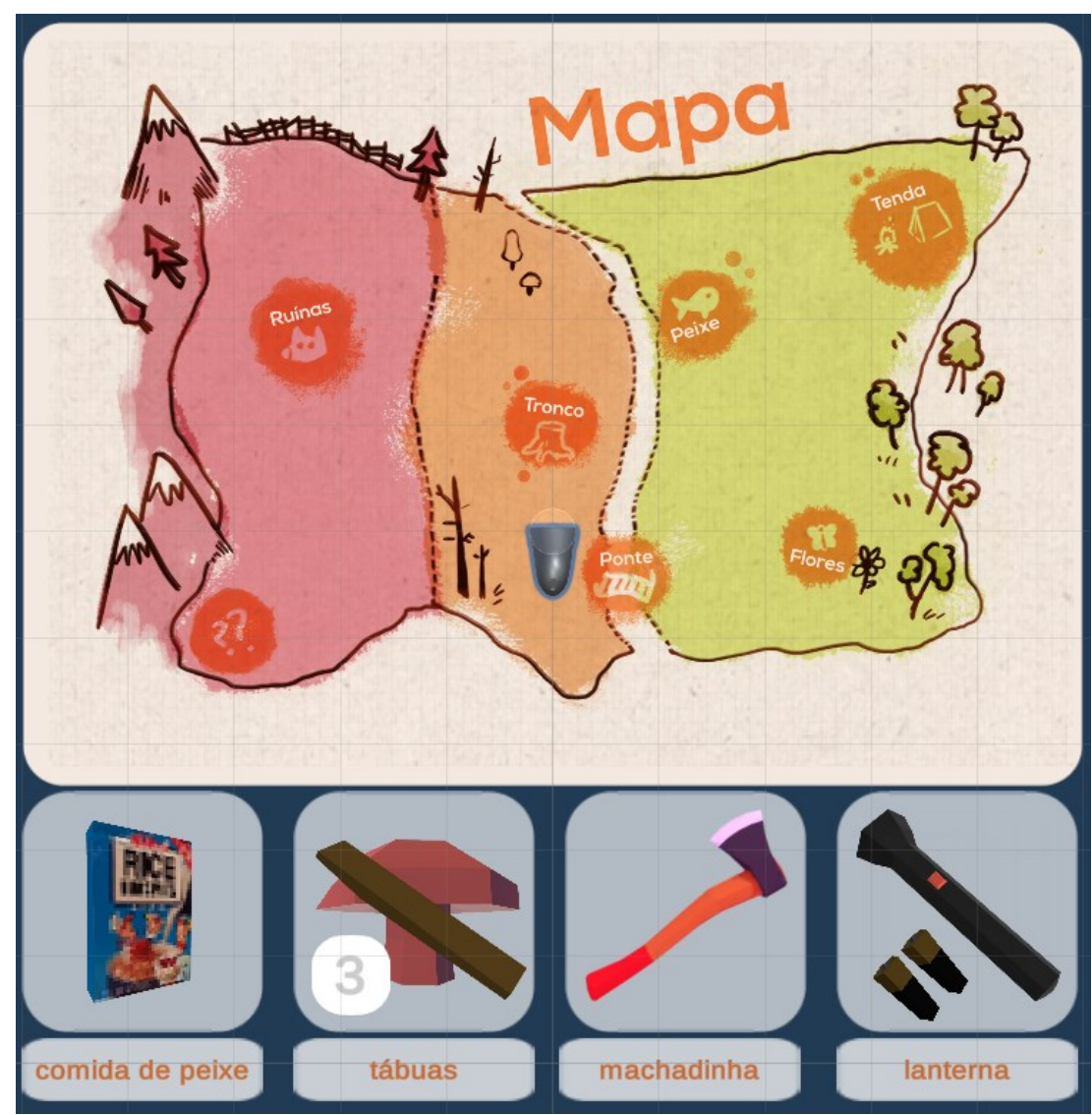

Figure 32: Inventory UI displayed in Unity's Editor (picture by the author) ${ }^{24}$

In order to open and/or close the inventory, the player must press "Button Two" of the Oculus Go controller (see figure 29 on page 65). The simple UI of the inventory allows for this simple input method, as the player doesn't need to navigate to other screens or press other buttons to access all the information of the inventory UI.

The trigger interaction requires an interactable object to be in its aim, per se, which has been arranged through Unity's raycasting mechanics. Unity's raycasting mechanics work by constantly casting a ray which "hits" the objects in the world. In order to help the player understand what this ray is targeting, a rendered line has been drawn in the same place as the raycast, which makes the controller look like a laser pointer (see figure 33). Unity's raycasting is what allows for teleportation and interaction with NPCs, items, and other UI.

\footnotetext{
${ }^{24}$ The map icons read, left to right: ruins, log, bridge, fish, flowers, tent. The map's title reads: map. The four items' captions read, left to right: fish food, planks, hatchet, flashlight.
} 


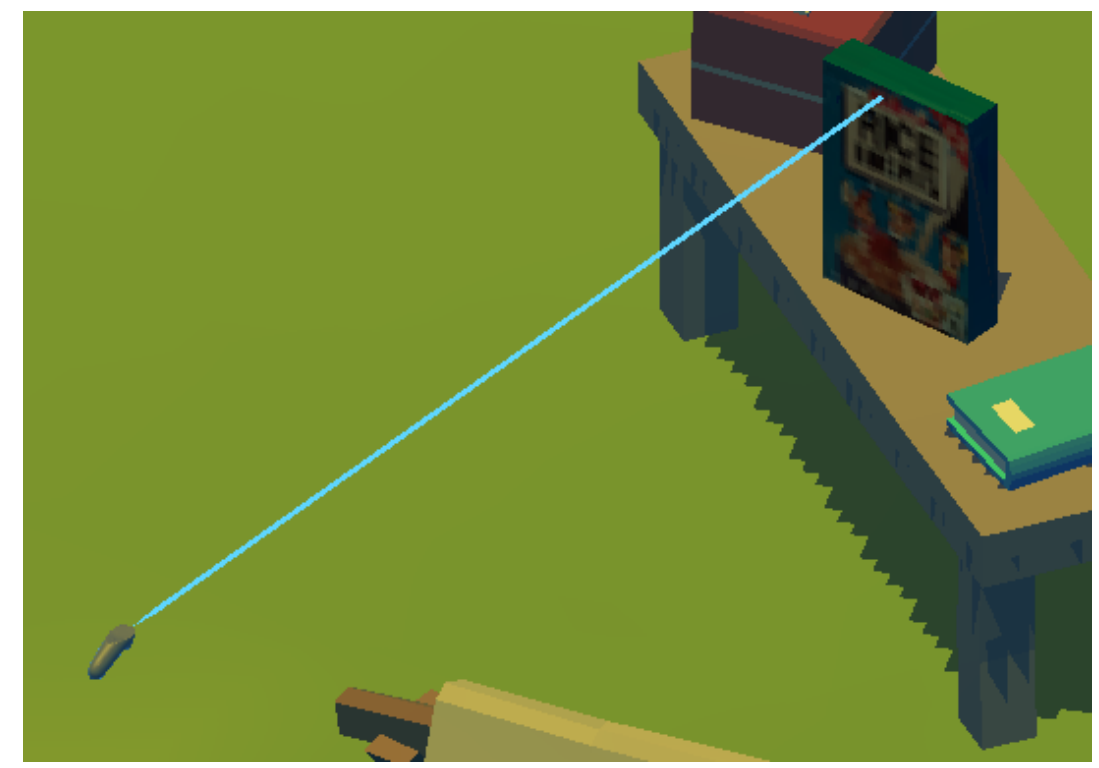

Figure 33: Example of raycasting and demonstration of laser pointer controller (targeting the inventory item "fish food") (picture by the author)

Another Unity mechanic often used throughout the game is Unity's trigger colliders, wherein Unity allows scripts to check if a particular object has entered a particular area. E.g., when dropping the fish food from the inventory, it will fall on the floor and stay there until picked up again; if the player is near the fish's location, however, and the fish food object collides with the invisible trigger area, the trigger will activate. The fish food object disappears, and the fish's dialogue will move forward, thus advancing the story and the player's progress.

In conclusion, the prototype's input system was designed to be as simple as possible, using only three different input types: the click of the trigger, the touchpad movement, and the button for accessing the inventory. The design of the input system was limited by the Oculus Go's controller, which boasts a minimalistic design in comparison to other VR controllers. E.g., the Oculus Rift controller has two mappable buttons, one joystick which can work as a third mappable button, one thumb touchpad, and two triggers, as opposed to the Go's single mappable button, trigger, and touchpad.

Early prototypes for movement functionality required the player to press a button on-screen to alternate between teleportation and touchpad movement, in order to limit trigger interaction to items or "pick-up" objects only. This functionality was scrapped for usability reasons and replaced with the teleportation point system currently in use by the prototype, which allows for both movements without additional player input.

In consequence, the current input system makes use of every possible input type allowed by the Oculus Go's controller without requiring the player to alternate between movement modes. 


\section{Level Navigation}

Upon selecting the app in the Oculus Go's library, the player, their therapist, or their caregiver will enter the game's start menu, wherein they may choose to begin a new game or exit the game. If the game has been completed once before, two other options become available to the player: they may choose to begin the game in Area 2 or Area 3. Choosing Area 2 or Area 3 from the start menu will always place the player at the same locations (after the bridge for Area 2 and after the fallen tree for Area 3), allowing them to quickly progress through the game if they wish to replay a specific part without having to start the game anew (see figure 34).

This functionality is important as it allows, e.g., for a therapist to go over more difficult parts of the game without repeating brightly lit areas such as Area 1.

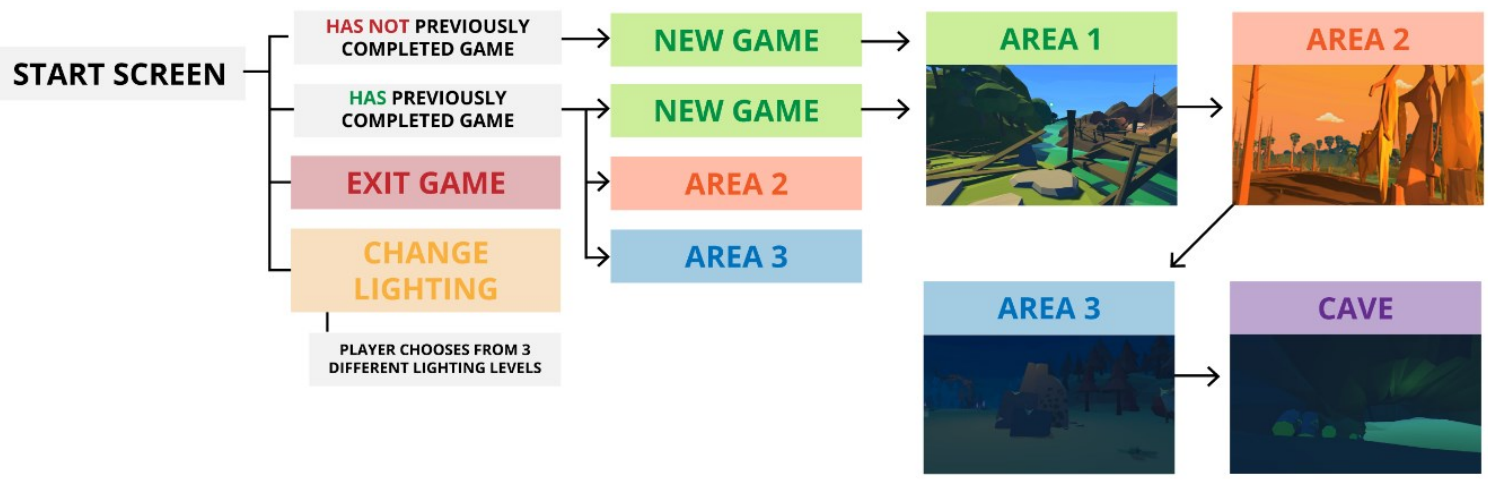

Figure 34: Start menu navigation schematic (picture by the author)

In the same vein, the lighting of the game can be adjusted on the start menu. There are three different levels of lighting to choose from: (1) normal lighting, (2) dimmer lighting, and (3) dark lighting (see figure 35). This functionality was added to further personalize the game, adjusting its darkness levels in accordance to a patient's level of fear. Lighting changes are applied from the start menu and last until the game has been finished.

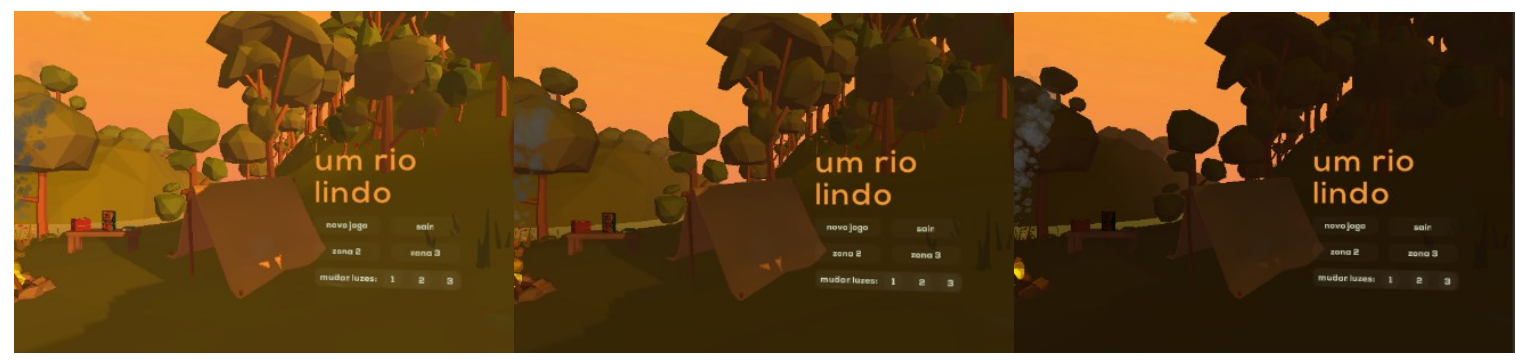

Figure 35: Demonstration of lighting levels on the start menu (picture by the author)

After beginning a new game, the player has several tasks to accomplish in order to reach the end of the game. As previously mentioned, the player must go through "gates", which require exploration and cognitive effort to go through. 
The first "gate" of the game is in the shape of a broken bridge which needs fixing (see figure 36). The player must find two missing wooden planks to fix the bridge.

One of the planks is near the bridge and does not require cognitive effort to find, while the other plank is placed in the river and is impossible to reach unless the player convinces an NPC, the fish, to help them get the plank. To convince the fish, the player must give him food, an inventory item that is placed near the tent. To give the fish food, the player must pick it up, return to the fish, and drop it from the inventory ${ }^{25}$ by selecting it. Once the fish has been fed, talking to it again will allow the player to access the plank.

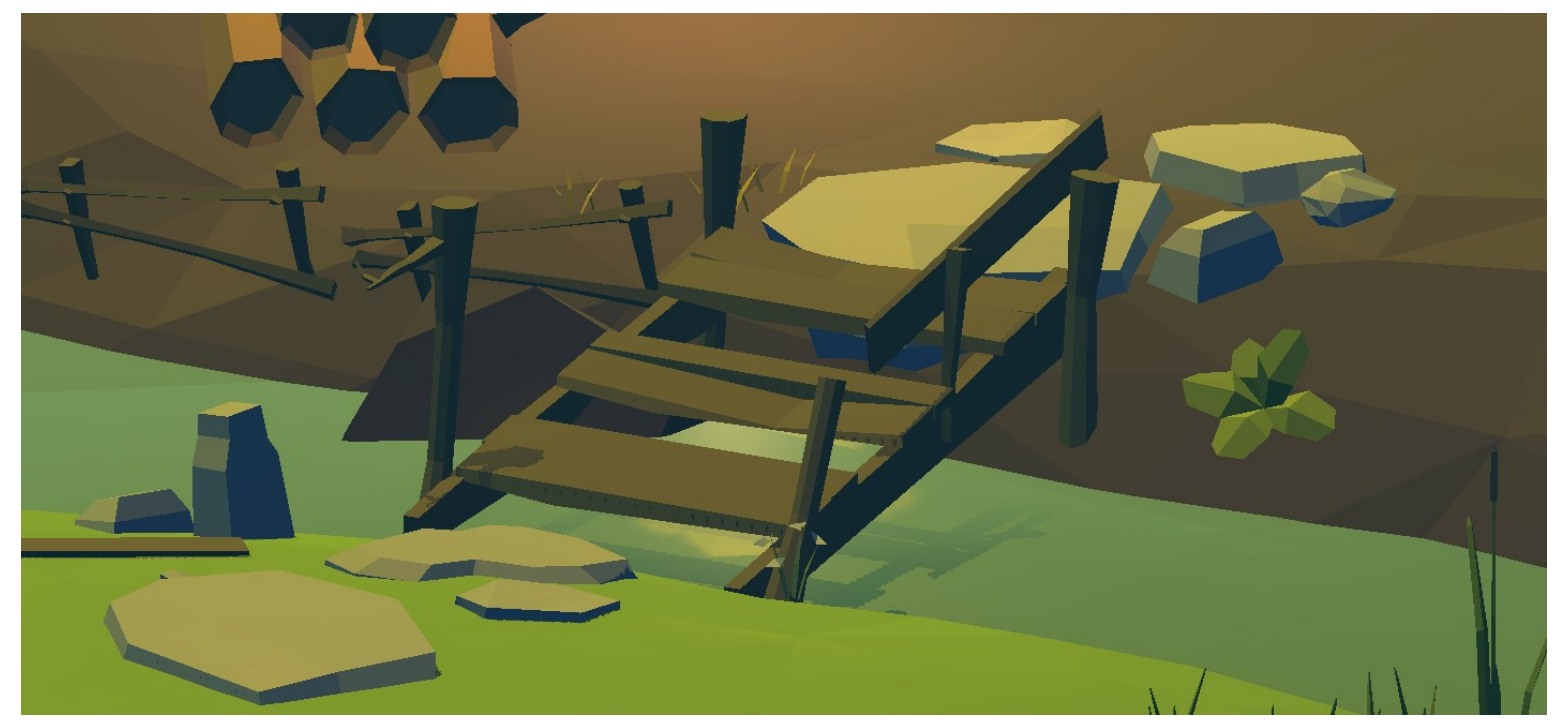

Figure 36: Prototype screenshot of bridge "gate" (picture by the author)

The second "gate" of the game is in the shape of a fallen tree barring the way (see figure 37). The player must find a hatchet and pick it up, therefore storing it in their inventory. Unlike the former gate, the NPCs do not offer information about the fallen tree or how to surpass it, nor do they talk about the existence of a hatchet.

This is meant to slightly raise the cognitive effort required by the player: as they now know that inventory items can be used to trigger events in the game's world, they should be able to infer that the hatchet that they've found is meant to be used on the fallen tree.

\footnotetext{
${ }^{25}$ The inventory is always accessible, except for when the player is at the start menu or while interacting with the NPCs (so as to not cover the start menu buttons or the in-game dialogue panels, and thus break immersion).
} 


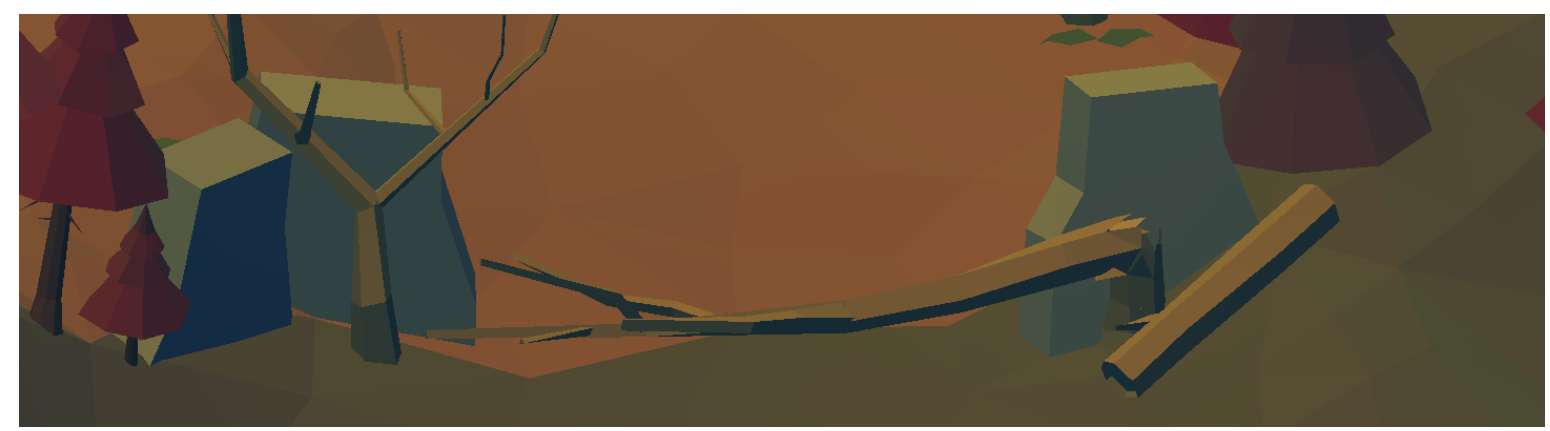

Figure 37: Prototype screenshot of fallen tree "gate" (picture by the author)

The third and final "gate" of the game is the cave's darkness (see figure 38). The player must find a flashlight and two batteries in order to access the cave, as they otherwise cannot see well enough to reach the cave's ending. The fox NPC will offer vague information about the three items' locations, in order to give the player motivation to explore the dark area. Once the flashlight and the batteries have been found, the fox will lead the player to the cave's entrance, and the darkness will dissipate enough to allow the player to see inside the cave.

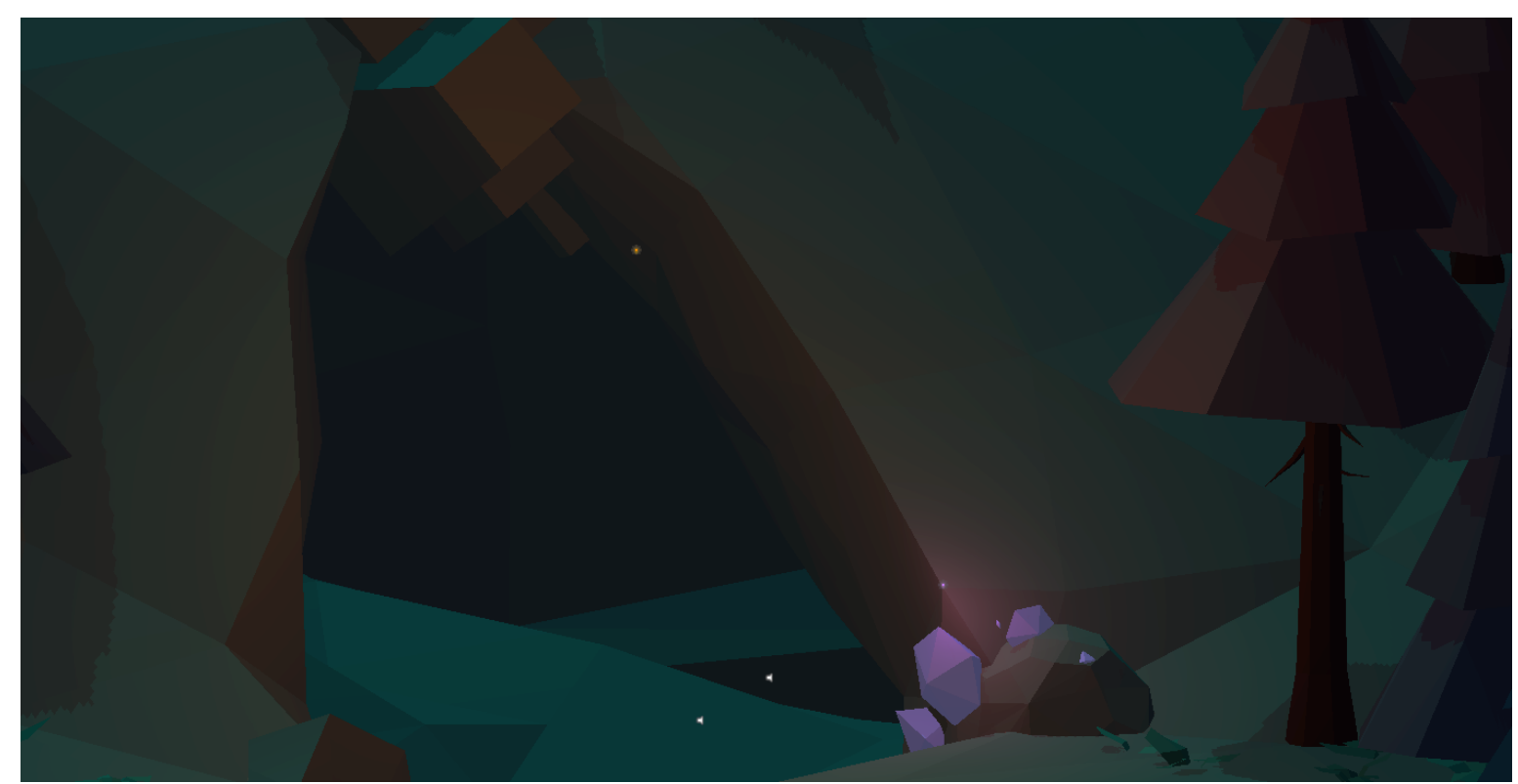

Figure 38: Prototype screenshot of darkened cave entrance "gate" (picture by the author)

Though not defined as a "gate" (as it does not bar the player from accessing a next level per se) the player must also feed the fox three "red mushrooms" to be able to interact with her (see figure 39).

Interacting with the fox is a requirement to be able to finish the game and requires a low level of cognitive effort, but, as the player has already reached the final stage of the game, this even is not a true "gate" in the sense that has been applied so far. Still, this can be considered a barrier of sorts, and thus should be referred in this list. 


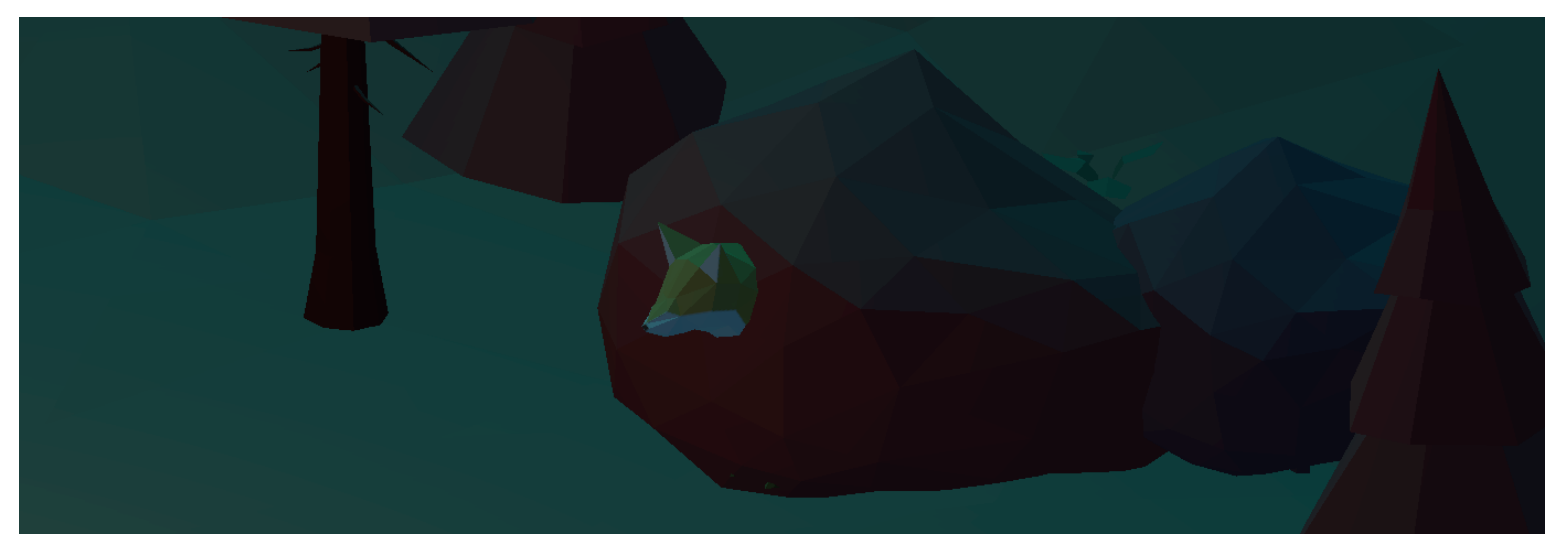

Figure 39: Prototype screenshot of fox hiding in bushes, before being fed (picture by the author)

To better understand the navigation of the game on a global basis, an ideal walkthrough of the game has been succinctly described (see table 8).

Table 8: Ideal walkthrough and environment description

\section{LEVEL REQUIREMENTS ENVIRONMENT DESCRIPTION}

Selecting a "new game" on the Start Screen will teleport the player to the starting point of the game, situated in Area 1.

Area $\mathbf{2}$ is only accessible after the player picks up the Fish Food, feeds the Fish, and fixes the Bridge by gathering its missing planks.

Area $\mathbf{3}$ is only accessible after the player finds and picks up the Hatchet, and chops down the fallen tree in their way.

The Cave is only accessible after the player finds and picks up the Flashlight and its two batteries, and after following the Fox to the cave's entrance.

\section{Sunny day, with normal} lighting. There are 2 NPCs to interact with: the Fish and the Bird, being that the Bird can talk to the player at two different locations.

Sunset, with somewhat dim lighting. There are 2 NPCs to interact with: the Bird and the Turtle.

Nighttime, with extremely dim lighting. There are 2 NPCs to interact with: the Bird and the Fox.

Darkness, with extremely dim lighting. The Flashlight can be turned on to light up the area. The Fox stays at the entrance of the cave.

\section{IDEAL WALKTHROUGH}

Player talks to Bird, picks up Fish Food, talks to and feeds Fish, receives Plank \#1, talks to Bird again, finds Plank \#2, and fixes Bridge.

Player talks to Bird, finds the Hatchet and Mushroom \#1 (same location), talks to and helps Turtle, finds Mushroom \#2, and chops down the Fallen Tree.

Player scares Fox, explores, talks to Bird, picks up Trash, finds Flashlight, two Batteries, and Mushroom \#3 (same location), talks to and follows Fox to the Cave.

Player explores the Cave until its end, finds four "radioactive" Barrels, pulls them over to a "safe area" away from the water, and returns to tell Fox (thus ending the game). 


\subsection{SYSTEM ARCHITECTURE}

Though the prototype is totally functional, it remains under development in Unity3 D for small functionality add-ons and fine-tuning performance, as the developers' main skills center around graphic design, 3D modelling, and level design.

Unity3 D was chosen for the prototype's development since it allows a greater abstraction from complex programming and a deeper focus on initiate-level logic (i.e. using triggers and Unity framework as opposed to scripting every encounter or puzzle). Thus, it is preferable to development programs with heavier frameworks which would require a more extensive study of the available programming languages and technical documentation, as well as requiring a team with a better programming ability. Unity3 $\mathrm{D}$ also benefits from an extremely in-depth documentation and has garnered a large userbase, which offers assets available for the development of the VR prototype as well as discussing technical issues on the Unity3D website. Furthermore, games in Unity3D are easily deployed on several operating systems (i.e. Windows, Mac, iOS, Android), and Unity3D offers readily available support for VR platforms through included SDK libraries. This ease of build and deployment in several operating systems was considered essential for a prototype which is meant to be easily accessible.

In terms of hardware, the Oculus Go headset was deemed the most appropriate technology for this project as it boasts an affordable price, allowing for the VR prototype to be deployed in universities, hospitals, private therapy practices, or patients' homes at a reasonable price.

Though HTC Vive was also available as a VR platform for this prototype, its system requirements were deemed too specific and fastidious to suit an easily carried and easily mounted VR game. The prototype thus requires an Oculus Go headset and controller to be played, which in turn require an Oculus ac-count, wireless internet access, and an Android smartphone to run the Oculus setup app (Machkovech, 2018) and the Unity app for the prototype.

The prototype was developed in Unity3D 2019 (version 2019.1.6f1) on a MSI GE-62 2QF Apache Pro laptop: Windows 10 OS, latest 5th Generation Intel Core i7 5950HQ / 5700HQ processor, GeForce GTX 970M graphics, 3GB GDDR5 VRAM, and 15.6" FHD (1920 x 1080) wide-view display. The prototype was concurrently tested on the Oculus Go headset for display and controller issues and fine-tuning (see figure 40 for a schematic representation). 

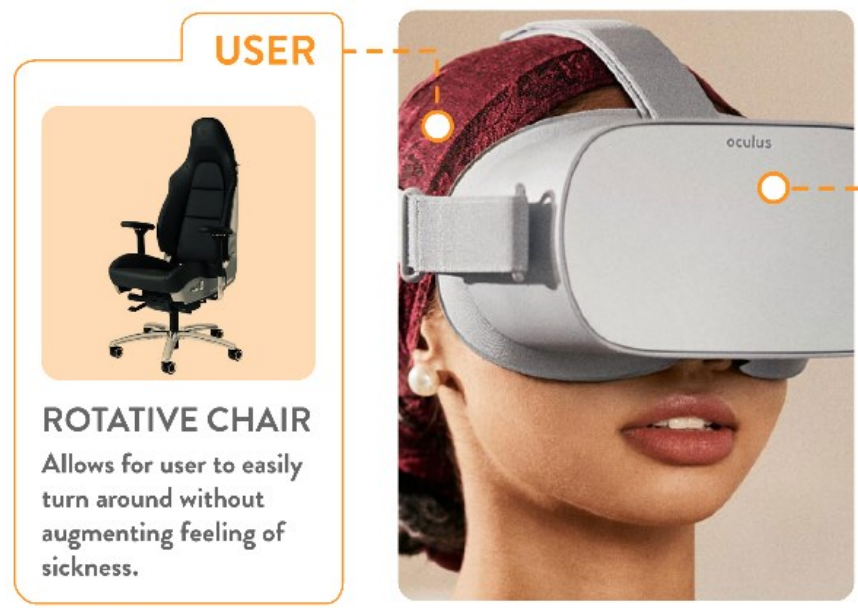

\section{INPUT SYSTEM}

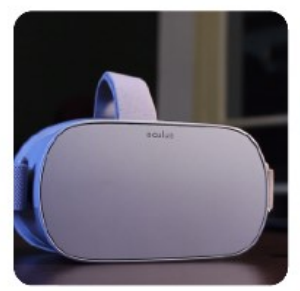

\section{HEADSET}

Includes a smartphone

running on Android OS, (one of which a trigger)

as well as VR glasses and and a trackpad.

stereo speakers.

Figure 40: System architecture schematic (picture by the author)

The use of a rotative chair allows the player to turn around in an uncomplicated manner, avoiding the possibility of colliding into objects around them while they are wearing the headset, and avoids causing VR sickness symptoms as it maintains the user in an upright, sitting position. A rotative chair is also commonplace in offices or even domestic environments, and does not take up much space, which allows for testing to occur even in somewhat limited spaces.

Ideal conditions for testing comprehend a quiet space, to avoid distractions and allow the player to focus on the prototype's narrative and sounds. Lighting of the space depends on the severity of the player's fear: as previously mentioned, wearing a headset which allows for partial view of their body can help mitigate anxiety resulting from playing (North et al., 1998, pp. 7, 8). 


\section{UX TESTING AND EVALUATION}

This chapter documents UX testing and evaluation proceedings, being that this testing phase follows the previously mentioned usability and UX methodologies.

The introduction of iterative design to the prototype development ensures that UX testing is a part of the development phase. UX testing sessions were intermingled within the prototype's development phase, as opposed to occurring after development was concluded.

At the current stage of development, functional design of the prototype has been ensured and the prototype is finished, enabling a player to finish the whole game without critical errors.

\subsection{UX TESTING AND QUESTIONNAIRE}

The UX testing of the prototype was conducted with a sample of convenience of six different players, wherein the participants were previous acquaintances of the researcher. All but one UX test was conducted in the researcher's house due to ease of geographical access; the single exception was caused by the final tester living in a city different than the one the researcher resides in. This particular test was conducted in the participant's house.

All UX testers' are Portuguese, and their ages range from 24 to 25 years of age. Out of the six testers, five are female and one is male. Their gaming experience varies from casual gamer to frequent gamer. For a more explicit profiling of the UX testers, see table 10 on page 78.

Upon arriving and after settling on a rotative office chair to ensure undemanding $360^{\circ}$ rotation of the headset ${ }^{26}$, participants were instructed on how to play using the Oculus Go headset and controller through verbal instructions from the researcher and written instructions on the questionnaire. Further verbal instructions related only to technical issues (such as the defective touchpad issue, as previously mentioned) and UX heuristics such as the "think aloud protocol" (Nielsen, 2012).

The players were verbally instructed to follow the "think aloud protocol" before beginning the test, which relies on the user constantly describing what they are thinking or doing, their motivations, likes, dislikes, among any other criticism or observations. In this manner, the researcher was able to document reactions or observations that could, otherwise, be forgotten by the time the testing was over. Most data from the UX testing was observational, as the researcher was responsible for personally transcribing any on-going events deemed relevant to

\footnotetext{
${ }^{26}$ As previously illustrated in subchapter 3.2. System Architecture (figure 40).
} 
the UX testing (see annex 10 for relevant researcher personal notes). As such, no videos, images, or sounds were recorded during the testing.

In order to see the players' progress in real time, the researcher used the open-source program Scrcpy to display the Oculus Go's screens on a computer while the game was running. Scrcpy only requires $\mathrm{ADB}$ debugging and a minimum of API 21 on the device (Android 5.0) to work. During testing, the headset was connected to the researcher's computer through USB to avoid lag, but Scrcpy also allows wi-fi connections.

Adding to the researcher's observational data, the players were asked to fill out a two-part questionnaire which inquired as to (1) their participant profile, relating to the context of this dissertation, (2) the difficulty and satisfaction level they felt while doing tasks, and (3) open questions meant to make them think more deeply about the prototype. The first part of the questionnaire relates to the participant profiling and reading of tasks, while the second part relates to the classification of said tasks and answering open questions about the prototype.

The questionnaire in question (see annex 1) was originally written and filled out in Portuguese (see annex 2) but was translated into English for the purpose of this dissertation.

The questionnaires filled out by the participants have also been annexed (see annexes 3, 4, 5, 6, 7 , and 8), and remain mostly unaltered ${ }^{27}$ from their original state (i.e. in the participants' own words and in their original language, Portuguese).

For easier accessibility, the UX-related tasks will be displayed in table 9.

${ }^{27}$ Participants' names have been modified to correspond to the chronological order of each test, in order to ensure their anonymity. 
Table 9: UX questionnaire tasks

\begin{tabular}{|c|c|}
\hline UX TASKS & DESCRIPTIONS \\
\hline \multirow{3}{*}{$\begin{array}{l}\text { \#1: Familiarize yourself } \\
\text { with the game controls. }\end{array}$} & Move your character with the touchpad. \\
\hline & Open and close the inventory with the inventory button. \\
\hline & Using the trigger, interact with the world around your character. \\
\hline \multirow{3}{*}{$\begin{array}{l}\text { \#2: World objects' } \\
\text { manipulation. }\end{array}$} & Identify objects with which you can interact. \\
\hline & Investigate which kinds of interaction there are. \\
\hline & $\begin{array}{l}\text { Store an object in your inventory, drop it in the world, and then store } \\
\text { it again in the inventory. }\end{array}$ \\
\hline $\begin{array}{l}\text { Task 3: Character mobility } \\
\text { in the world. }\end{array}$ & Move your character through the teleport points placed in the world. \\
\hline Task 4: Finish level 1. & $\begin{array}{l}\text { With the information that is given to you in-game, explore the world } \\
\text { and reach the orange area on the inventory map. }\end{array}$ \\
\hline Task 5: Finish level 2. & $\begin{array}{l}\text { With the information that is given to you in-game, explore the world } \\
\text { and reach the pink area on the inventory map. }\end{array}$ \\
\hline Task 6: Finish level 3. & $\begin{array}{l}\text { With the information that is given to you in-game, explore the world } \\
\text { and finish the game. }\end{array}$ \\
\hline
\end{tabular}

The open questions placed at the end of the questionnaire are also listed here for accessibility:

1. What would you change in the game, and why?

2. What wouldn't you change in the game, and why?

3. Did you feel any emotion towards the characters of the game (e.g. friendship, disinterest, etc.)?

4. Did you feel interested on disinterested by the game's narrative?

5. Do you have any final suggestions that you would like to see implemented in the game?

\subsubsection{PARTICIPANT PROFILING}

The UX testing participants can be divided into four relevant categories: age, preferred gaming platform, the frequency with which they play games, and if they were propense to feeling nausea 
during (1) previous VR-related experiences, if applicable, or (2) while being transported in vehicles (see table 10).

Table 10: Participant profiling table

\begin{tabular}{|c|c|c|c|c|}
\hline $\begin{array}{c}\text { Participant } \\
\text { ID }\end{array}$ & Age & $\begin{array}{c}\text { Preferred gaming } \\
\text { platform }\end{array}$ & $\begin{array}{l}\text { Frequency of } \\
\text { gaming }\end{array}$ & $\begin{array}{c}\text { Propensity to } \\
\text { feel nausea }\end{array}$ \\
\hline \multirow[b]{2}{*}{ P1 } & \multirow[b]{2}{*}{25} & \multirow[b]{2}{*}{ Computer } & \multirow[b]{2}{*}{ Frequent } & 1. $Y^{2} s^{28}$ \\
\hline & & & & 2. No \\
\hline \multirow{2}{*}{ P2 } & \multirow{2}{*}{25} & \multirow{2}{*}{ Smartphone } & \multirow{2}{*}{ Non-frequent } & 1. No \\
\hline & & & & 2. No \\
\hline \multirow{2}{*}{ P3 } & \multirow{2}{*}{25} & \multirow{2}{*}{ Smartphone } & \multirow{2}{*}{ Non-frequent } & 1. $N / A$ \\
\hline & & & & 2. No \\
\hline \multirow{2}{*}{ P4 } & \multirow{2}{*}{24} & \multirow{2}{*}{ Smartphone } & \multirow{2}{*}{ Non-frequent } & 1. N/A \\
\hline & & & & 2. $\mathrm{Yes}^{28}$ \\
\hline \multirow{2}{*}{ P5 } & \multirow{2}{*}{25} & \multirow{2}{*}{ Smartphone } & \multirow{2}{*}{ Non-frequent } & 1. $N / A$ \\
\hline & & & & 2. No \\
\hline \multirow{2}{*}{ P6 } & \multirow{2}{*}{25} & \multirow{2}{*}{ Computer } & \multirow{2}{*}{ Frequent } & 1. $\mathrm{Yes}^{28}$ \\
\hline & & & & 2. Yes \\
\hline
\end{tabular}

During the UX testing, P1 and P6 managed to pinpoint the highest number of errors (both critical and non-critical), which makes sense considering they self-described themselves as frequent gamers. The remaining participants were especially useful in criticizing the narrative and aesthetics of the game, as well as offering insight as to how non-frequent gamers interact with the prototype's UI and its input system.

\subsubsection{UX TESTING: RESULTS' ANALYSIS}

Once a participant had finished playing the game, they were asked to fill out the secondary part of the questionnaire, which entailed the qualitative classification of the six tasks described in the questionnaire.

\footnotetext{
${ }^{28}$ P1 stated that their propensity for feeling nauseated whilst experiencing VR applications was not frequent and wished to carry on with the testing. Despite P4 and P6 having self-ranked themselves as nausea-propense, they voluntarily joined the UX testing and suffered no feelings of motion sickness whatsoever throughout the experience.
} 
Difficulty and satisfaction classification were displayed in qualitative levels which depended on task difficulty (ranging from "very hard" to "very easy") or on task satisfaction (ranging from "very unsatisfactory" to "very satisfactory"). Qualitative levels were deemed to be easier to respond to by the participants. However, after the UX and usability testing phase of this investigation, each of these qualitative levels was adapted into a numerical value for easier analysis of the results (see table 11).

Table 11: Adaptation of qualitative data into quantitative data

\begin{tabular}{|c|c|c|c|c|c|}
\hline \multirow{2}{*}{ QUALITATIVE } & Very hard & Hard & Neutral & Easy & Very easy \\
\cline { 2 - 6 } & $\begin{array}{c}\text { Very } \\
\text { unsatisfactory }\end{array}$ & Unsatisfactory & Neutral & Satisfactory & $\begin{array}{c}\text { Very } \\
\text { satisfactory }\end{array}$ \\
\hline QUANTITATIVE & -2 & -1 & 0 & 1 & 2 \\
\hline
\end{tabular}

After this data adaptation, the difficulty and satisfaction levels were compiled into tables (see table 12 and table 13, respectively) and histograms (see figure 41, figure 42, figure 43, figure 44, figure 45 , figure 46 , figure 47 , figure 48 , figure 49, figure 50, figure 51, and figure 52) and analyzed. Calculations and tables were made in Microsoft Excel; the average values were rounded up for easier readability.

Table 12: Difficulty levels by participant

\begin{tabular}{|c|c|c|c|c|c|c|c|}
\hline \multicolumn{7}{|c|}{ DIFFICULTY } \\
\hline Participants & Age & Task 1 & Task 2 & Task 3 & Task 4 & Task 5 & Task 6 \\
\hline P1 & 25 & 2 & 2 & 2 & 1 & 1 & 2 \\
\hline P2 & 25 & 1 & 1 & 2 & 1 & 2 & 1 \\
\hline P3 & 25 & 0 & 1 & -1 & 1 & 1 & 1 \\
\hline P4 & 24 & 1 & 2 & 2 & 1 & 0 & 1 \\
\hline P5 & 25 & 1 & 1 & 0 & 1 & 1 & -1 \\
\hline P6 & 25 & 1 & 1 & 1 & 1 & 1 & 1 \\
\hline & Total: & 6 & 8 & 6 & 6 & 6 & 5 \\
\hline & Average: & 1 & $\sim 1.33$ & 1 & 1 & 1 & $\sim 0.83$ \\
\hline
\end{tabular}


Table 13: Satisfaction levels by participant

\begin{tabular}{|c|c|c|c|c|c|c|c|}
\hline \multicolumn{7}{|c|}{ SATISFACTION } \\
\hline Participants & Age & Task 1 & Task 2 & Task 3 & Task 4 & Task 5 & Task 6 \\
\hline P1 & $\mathbf{2 5}$ & 2 & 2 & 2 & 1 & 1 & 1 \\
\hline P2 & $\mathbf{2 5}$ & 1 & 1 & 2 & 2 & 2 & 2 \\
\hline P3 & $\mathbf{2 5}$ & 1 & 1 & 0 & 2 & 2 & 2 \\
\hline P4 & $\mathbf{2 4}$ & 0 & 2 & 2 & 2 & 1 & 2 \\
\hline P5 & $\mathbf{2 5}$ & 1 & 1 & 1 & 1 & 1 & 0 \\
\hline P6 & $\mathbf{2 5}$ & 1 & 2 & 1 & 2 & 2 & 2 \\
\hline & Total: & 6 & 9 & 8 & 10 & 9 & 9 \\
\hline & Average: & 1 & 1.5 & $\sim 1.33$ & $\sim 1,67$ & 1.5 & 1.5 \\
\hline
\end{tabular}

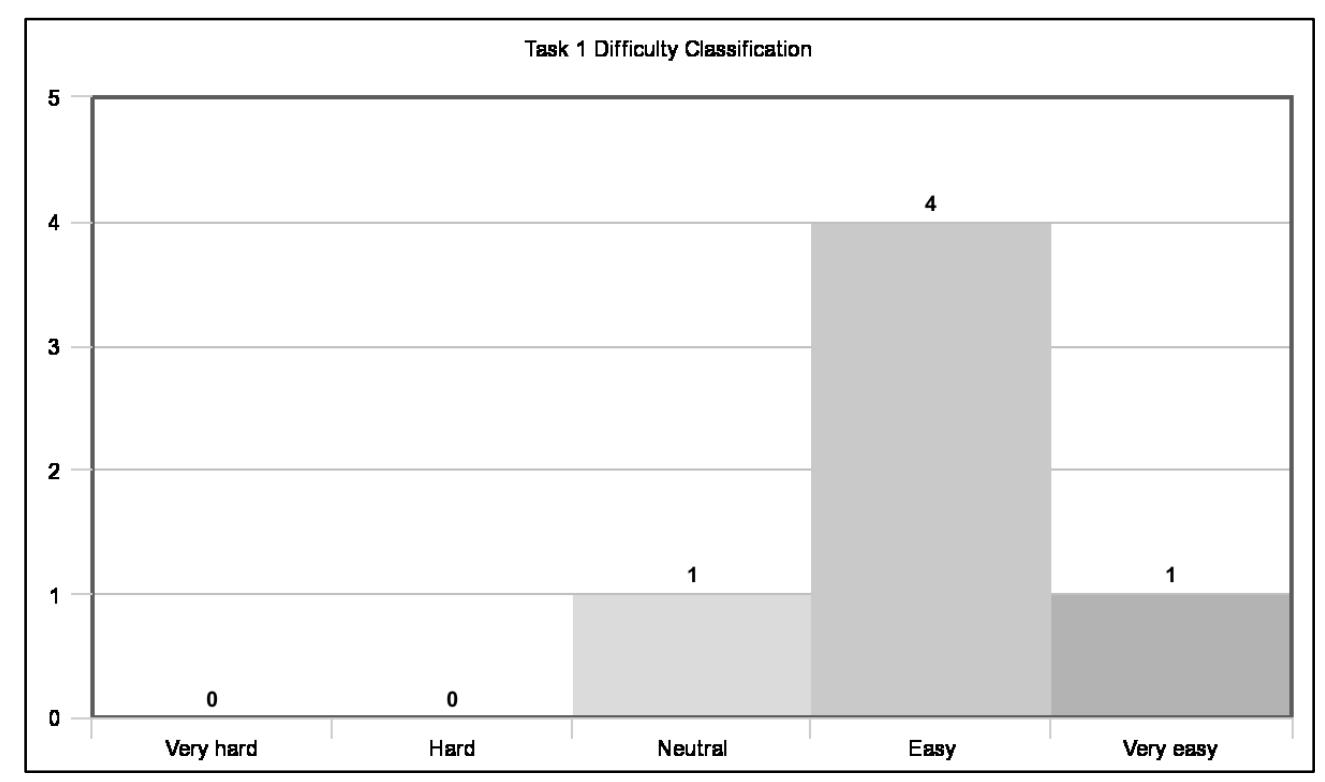

Figure 41: Histogram detailing Task 1 difficulty classifications (picture by the author)

In the histogram relating to the difficulty of the first task, "Familiarize yourself with the game controls", four participants classified it as "easy", while the other two classified it as "neutral" and "very easy". As none of the participants rated this task at a negative level, Task 1 can be considered an accomplishable task. 


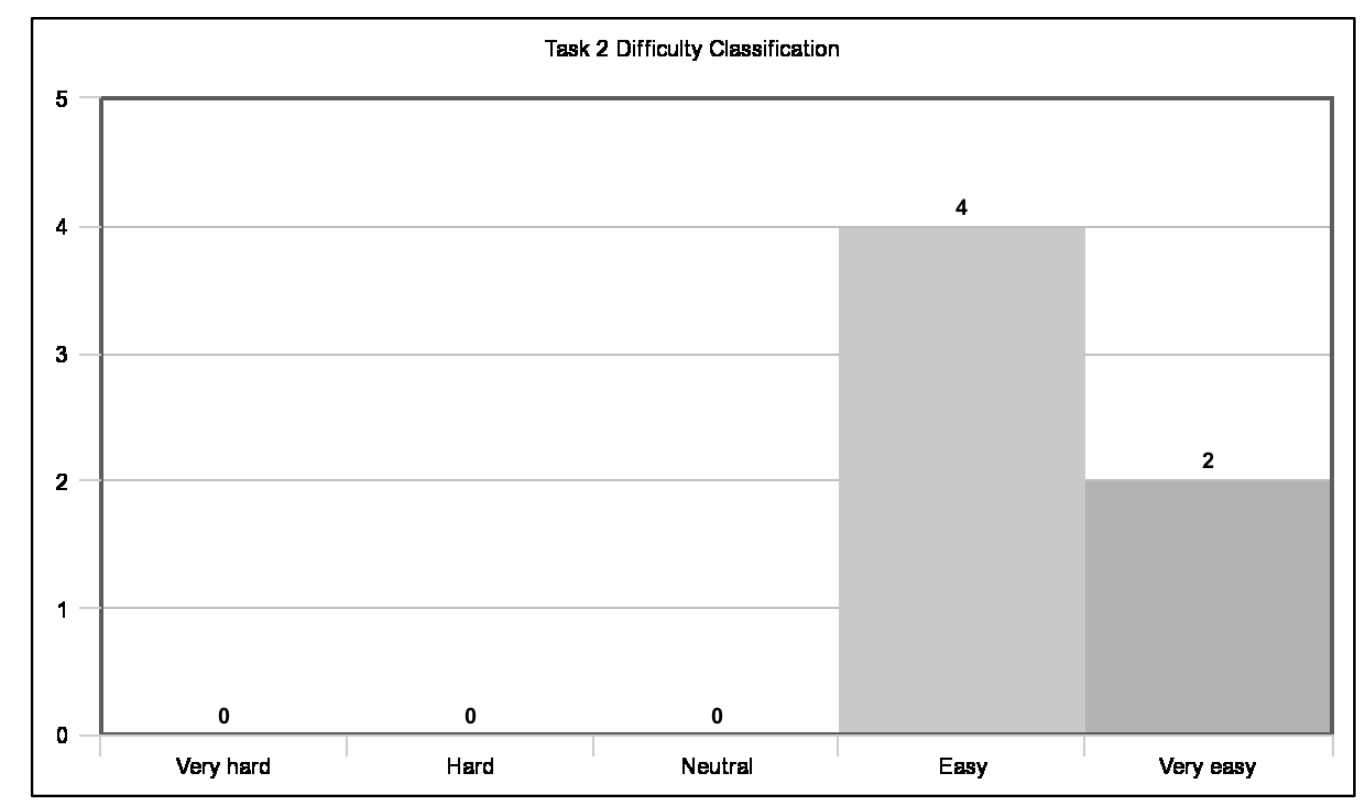

Figure 42: Histogram detailing Task 2 difficulty classifications (picture by the author)

In the histogram relating to the difficulty of the second task, "World objects' manipulation", four participants classified it as "easy", while the other two classified it as "very easy". As none of the participants rated this task at a negative level, Task 2 can be considered an accomplishable task, even more so than Task 1.

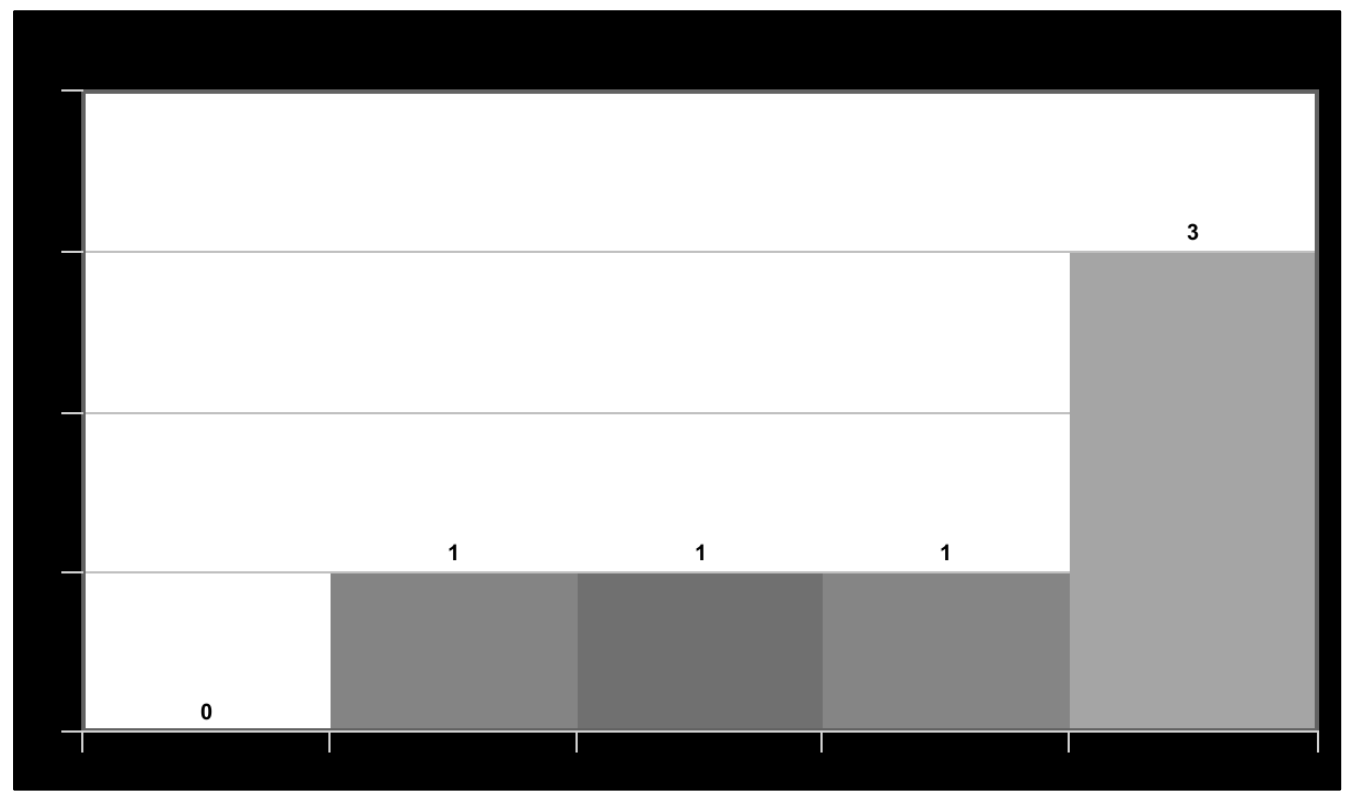

Figure 43: Histogram detailing Task 3 difficulty classifications (picture by the author)

In the histogram relating to the difficulty of the third task, "Character mobility in the world", one participant rated it as "hard", one as "neutral", another as "easy", and other three as "very easy". Though most ratings are non-negative, this task cannot be considered easily attainable on account of its single negative classification. 


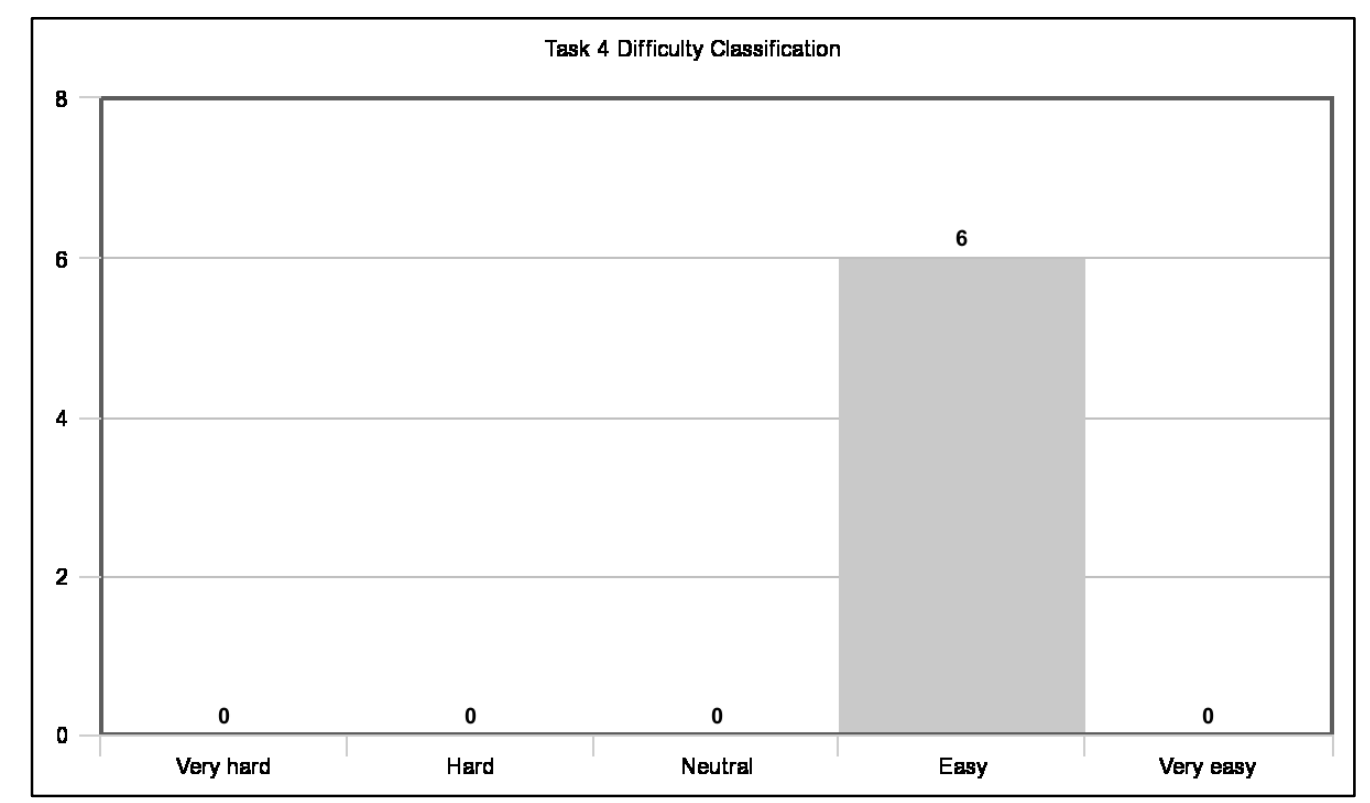

Figure 44: Histogram detailing Task 4 difficulty classifications (picture by the author)

In the histogram relating to the difficulty of the fourth task, "Finish level 1", all participants rated it as "easy". This task can therefore be considered easily attainable on account of its unanimous classification.

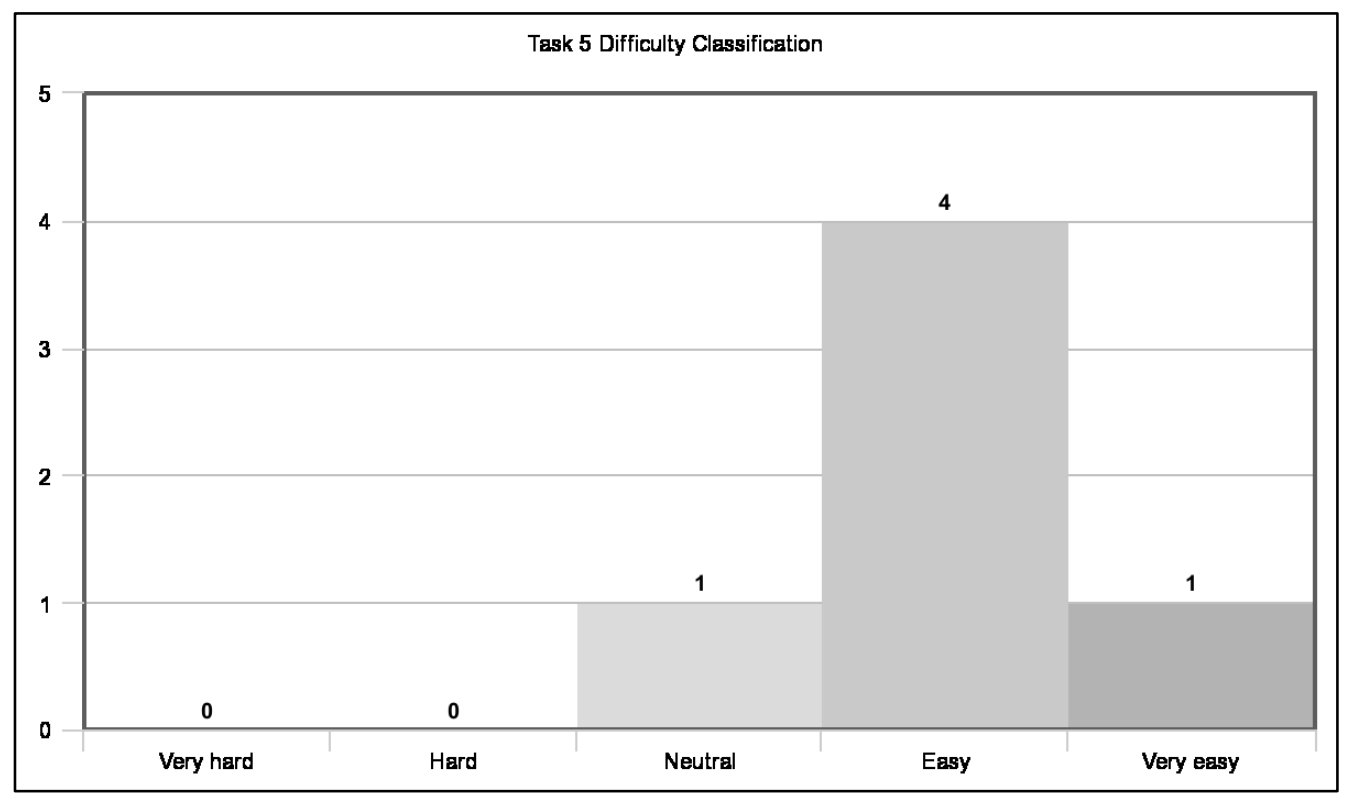

Figure 45: Histogram detailing Task 5 difficulty classifications (picture by the author)

In the histogram relating to the difficulty of the fifth task, "Finish level 2", one participant rated it as "neutral", four as "easy", and one as "very easy". All ratings are non-negative, so this task can be considered attainable. 


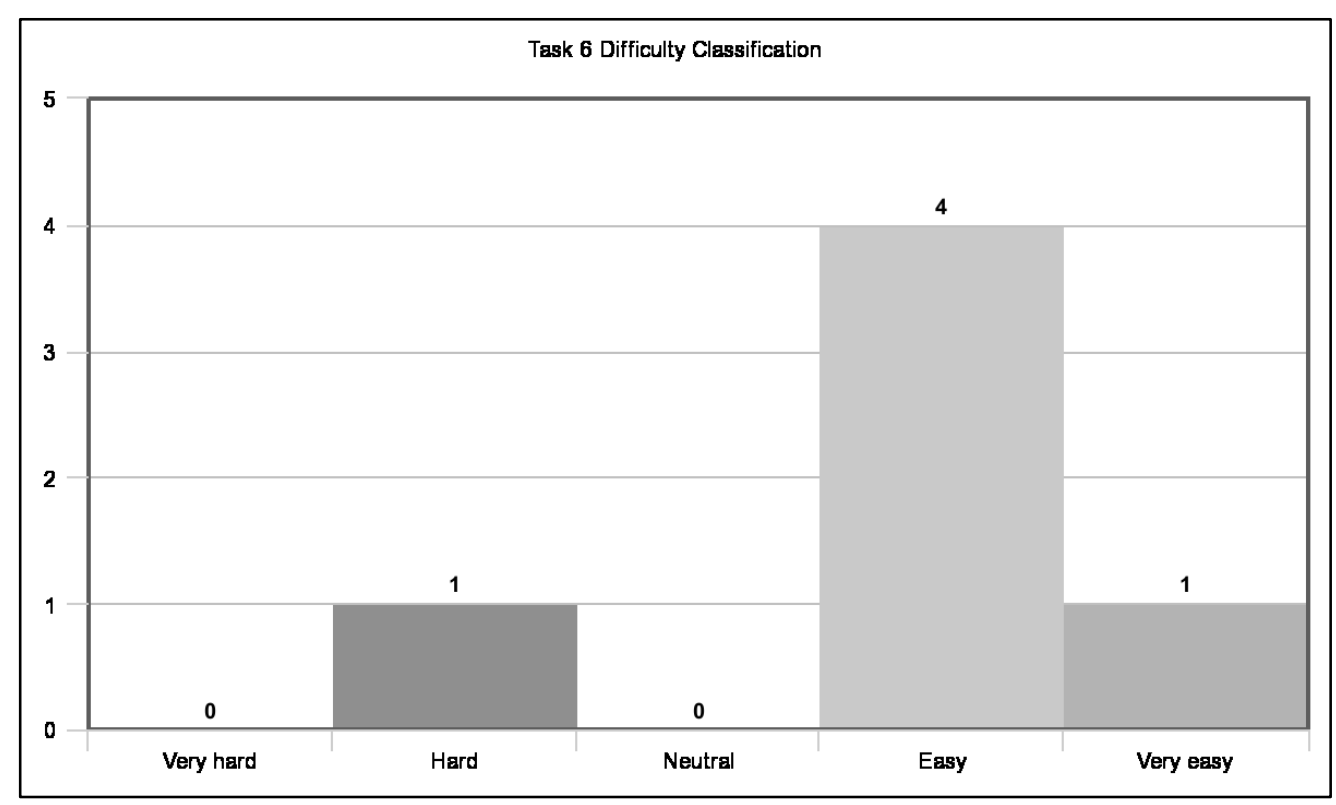

Figure 46: Histogram detailing Task 6 difficulty classifications (picture by the author)

In the histogram relating to the difficulty of the sixth task, "Finish level 3", one participant rated it as "hard", four as "easy", and one as "very easy". Though most ratings are positive, this task cannot be considered easily attainable on account of its negative classification.

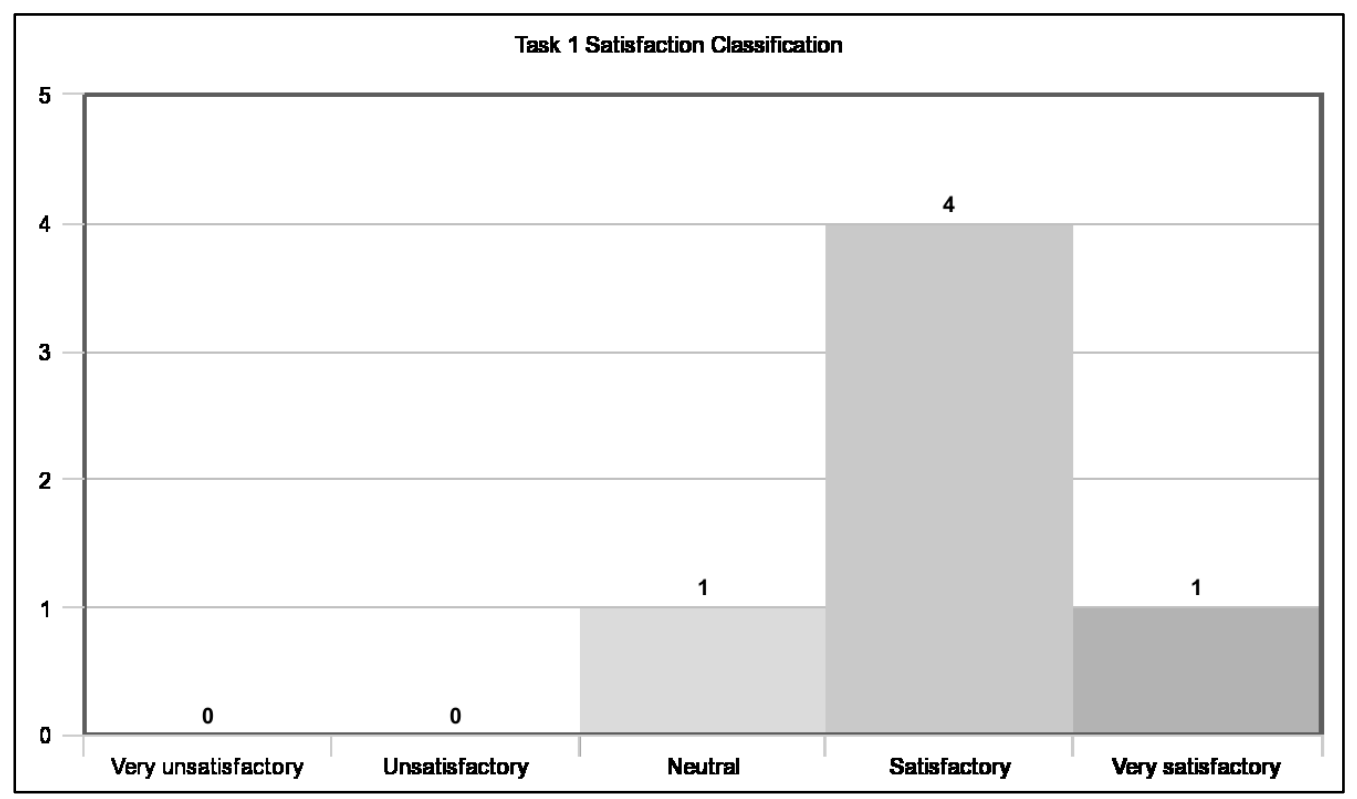

Figure 47: Histogram detailing Task 1 satisfaction classifications (picture by the author)

In the histogram relating to the satisfaction of the first task, "Familiarize yourself with the game controls", one participant rated it as "neutral", four as "satisfactory", and another as "very satisfactory". As all ratings are non-negative, this task can be considered satisfactory on account of its neutral or positive classifications. 


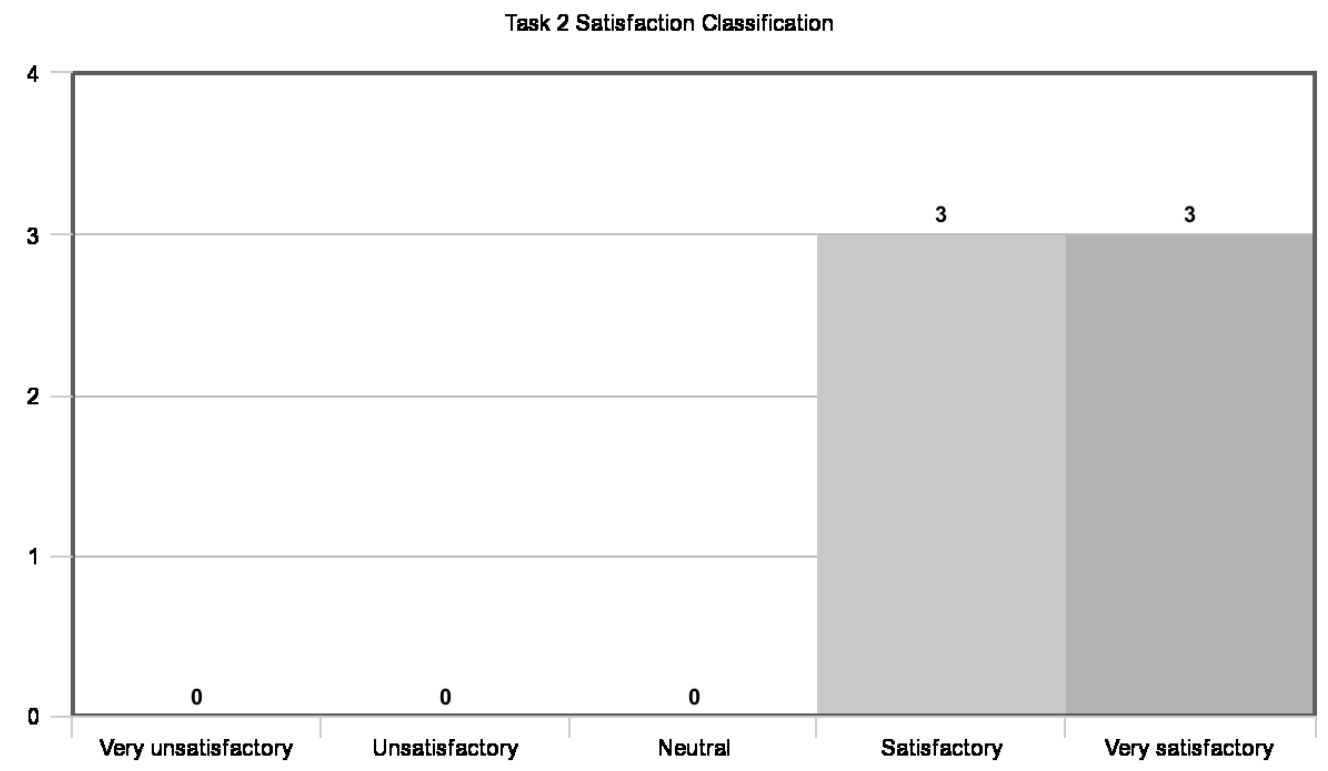

Figure 48: Histogram detailing Task 2 satisfaction classifications (picture by the author)

In the histogram relating to the satisfaction of the second task, "World objects' manipulation", three participants classified it as "satisfactory", and the other three as "very satisfactory". As all ratings are positive, and as half the participant group rated this task at a maximum of satisfaction, this task can be considered very satisfactory.

Task 3 Satisfaction Classification

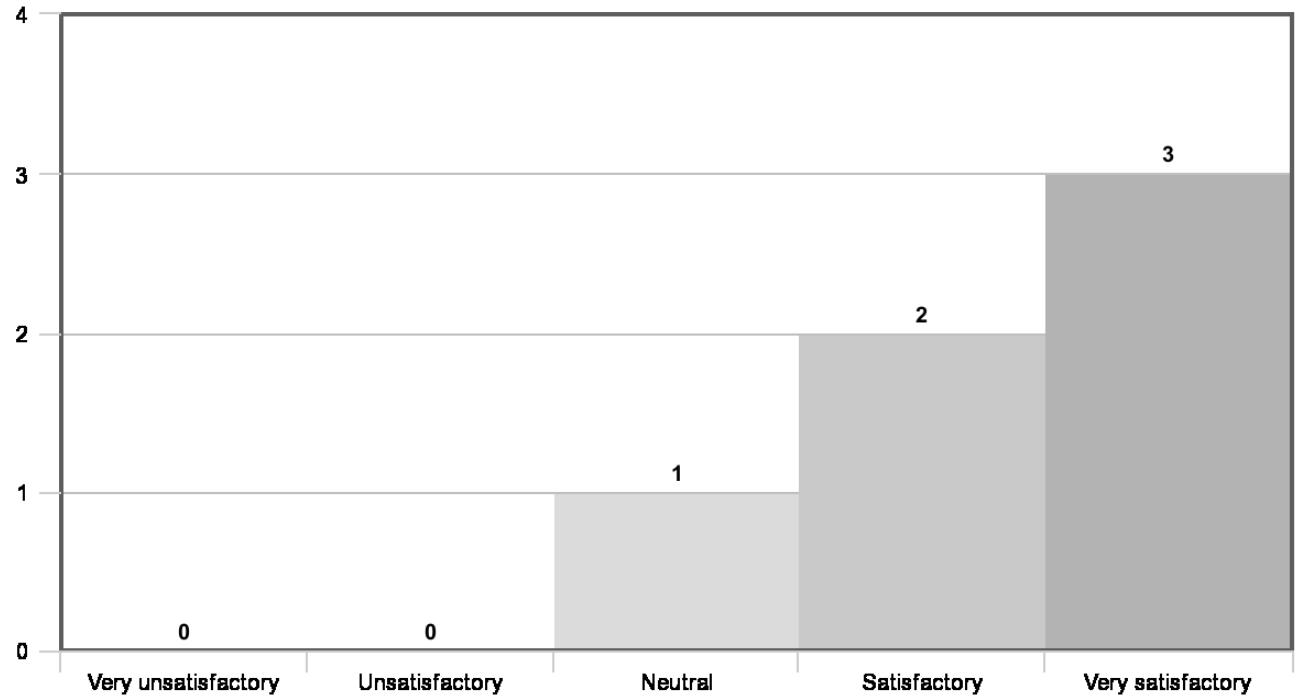

Figure 49: Histogram detailing Task 3 satisfaction classifications (picture by the author)

In the histogram relating to the satisfaction of the third task, "Character mobility in the world", one participant rated it as "neutral", two as "satisfactory", and the remaining three as "very 
satisfactory". As all ratings are non-negative, and as the majority of classifications fall into the "very satisfactory" rating, this task can be considered very satisfactory.

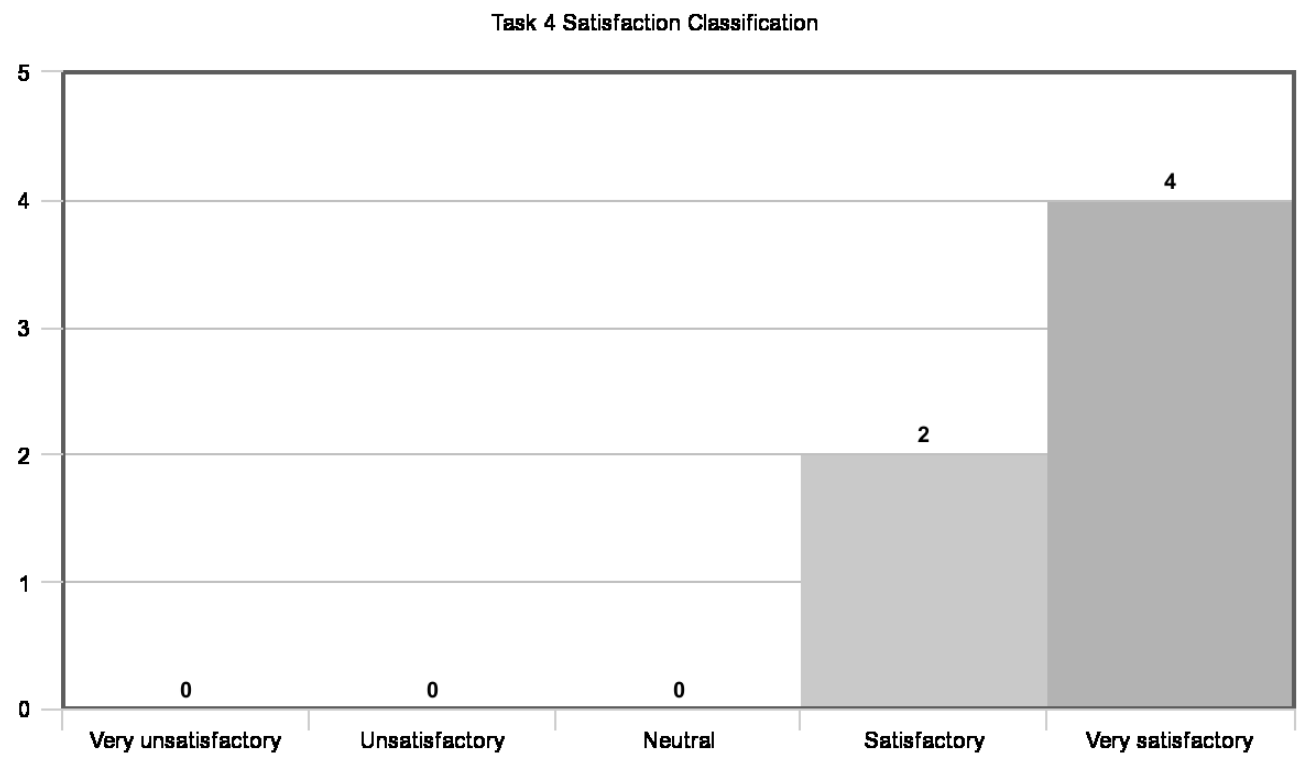

Figure 50: Histogram detailing Task 4 satisfaction classifications (picture by the author)

In the histogram relating to the satisfaction of the fourth task, "Finish level 1", two participants rated it as "satisfactory", and the other four as "very satisfactory". In this manner, this task can be considered very satisfactory on account of its positive classifications.

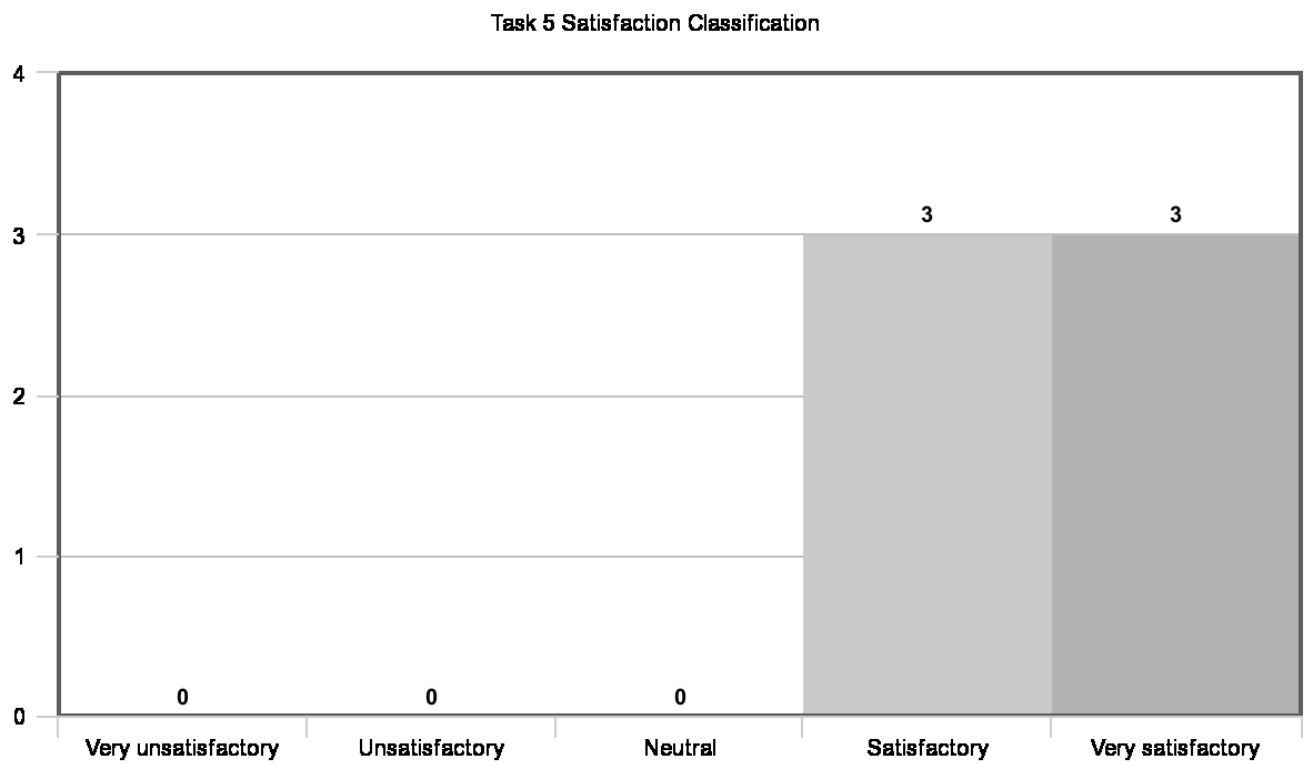

Figure 51: Histogram detailing Task 5 satisfaction classifications (picture by the author)

In the histogram relating to the satisfaction of the fifth task, "Finish level 2", three participants rated it as "satisfactory", and the other three rated it as "very satisfactory". As all ratings are positive, this task can be considered substantially satisfactory. 


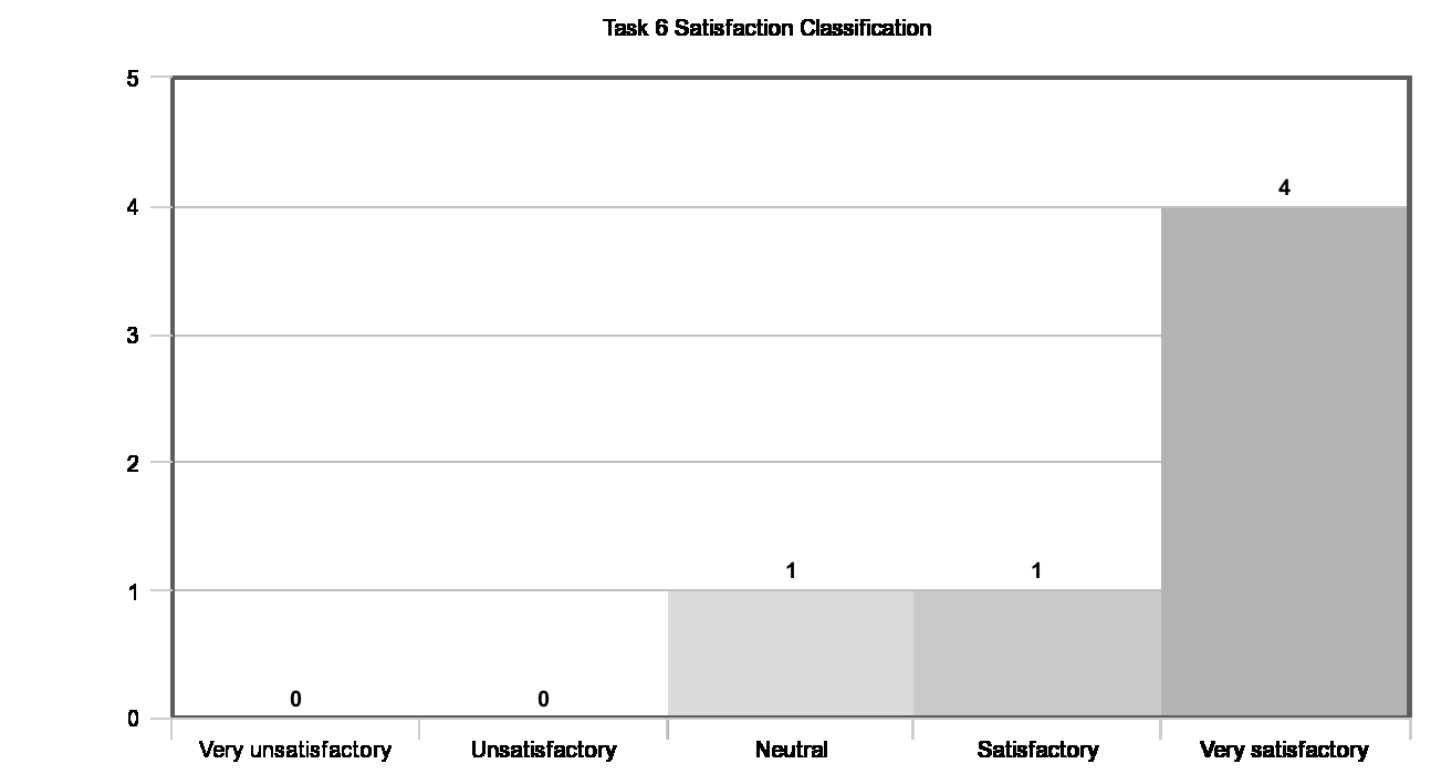

Figure 52: Histogram detailing Task 6 satisfaction classifications (picture by the author)

In the histogram relating to the satisfaction of the sixth task, "Finish level 3", one participant rated it as "neutral", another one as "satisfactory", and the remaining four as "very satisfactory". As all ratings are non-negative, and as the majority of the classifications relate to the highest degree of satisfaction, this task can be also be considered significantly satisfactory.

Upon analyzing the previous tables and graphs, one can determine that the task deemed most difficult by the participants was task 6 , while the easiest task was task 2 . The task deemed least satisfying was task 1 , while the most satisfying task was task 4 .

As per iterative design, each UX/usability test was followed by prototype fine-tuning and error correction, which in turn reflects on rising satisfaction levels and declining number of errors between test sessions.

Task 1 relates to touchpad movement. As previously mentioned, the Oculus Go controller touchpad has sensitivity issues which were out of the researcher's control. Even after the code was corrected to avoid these issues ${ }^{29}$, task 1 failed to reach a single score of 2 in both tables (very easy/very satisfying).

Task 2 relates to picking up world items, storing inventory items in the inventory, removing them, and storing them again. None of the participants had any major difficulties with this task.

Task 3 relates to teleport movement. Most participants opted to use the touchpad for all their movements (apart from $\mathrm{P}_{5}$, which used teleport points more often than the touchpad). This

\footnotetext{
${ }^{29}$ These corrections were implemented after P2's test.
} 
implies that the touchpad movement is far more immersive than teleporting, as it emulates walking through the woods as opposed to jumping to specific places; in fact, P1 specifically stated that they preferred walking with the touchpad instead of using the teleport points.

Seemingly related to this matter, $\mathrm{P}_{5}$ 's play session had to be interrupted for a moment as they felt nauseated - perhaps because they mainly used teleport points to move around. Further controlled testing of the movement mechanics could help clarify these matters.

Task 4 relates to finishing the first level and reaching the second level and was a task none of the participants had difficulty finishing. This can be justified by the low difficulty level of the first level, as it serves to ease the player into the world's input and interaction system. The tasks of the first level are quite linear and the NPCs of the first level offer clearer information that the NPCs of following levels, which have purposefully vaguer dialogue.

Task 5 relates to finishing the second level and reaching the third level. The lower difficulty score on this task was initially caused by level design errors, as participants assumed there was a different path they could follow into the third level. Because of this, P1 managed to fall out of the game world and pass into the third level without dealing with its "gate". Once the level design was corrected and the "gate" was made more obvious to the player, the following participants were quicker to understand what they were meant to do. However, the lack of information relating to the fallen tree "gate" has, so far, only confused players as opposed to making them realize they must use the hatchet. This implies players seemingly forget they have picked up the hatchet altogether, or that the fallen tree isn't assimilated properly as a "gate". This can be easily corrected by adding information relating to the "gate" in form of a dialogue line.

Adding to the "gate" issue, the players' own lack of attention relating to information given by the NPCs can also be a cause for the low score (e.g., the turtle says there are mushrooms in area 2 and area 3, but several participants tried to find the final mushroom by backtracking to area 1). This could possibly be corrected by shortening the NPCs' lines or repeating in-game information, but this error can ultimately be justified by the players' inattention.

Task 6 refers to finishing the game by exploring area 3 and cleaning the cave. Some players had to be given hints on what they were expected to do, as the final event in the cave was described as "vague" in terms of NPC-given and UI-given information. Though all players managed to finish the game, this task should be improved in future work.

Open questions' answers include suggestions of usability improvements such as:

1. Addition of more physics-affected items such as throwable rocks, grabbable rocks, or other immersion-raising objects that the players can manipulate freely just for fun;

2. Perfection of dialogue system in terms of usability: 
a. Making it more obvious when a dialogue line is finished or when the character has more information to give;

3. Perfection of dialogue in terms of cohesive narrative:

a. Ensuring the characters do not mention key items before the player knows that they are meant to use them (e.g. the fish can mention the plank before the player has reached the bridge and realized they need a plank);

4. The addition of a tutorial level to help players master the prototype's controls, as opposed to being taught by the researcher or, in future work, another investigator;

Regarding motion sickness, only three participants suffered from varying degrees of motion sickness:

1. P1 mentioned feeling slightly nauseated during the first level, but the nausea was described as "light" and was quick to pass. This might have been caused by a period of visual adaptation to the headset's screens, as the feeling of nausea did not return.

2. $\mathrm{P}_{3}$ only mentioned feeling motion sickness once they finished the test. They added, upon being questioned by the researcher, that their degree of discomfort had never been too high as to require them to stop playing.

3. $\mathrm{P}_{5}$ had to take a short break approximately ten minutes into the test (having reached the second area), saying that they felt nauseated; they voluntarily finished the test after the feeling had passed, and did not mention feeling any signs of motion sickness after that. It is important to note that this participant described the headset as "very warm", and stated that its lenses would sometimes fog up, which might have influenced their experience.

On a final note, the Oculus Go headset overheated during every single test, requiring the participants to take at least one short break to allow the headset to cool down. The number of breaks was dependent on the time the participant took to progress through the level: P6 only needed to take one break, while P1 and P2 took four breaks.

\subsubsection{ANALYSIS' CONCLUSION}

Despite some usability mishaps, none of the tasks were globally evaluated at a negative level, as it is possible to see in the average values of each task. Difficulty levels are overall much lower than satisfaction levels, however, which implies that the prototype should still be perfected and developed in future work. Alternatively, this can also imply that the satisfaction of solving the 
game's puzzles through exploration and NPC interaction is great enough that it overshadows the aforementioned usability issues.

In terms of development, the usage of iterative design greatly improved the prototype, as the researcher was able to continuously correct the prototype between UX testing sessions; this culminated in the prototype reaching the status of "functional" after six UX tests. 


\section{CASE STUDY}

This chapter refers to the case study proceedings, namely participant profiling, real environment testing and analysis of the test results.

As previously mentioned, the methodology used in this phase belongs to the instrumental case study category - an empiric investigation based on inductive reasoning, depending on field work and based off several sources - which aims to collect data from the case (i.e. phobia of the dark) in order to understand another phenomenon (i.e. VR gaming as therapy) (Coutinho, 2013).

As this prototype is meant to satisfy specific requirements, there is only one participant in this case study, which will be profiled in the first subchapter, Participant Profiling.

Testing and analysis of the test results have been documented in the second subchapter, Real Environment Test.

\subsection{PARTICIPANT PROFILING}

As the case study participant is underage, the only data that can be published about him is his gender, his age, as to ascertain relevance to this study, and that he has a fear of the dark that is considered "normal" in his age range, i.e. it relates to developmental and environmental factors, which needn't be realistic or logical (Levos \& Zacchilli, 2015). The participant's fear is not particularly acute, though it requires him to sleep with a nightlight or another lighting source, as opposed to sleeping in complete darkness.

It can be established, then, that the case study participant is a ten-year-old male child with a normal degree of fear of the dark, from hereon named CSP (Case Study Participant).

Documented proceedings and analysis of CSP's testing will be described in the following subchapter, Real Environment Test.

\subsection{REAL ENVIRONMENT TEST}

Though the case study's main concern does not touch upon UX/usability testing, the questionnaire used during the UX/usability testing phase was reutilized to better ascertain CSP's feelings towards the prototype. The testing proceedings for CSP were also similar to the proceedings of the UX testing: CSP sat on a rotative chair, was instructed on how to handle the Oculus Go headset and controller, and was given a short briefing on how to use the prototype's input system. 
CSP's testing was preceded by the creation of a consent form, which both CSP and his legal guardian signed (see annex 9).

Unlike the previous UX/usability testing proceedings, which happened in the researcher's house, CSP's tests happened in his own house, with a family member present. Furthermore, CSP was tested twice, being that the two sessions were one week apart. On the first session, CSP played the game at its brightest (level 1 on the options' menu); on the second session, CSP played the game at its darkest (level 3 on the options' menu).

The case study data was observational in nature and the researcher was present during the tests. The researcher was responsible for personally transcribing any ongoing events deemed relevant to the UX testing. At this phase, securing CSP's anonymity was obligatory on account of his age: absolutely no videos, images, or sounds were recorded during CSP's testing.

Also accounting for CSP's age, some parts of the questionnaire were read aloud, while others were adapted into a more simplified verbal manner. E.g., a task such as "identifying which kinds of interactions there are" was divided into two casually worded questions:

1. "Do you think there are different kinds of ways you can grab objects?"

2. "Can you tell the difference between them?"

In this manner, CSP was able to fill out ${ }^{\circ}$ the difficulty and satisfaction tables present in the questionnaire. Garnering this data is especially useful to evaluate what the target audience for this game thinks of the game's task. CSP also answered the open questions at the end of the questionnaire, which allowed the researcher to further understand the way he felt about the game.

CSP attended two tests under different environments, one for bright light and another for dark light. Each session's results will be described individually, since the game's narrative was not altered after his first test, and CSP's criticisms and suggestions regarding the story and aesthetics did not change from one session to another. This particular set of data will only be described in the first session, which was when CSP first played the game, as CSP had no new criticisms or observations to share during the second session.

\subsubsection{FIRST TESTING SESSION}

Upon starting the test, the prototype's objectives were explained to the participant, in specific the objective of helping children with fear of the dark. After listening, the participant was not

\footnotetext{
${ }^{30}$ CSP's questionnaire was not literally filled out as the first part of the questionnaire was meant to profile its testers, and this would arguably put CSP's anonymity in jeopardy.
} 
anxious about the subject of the game; rather, CSP was extremely excited about the opportunity to play a VR game. CSP's family member added that CSP's fear of the dark usually only manifested when it was bedtime, and that it was easily alleviated with the use of a nightlight or by "leaving the corridor's light on".

To ensure undemanding $360^{\circ}$ rotation of the headset, CSP was sat on a rotative chair adjusted to his short height, allowing him to use his legs to rotate the chair around. The headset was then properly fitted onto his head and he was handed the controller, using it to start a new game as per researcher instructions.

Before allowing the participant to explore the world, the researcher explained the game's controls to CSP and asked him to complete the first three tasks of the UX questionnaire: moving with the touchpad, accessing the inventory, using the controller to interact with items and the NPC in front of the camera, and using at least two teleport points. These were done sequentially and repeated until CSP could comfortably accomplish these tasks without previous instruction.

CSP was then allowed to explore the game without further interruptions; observed findings have been compiled on subchapter 5.3 Case Study Test: Results' Analysis.

\subsubsection{SECOND TESTING SESSION}

The main difference between testing sessions was the inclusion of the lighting options, as the rest of the prototype remained unchanged. The objective of this test was the observation of CSP's playthrough at the darkest level of lighting, and the documentation of his emotional responses.

Before beginning the test, CSP was warned of its objectives, as well as being assured that the only thing that had changed in the prototype was the lighting levels and the addition of a uncanny and grim ambience sound in the cave. The remaining proceedings were the same as the previous test: the same family member was present through the whole test, and CSP was again sat on a rotative office chair and allowed to explore the world at his own pace.

\subsection{CASE STUDY TEST: RESULTS' ANALYSIS}

As previously mentioned, CSP attended two tests under different environments, one for bright light and another for dark light (see figure 35 on page 69 for lighting level demonstrations). Lighting changes are applied on the start menu and last until the game has been finished.

Lighting levels are dependent on source lighting, which sheds a variable amount of lighting on the game world, and the sky, which reflects color onto the game world. Normal lighting has an intensity of 1, dimmer lighting has an intensity of 0.7 , and dark lighting has an intensity of 0.5 . 
Sky reflection levels have also been adapted in order to frame the world's colors in a more muted, realistic way.

\subsubsection{FIRST TESTING SESSION}

CSP was able to finish the game in one single session, though he had to take a break on account of the Oculus Go's headset overheating, after which he rated his experience using the difficulty and satisfaction rankings (see table 14).

Table 14: CSP's difficulty and satisfaction ratings

\begin{tabular}{|c|c|c|c|c|c|c|c|}
\hline & \multicolumn{7}{c|}{ DIFFICULTY } \\
\hline Participants & Age & Task 1 & Task 2 & Task 3 & Task 4 & Task 5 & Task 6 \\
\hline CSP & $\mathbf{1 0}$ & 0 & 1 & 2 & 1 & 0 & 0 \\
\hline Participants & Age & Task 1 & Task 2 & Task 3 & Task 4 & Task 5 & Task 6 \\
\hline CSP & $\mathbf{1 0}$ & 1 & 0 & 2 & 1 & 0 & 1 \\
\hline
\end{tabular}

Upon finishing the game, CSP was asked several questions based off the open questions in the UX questionnaire:

1. Did you feel any emotion towards the characters of the game (e.g. friendship, disinterest, etc.)?

CSP was compelled to help the animals and felt friendship towards them, because "they were nice". CSP also added that he had realized that if the animals weren't helped, the game wouldn't progress.

\section{Did you feel interested on disinterested by the game's narrative?}

CSP felt interested by the game's narrative. He said it appealed to him because of the animals' presence as NPCs, but also because the story allowed him to explore the world freely in order to solve a light mystery.

\section{What did you think of the game?}

CSP enjoyed the game but said that there were a lot of things he had to remember. The game was described as "challenging", and, upon being asked to clarify, CSP said that the game was "not impossible to win", but it also required some mental effort. Adding to that, CSP felt that the game was creative, and its environmental message could be a good influence on other players. 


\section{What did you think of the animals?}

CSP said that he thought that the animals were easily recognizable, even though the style of the game was not as realistic as the games he usually played. Adding to that, CSP enjoyed the style of the game and said that it was aesthetically pleasing and "cool".

\section{Were you afraid or uncomfortable during the game?}

CSP was not negatively impacted by the game, even at its darkest parts, as he said he was always able to see clearly (on his first session, CSP played the game at its brightest settings).

Despite not ranking the game with a negative score on either questionnaire scale, CSP struggled with several parts of the game.

In terms of game difficulty, the player was unsure of what he needed to do next at two specific times: when CSP needed to cut down the fallen tree to progress to the third level, as CSP forgot he had picked up a hatchet a few minutes earlier, and when he was trying to interact with the fox, as CSP did not recall he needed to give the fox the mushrooms in his inventory. Simply reminding the player that he could see what items were in his inventory was enough to make him progress on both times. This might mean that the NPCs who give hints are placed too far apart, both spatially and temporally, and that the players forget what the last NPC hint was as they explore the world. Adding to that, perhaps cutting down on the NPCs' lines will help younger players focus on what they are saying. In CSP's case, he read all lines aloud without being asked, so his attention to the characters' lines can be accounted for.

In terms of usability flaws, the player did not understand what his goal was after entering the cave. Though CSP was able to immediately identify that the barrels near the river were trash and were polluting the river, he did not know where he was meant to put the barrels. After the researcher pointed out that there was a glowing area with the same green color as the barrels, CSP concluded that the barrels were meant to go into the glowing area.

This usability flaw could be corrected by adding lines to the fox's dialogue in which she could help the player understand what to do with the barrels ${ }^{31}$. CSP also commented that the fox could accompany the player into the cave in order to help him, instead of placing the fox at the cave's entrance.

Another usability flaw that CSP encountered was during his exploration. Upon finding the flashlight, CSP immediately headed into the cave and proceeded until he found the barrels. However, as the fox was left behind waiting for player interaction, CSP was understandably

\footnotetext{
${ }^{31}$ After CSP's first test, the researcher implemented new coding on the barrel objects, which now shrink and disappear upon being placed on the green area, as opposed to simply playing a feedback sound.
} 
confused on what he was meant to do. This flaw can be corrected by adding a barrier of sorts to the cave's entrance, which would only allow passage if all the fox's information has already been passed onto the player.

The segments of the game in which CSP showed a higher state of fun were those related to the manipulation of physics-affected objects. At the very start of the game CSP spent circa ten minutes handling wooden logs by the tent instead of exploring, repeatedly throwing the objects into the distance and retrieving them. This state of excitement was repeated when CSP was asked by an NPC to gather litter and place it inside a trash bin.

CSP's positive reaction to this manipulation of objects might signify that, the addition of more mini-games with pick-up objects could heighten the prototype's "fun" factor. Further development of the prototype could include the creation of similar mini-games, and draw inspiration from Mikulas' (2011) games for children with fear of the dark.

\subsubsection{SECOND TESTING SESSION}

The first level of the prototype was received with the same enthusiasm as the first session. The lighting at this level, though darker, may be too reminiscent of daylight environments to augment CSP's anxiety levels. However, though the following levels emulate darker times of day, both the second and third levels of the prototype failed to garner any negative reactions; this might be caused by CSP's fear being designated "normal" for a child's development.

As previously mentioned, normal lighting has an intensity of 1 , dimmer lighting has an intensity of 0.7 , and dark lighting has an intensity of 0.5. Thus the second testing session displayed a much darker world, with half the lighting amounts in comparison to the first session.

Despite the visual and auditive changes, CSP stated that he had not felt uncomfortable or scared, and that he had once again enjoyed playing the prototype. In conclusion, CSP's feelings towards the prototype did not change between sessions; the sessions' outcomes are quite similar in nature. As a result, the second testing's results have been strictly summarized to avoid irrelevant repetition, and focus mainly on CSP's reaction to the modifications to lighting and audio.

There are two hypothesis to substantiate CSP's reaction to the revised prototype: (1) the participant's fear is not as severe as a clinical phobia, so he would not show symptoms of severe anxiety or distress, and (2) the participant has already played the prototype, and is familiarized with its environment and narrative, so his susceptibility to the darkening environments is greatly diminished. 


\section{CONCLUSION}

This chapter comprises the final commentaries about the project of this dissertation, spanning across three topics.

The first topic, Final Observations, refers to the presentation of the investigation's findings and how they complement the previously established objectives and research questions.

The second topic, Limitations, lists the difficulties found throughout the writing of this dissertation, spanning technical and investigative issues.

Several aspects which should be bettered in the future, both in terms of game difficulty and usability, are listed in the third topic, Future Work.

\section{FINAL OBSERVATIONS}

One of the objectives of this dissertation was the attainment of knowledge related to the development of the VR prototype. The first phase of this dissertation, preliminary/review, consisted in the study of literature relevant to the conception of a VR prototype targeted at children with phobia of the dark. The main subjects studied during this phase were virtual reality, gaming, and phobia; each of these subjects has a corresponding subchapter in the Theoretical Framework chapter.

The study of these topics allowed the researcher to gain insight as to how development of a game could result in a functional, efficient, and self-sufficient prototype. Gaming as a tool to channel feelings of satisfaction and self-efficacy into the player is also one of the key concepts of this prototype, as it bolsters player motivation to keep playing. The "fun" factor intrinsic to gaming is also considered a key concept in the prototype's construction.

Understanding the differences between "normal" fear and a phobia was essential for this dissertation, which resulted in discerning the criteria for a phobia and how it could be treated. The analysis of scientific papers related to VR-based therapy as a tool to treat phobias was also included in the theoretical framework. These papers advised the researcher about the dangers of traumatizing phobic patients through desensitization therapy, which can be avoided through the presence of a trained therapist or psychologist during the VR experience.

The second phase of this investigation, concept/development, purposed to conceptualize and develop a functional VR prototype targeted at children with phobia of the dark. Drawing from the methodological approaches defined in the Methodology chapter, artistic and narrative conceptualization of the game's world was the first phase of the development, followed by practical development (i.e. programming and level design). The development phase also 
included UX testing as per iteration design guidelines; the prototype was corrected and further developed after each test session, until the prototype could be deemed functional.

The UX/usability tests incorporated a two-part questionnaire which profiled the testers and gave them a list of tasks to accomplish. After the tasks were complete and the testers finished the game, they rated the game in difficulty and satisfaction, and answered open questions related to the game's functionalities and narrative. The UX testing data was transcribed by the researcher through close observation of each tester's playthrough, as opposed to recording video, image, or sound.

The third phase of the investigation, testing/evaluation, comprised the real environment testing of a child with "normal" fear of the dark and analysis of said testing sessions. Initial testing proceedings foresaw a case study with a clinically diagnosed participant. As finding a phobic participant was not possible, proceedings were adjusted and adapted to a new participant with a lesser degree of fear. The questionnaire used in the testing was the same questionnaire used in the UX/usability testing, adapted to a more casual language and without filling out the profiling questions so as to ensure the child's anonymity. The participant filled out the difficulty and satisfaction tables and answered questions based off the open questions listed in the UX questionnaire.

After the mentioned phases of the investigation, it is now possible to correlate the investigation's findings with the research questions asked at the start of this dissertation:

1. CAN A VR STORYTELLING GAME POSITIVELY IMPACT A CHILD'S PHOBIA OF THE DARK?

\section{CAN PHOBIA OF THE DARK BE INCORPORATED AS A PIVOTAL CONCEPT IN A GAME'S NARRATIVE AND/OR IMPROVE USER EXPERIENCE?}

Though the lack of a participant with a diagnosed phobia leaves the primary research question unanswered, the collected test data could arguably answer the secondary question. This can be justified as the participant is afraid of the dark, though at a "normal" degree, and his young age allows him to be a part of the target audience in matters of user experience.

Though the primary question was not definitely answered, this study concluded that the investigation results are promising: there is a positive user satisfaction level regarding the prototype, a successfully incorporation of user motivation based on virtual environments and narrative, and the developed interface, interaction and game systems were found to work with the target audience. These results allowed the creation of an adequate experiment for future clinical testing.

Regarding the second question, the aspects of the game most enjoyed by the target audience were the game aesthetics and the manipulation of physics-affected objects, as previously 
described, though the participant also enjoyed the story and its mystery to a lesser degree, having mentioned that the narrative motivated them to finish the game.

\section{LIMITATIONS}

Though the real environment testing in this dissertation ideally counted with the participation of a child with the appropriate age, the actual participant was not diagnosed with a phobia of the dark. As such, this testing could not properly answer the primary research question posed at the beginning of the investigation, and any hypothesis regarding the VR prototype's positive impact on a child's phobia have gone unanswered.

Additional limitations of this study comprehend: (1) an absence of prototype evaluation by diagnosed phobic children while accompanied by psychologists and/or therapists; (2) a lack of game design limitations such as saved games management, game design options like volume or text size, and difficulty/lighting control at runtime; (3) a prototype which offers a limited number of levels, resulting in a short game with little replay value on a narrative level.

\section{FUTURE WORK}

Future work on the prototype should be continuously based upon children's feelings and opinions, which means that it would doubtlessly benefit from more careful testing and observation of children playing the prototype.

The inclusion of more mini-games should also be considered, as they could make the game more fun, and give the player the feeling that they interact even more with the world around them. These mini-games could be inspired by Mikulas' (2011) list of games for children with fear of the dark, in order to include more aspects related to the child's phobia. These mini-games should also include physics-affected objects, as suggested by UX testers and the real environment tests.

An overhaul of the Unity3D project should also be considered. The removal of irrelevant assets and proper programming practices could result in a more organized project, which would ideally make future outside investigation more accessible.

In terms of narrative and NPC interaction, the NPCs could be even more supportive and thankful of the NPCs actions, so that child players could feel more confident about facing their fear of the dark. However, the dialogue text should never be too long, to allow child players to remember whatever information is available to them and to keep them focused on the task at hand. Further UX testing with young children could help find a balance between narrative and essential 
information and ensure that the game's objectives are easy to remember and identify. It could also help understand how other children react to the prototype.

The dialogue UI system should also be made clearer, by making the player realize when they have finished a dialogue line or the character has new information. Dialogue lines that refer to items or narrative branches that the player has yet to learn about should be polished and overhauled, in order not to break immersion or confuse the player.

In terms of clinical testing, testing a child that has been properly diagnosed with phobia of the dark would positively impact the investigation, though it must be noted that the phobic child should also be accompanied by a psychologist or therapist during any testing sessions. Any documented proceedings and findings of such testing would improve the prototype and, ideally, ensure that its usage as a therapeutic device would not traumatize future patients.

Accomplishing said clinical testing would furthermore allow the creation of a set of guidelines for implementing VR therapy for children with phobia of the dark, enabling the area of therapeutic psychology to have the contribution of digital storytelling and Human-Computer Interaction.

The creation of a network of therapists willing to try out the prototype with their patients could greatly advance the development of the prototype into a full-fledged therapeutic device, as well as gather useful data regarding the usage of the prototype with phobic patients. 


\section{BIBLIOGRAPHICAL REFERENCES}

American Psychiatric Association. (2013). Diagnostic and Statistical Manual of Mental Disorders (5th ed.). American Psychiatric Association.

Anthes, C., García-Hernández, R. J., Wiedemann, M., \& Kranzlmüller, D. (2016). State of the art of virtual reality technology. IEEE Aerospace Conference Proceedings, 2016-June. https://doi.org/10.1109/AERO.2016.7500674

Bakker, A., \& van Eerde, D. (2015). An Introduction to Design-Based Research with an Example From Statistics Education (pp. 429-466). https://doi.org/10.1007/978-94-017-9181-6_16

Bouchard, S. (2011). Could virtual reality be effective in treating children with phobias? Expert Review of Neurotherapeutics, 11(2), 207-213. https://doi.org/10.1586/ern.10.196

Bowman, D. A., Mcmahan, R. P., \& Tech, V. (2007). Virtual reality - how much immersion is enough. Computer, 40(7), 36-43. https://doi.org/10.1109/MC.2007.257

Churm, T. (2012). An Introduction To Website Usability Testing - Usability Geek. Retrieved October 13, 2019, from https://usabilitygeek.com/an-introduction-to-website-usabilitytesting/

Cooper, A., Reimann, R., Cronin, D., Noessel, C., Csizmadi, J., \& Lemoine, D. (2014). About Face The Essentials of Interaction Design (4th ed.).

Coutinho, C. P. (2013). Metodologia de Investigação em Ciências Sociais e Humanas: Teoria e Prática. (Edições Almedina, Ed.) (2nd ed.). Edições Almedina.

Crawford, C. (1997). The Art of Computer Game Design. McGraw-Hill/Osborne Media.

Cuesta, M. H. (2014). Livia_Prima_Porta_10. Wikimedia Commons.

Davis, S., Nesbitt, K., \& Nalivaiko, E. (2014). A Systematic Review of Cybersickness. IE2014 Proceedings of the 2014 Conference on Interactive Entertainment, 1-9. https://doi.org/10.1145/2677758.2677780

Dichgans, J., \& Brandt, T. (1978). Visual-Vestibular Interaction: Effects on Self-Motion Perception and Postural Control. In Perception (pp. 755-804). Berlin, Heidelberg: Springer Berlin Heidelberg. https://doi.org/10.1007/978-3-642-46354-9_25

Dubberly, H. (2001). Alan Cooper and the Goal Directed Design Process. AlGA Journal of Design for the Network Economy, 1(2), 15.

Elaine.T. (2016). 17. Retrieved from http://etsanggarp.blogspot.com/2016/03/

Encyclopædia Britannica. (1997). maculae-vertebrates-otoconia-ear-hair-cells-membrane.

Federoff, M. A. (2002). Heuristics and Usability Guidelines for the Creation and Evaluation of Fun in Video Games.

Freeman, D., Haselton, P., Freeman, J., Spanlang, B., Kishore, S., Albery, E., ... Nickless, A. (2018). Automated psychological therapy using immersive virtual reality for treatment of fear of heights: a single-blind, parallel-group, randomised controlled trial. The Lancet Psychiatry, 5(8), 625-632. https://doi.org/10.1016/S2215-0366(18)30226-8

Garcia-Palacios, A., Botella, C., Hoffman, H., \& Fabregat, S. (2007). Comparing Acceptance and Refusal Rates of Virtual Reality Exposure vs. In Vivo Exposure by Patients with Specific Phobias. CYBERPSYCHOLOGY \& BEHAVIOR, 10(5). https://doi.org/10.1089/cpb.2007.9962 
Giacomin, J. (2014). What Is Human Centred Design? The Design Journal, 17(4), 606-623. https://doi.org/10.2752/175630614X14056185480186

Grau, O. (2003). Virtual Art; From Illusion To Immersion (1st ed.). MIT Press.

Gutiérrez-Maldonado, J., Magallón-Neri, E., Rus-Calafell, M., \& Peñaloza-Salazar, C. (2009). Virtual reality exposure therapy for school phobia Virtual reality exposure therapy for school phobia *. Anuario de Psicología (Vol. 40).

Hansen, D. (2016). Game On! Video Game History (1st ed.). Macmillan Publishing Group.

Heilig, M. L. (1992). EL Cine del Futuro: The Cinema of the Future. Presence: Teleoperators and Virtual Environments, 1(3), 279-294. https://doi.org/10.1162/pres.1992.1.3.279

Interaction Design Foundation. (n.d.). What is User Experience (UX) Design? Retrieved January 31, 2019, from https://www.interaction-design.org/literature/topics/ux-design

ISO 25010. (n.d.). Retrieved October 13, 2019, from https://iso25000.com/index.php/en/iso25000-standards/iso-25010

Jacob, R. J. K., Girouard, A., Hirshfield, L. M., Horn, M. S., Shaer, O., Solovey, E. T., \& Zigelbaum, J. (2008). Reality-Based Interaction: A Framework for Post-WIMP Interfaces.

Kennedy, R. S., Hettinger, L. J., \& Lilienthal, M. G. (1998). Simulator sickness. Motion and Space Sickness, 317-341.

Kennedy, Robert S., Drexler, J., \& Kennedy, R. C. (2010). Research in visually induced motion sickness. Applied Ergonomics, (41), 494-503. https://doi.org/10.1016/j.apergo.2009.11.006

Laviola Jr., J. J. (2000). A Discussion of Cybersickness in Virtual Environments. SIGCHI Bulletin, $32(1), 47-56$.

Levos, J., \& Zacchilli, T. L. (2015). Nyctophobia: From Imagined to Realistic Fears of the Dark.

Lewis, K. M., Amatya, K., Coffman, M. F., \& Ollendick, T. H. (2015). Treating nighttime fears in young children with bibliotherapy: Evaluating anxiety symptoms and monitoring behavior change. Journal of Anxiety Disorders, 30, 103-112. https://doi.org/10.1016/j.janxdis.2014.12.004

Lowood, H. E. (2018). Virtual reality. Retrieved November 10, 2018, from https://www.britannica.com/technology/virtual-reality

Lucas, S. (2018). Oculus Go Review: The First Stand-Alone VR Headset Is a Winner. Retrieved October 23, 2019, from https://www.tomsguide.com/us/oculus-go,review-5368.html

Machkovech, S. (2018). Oculus Go review: The wireless-VR future begins today for only \$199 | Ars Technica. Retrieved July 27, 2019, from https://arstechnica.com/gaming/2018/05/oculus-go-review-the-wireless-vr-future-beginstoday-for-only-199/

Marques, B. J. S. (2016). Veracity-Low cost physiology assessment tool using Virtual Reality. Veracity-Ferramenta de baixo custo para avaliação fisiológica utilizando Realidade Virtual.

Mazuryk, T., \& Gervautz, M. (1999). Virtual Reality - History, Applications, Technology and Future.

Mikulas, W. L. (2011). Graduated Exposure Games to Reduce Children's Fear of the Dark. In Behavioral Treatments for Sleep Disorders. https://doi.org/10.1016/B978-0-12-3815224.00033-X 
Moore, K., Wiederhold, B. K., Wiederhold, M. D., \& Riva, G. (2002). Panic and Agoraphobia in a Virtual World. CyberPsychology \& Behavior, 5(3), 197-202. https://doi.org/10.1089/109493102760147178

Nielsen, J. (1993). Iterative Design of User Interfaces. IEEE Computer, 26(11), 32-41.

Nielsen, J. (1995). 10 Usability Heuristics for User Interface Design. Retrieved January 28, 2019, from https://www.nngroup.com/articles/ten-usability-heuristics/

Nielsen, J. (2000). Why You Only Need to Test with 5 Users. Retrieved January 31, 2019, from https://www.nngroup.com/articles/why-you-only-need-to-test-with-5-users/

Nielsen, J. (2001). Usability Metrics. Retrieved January 28, 2019, from https://www.nngroup.com/articles/usability-metrics/

Nielsen, J. (2012). Thinking Aloud: The \#1 Usability Tool. Retrieved October 28, 2019, from https://www.nngroup.com/articles/thinking-aloud-the-1-usability-tool/

Nielsen, J. (2013). Usability 101: Introduction to Usability. Retrieved October 13, 2019, from https://www.nngroup.com/articles/usability-101-introduction-to-usability/

Norman, D. (2013). The Design of Everyday Things (R\&E). Basic Books.

Norman, D., \& Nielsen, J. (n.d.). The Definition of User Experience (UX). Retrieved January 31, 2019, from https://www.nngroup.com/articles/definition-user-experience/

North, M. M., North, S. M., \& Coble, J. R. (1998). Virtual reality therapy: An effective treatment for phobias. Studies in Health Technology and Informatics, 58, 112-119. https://doi.org/10.3233/978-1-60750-902-8-112

Opriş, D., Pintea, S., García-Palacios, A., Botella, C., Szamosközi, Ş., \& David, D. (2012). Virtual reality exposure therapy in anxiety disorders: A quantitative meta-analysis. Depression and Anxiety, 29(2), 85-93. https://doi.org/10.1002/da.20910

OVRInput. (n.d.). Retrieved October 23, 2019, from https://developer.oculus.com/documentation/unity/latest/concepts/unity-ovrinput/

Pinto, J. H. B. (2015). Virtual Reality Environment for immersive walkthroughs and interaction. Universidade de Aveiro.

Qi, W. (2014). (Serious) Games Development: The State of the Art.

Quivy, R., \& Campenhoudt, L. Van. (2005). Manual de Investigação em Ciências Sociais. Gradiva, Lisboa, Portugal. ISBN (4ª). Gradiva. https://doi.org/10.1145/2018602.2018605

Reichelt, S., Häussler, R., Fütterer, G., \& Leister, N. (2010). Depth cues in human visual perception and their realization in 3D displays. Three-Dimensional Imaging, Visualization, and Display, (May). https://doi.org/10.1117/12.850094

Ritter, F. E., Baxter, G. D., \& Churchill, E. F. (2014). User-Centered Systems Design: A Brief History. In Foundations for Designing User-Centered Systems. https://doi.org/10.1007/978-14471-5134-0

Roth, C., \& Koenitz, H. (2016). Evaluating the User Experience of Interactive Digital Narrative. Proceedings of the 1st International Workshop on Multimedia Alternate Realities - AltMM '16, 31-36. https://doi.org/10.1145/2983298.2983302

Salen, K., \& Zimmerman, E. (2004). Rules of Play - Game Design Fundamentals. 
Samsung \#BeFearless Fear of Public Speaking: School Life. (n.d.). Retrieved October 7, 2019, from https://www.etr.fr/app/samsung-befearless-fear-of-public-speaking-school-life/

Samsung \#BeFearless Fear of Public Speaking - School Life on Gear VR | Oculus. (n.d.). Retrieved August 16, 2019, from https://www.oculus.com/experiences/gearvr/1052195828241004/

Schell, J. (2008). The Art of Game Design (1st ed.). Morgan Kaufmann Publishers.

Sekuler, R., \& Blake, R. (1994). Perception (3rd ed.). McGraw-Hill International Editions.

Simon, H. (1967). An Information-Processing Explanation of Some Perceptual Phenomena. British Journal of Psychology, 58(1 \& 2), 1-12.

Smithsonian Institution. (2017). Video Game History. Retrieved January 27, 2019, from https://www.si.edu/spotlight/the-father-of-the-video-game-the-ralph-baer-prototypesand-electronic-games/video-game-history

Sound Systems: Mono vs. Stereo. (n.d.). Retrieved November 26, 2018, from http://www.mcsquared.com/mono-stereo.htm

St-Jacques, J., \& Bouchard, S. (2005). Clinical applications of virtual reality and cybersickness. In The 10th Cybertherapy Conference.

Steuer, J., \& Reeves, B. (1992). Virtual Reality - Dimensions Determining Telepresence. Journal of Communication, 42(4), 73-93. https://doi.org/10.1111/j.1460-2466.1992.tb00812.x

Sutherland, I. E. (1968). A head-mounted three dimensional display. Proceedings of the December 9-11, 1968, Fall Joint Computer Conference, Part I, 757-764. https://doi.org/10.1145/1476589.1476686

The History Of Gaming: An Evolving Community | TechCrunch. (n.d.). Retrieved January 29, 2019, from https://techcrunch.com/2015/10/31/the-history-of-gaming-an-evolvingcommunity/?guccounter $=1$

Unity - Manual: Audio Spatializer SDK. (n.d.). Retrieved October 8, 2019, from https://docs.unity3d.com/Manual/AudioSpatializerSDK.html

Ventura, S., Baños, R. M., \& Botella, C. (2018). Virtual and Augmented Reality: New Frontiers for Clinical Psychology. In State of the Art Virtual Reality and Augmented Reality Knowhow (p. 21). https://doi.org/10.5772/32009

Watson, M. R., \& Enns, J. T. (2011). Depth Perception. Vancouver.

Weerdmeester, J., van Rooij, M., Harris, O., Smit, N., Engels, R., \& Granic, I. (2017). Exploring the Role of Self-efficacy in Biofeedback Video Games. https://doi.org/10.1145/3130859.3131299

What is Usability Testing? | Interaction Design Foundation. (n.d.). Retrieved October 13, 2019, from https://www.interaction-design.org/literature/topics/usability-testing

Zeltzer, D. (1992). Autonomy, Interaction, and Presence. Presence: Teleoperators and Virtual Environments, 1(1), 127-132. https://doi.org/10.1162/pres.1992.1.1.127

Zheng, B. (n.d.). Illustration of the basic monocular depth cues.

Zimmerman, T. G., Lanier, J., Blanchard, C., Bryson, S., \& Harvill, Y. (1987). A Hand Gesture Interface Device. $\mathrm{CHI}+\mathrm{Gl}$ Conference, 189-192. 
Zyda, M. (2005). From visual simulation to virtual reality to games. Computer, 38(9), 25-32. https://doi.org/10.1109/MC.2005.297 


\section{ANNEXES}

All documents annexed to this dissertation are in digital format, as to ensure the prevention of quality loss. The folder hierarchy of the annexes is as follows:

\section{$\backslash$ Data Collection}

1. UX Test Questionnaire.pdf

2. Teste de UX e Questionário.pdf

3. P1 Questionnaire.pdf

4. P2 Questionnaire.pdf

5. P3 Questionnaire.pdf

6. P4 Questionnaire.pdf

7. P5 Questionnaire.pdf

8. P6 Questionnaire.pdf

9. Consent Form.pdf - (blacked out for anonymity purposes)

10. Researcher Transcriptions.pdf

\section{$\backslash$ Documentation}

11. Contingency Plan.pdf

\section{$\backslash$ Functional Prototype}

12. Um Rio Lindo.unitypackage - (requires Unity3 D to open)

13. Um Rio Lindo Android.apk - (Android application for use on Oculus Go headset)

14. Asset Credits.pdf - (a list of the assets used in development)

15. Game Script.pdf - (written in Portuguese) 